Universidade de São Paulo

Faculdade de Filosofia, Ciências e Letras de Ribeirão Preto Departamento de Química

Programa de Pós-Graduação em Química

\title{
“Filmes de óxidos mistos de estanho e irídio: caracterização e estudo da atividade para a eletrooxidação de etanol"
}

\author{
Demetrius Profeti
}

Tese apresentada à Faculdade de

Filosofia, Ciências e Letras de Ribeirão Preto da

Universidade de São Paulo, como parte das exigências

para a obtenção do título de Doutor em Ciências, Área:

Química

RIBEIRÃO PRETO -SP 
Universidade de São Paulo

Faculdade de Filosofia, Ciências e Letras de Ribeirão Preto Departamento de Química

Programa de Pós-Graduação em Química

\title{
“Filmes de óxidos mistos de estanho e irídio: caracterização e estudo da atividade para a eletrooxidação de etanol"
}

\author{
Demetrius Profeti
}

Tese apresentada à Faculdade de

Filosofia, Ciências e Letras de Ribeirão Preto da

Universidade de São Paulo, como parte das exigências

para a obtenção do título de Doutor em Ciências, Área:

Química

Orientador: Prof. Dr. Paulo Olivi

RIBEIRÃO PRETO -SP 
Este trabalho é dedicado... 
a Luciene pelo amor, apoio, dedicação, carinho....

Enfim, por todos os momentos 
ao Giuliano por presentear-me com seu doce sorriso todos os dias 
aos meus pais, Eduardo e Shirley, e ao meus irmãos, Hercules e Cesar, pelo apoio e torcida . 


\section{Agradecimentos}

... ao Prof. Dr. Paulo Olivi pela orientação e contribuição na minha formação enquanto pesquisador e, também, pela amizade;

...aos Professores Jean Michel Léger e Claude Lamy pela acolhida no "Laboratoire de Chimie 1"da Universidade de Poitiers;

... aos amigos e Professores do "Laboratoire de Chimie 1", Boniface, Christophe,

Françoise e Karine pela grande ajuda, discussões e sugestões que muito contribuíram para este trabalho;

... à Professora Adalgisa pelo auxílio em vários momentos deste trabalho ;

.... aos amigos do laboratório, Luiza, Roberta, Josimar, Fernando Teruel, Fernando Carmona, Marlene, Dane, Helder, Alexandre, André e Regina pela amizade, companheirismo, discussões e ajuda em todos os momentos;

.... aos amigos do laboratório "vizinho", Fernando Grine, Adriano, Jorge, Valdir e Leandro pelas longas conversas e momentos de reflexão;

... aos funcionários do Departamento de Química e da Secretaria de PósGraduação;

... ao meu sogro e sogra, Antônio e Zeni,e à tia Cida pelo apoio;

... a Luciene pelas coisas que não temos palavras para agradecer;

... ao Giuliano pelas agradáveis interrupções do meu trabalho;

... aos meus pais que me apoiaram e me incentivaram não apenas para a realização deste trabalho, mas também durante toda a minha formação;

... à CAPES pela bolsa concedida para o estágio no exterior;

... à FAPESP pela bolsa concedida e apoio financeiro durante a realização deste trabalho. 


\section{SUMÁRIO}

Índice de Figuras $i$

Índice de Tabelas $x$

Lista de Símbolos e Abreviaturas xii

Resumo xiii

Abstract xiv

\section{CAPÍTULO I}



1.1 - Aspectos Gerais............................................................................. 1

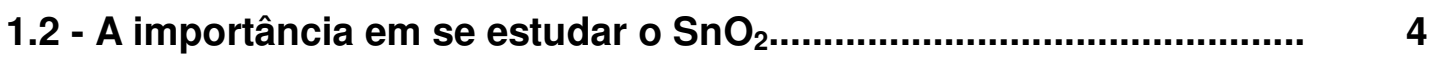

1.2.1- Métodos de preparação de eletrodos recobertos por óxidos metálicos.................................................................... 6

1.2.2 - Morfologia, Estrutura e Composição Química...................... 9

1.2.3 Caracterização eletroquímica................................................. 11

1.2.4 Determinação da área eletroquimicamente ativa.................... 13

1.3. Estudo do mecanismo de oxidação de etanol................................. 15

\section{CAPÍTULO II}

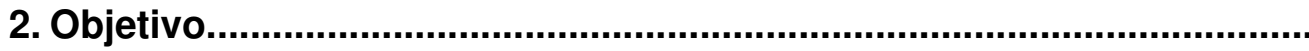

\section{CAPÍTULO III}

3. Parte Experimental.................................................................................... 20

3.1 - Preparação e padronização das soluções precursoras.................. 20

3.1.1 - Síntese do Precursor de Sn (Citrato de Estanho)................ 20

3.1.2 - Preparação da resina precursora de estanho..................... 20 
3.1.3 - Gravimetria da resina precursora de estanho.

3.1.4 - Dopagem da resina de estanho com antimônio................... 21

3.1.5 Preparação da solução de cloreto de irídio............................. 21

3.1.6 Gravimetria da solução precursora de irídio........................... 22



3.2.1 - Confecção final do eletrodo.............................................. 23

3.3 - Equipamentos utilizados na caracterização física e química dos

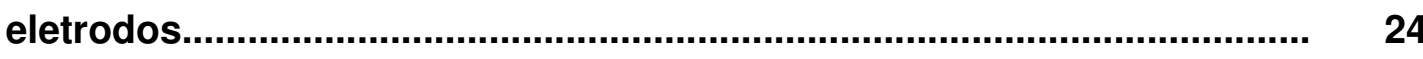

3.4 - Equipamentos eletroquímicos....................................................... 24

3.4.1 - Condições utilizadas nos experimentos de eletrólise com

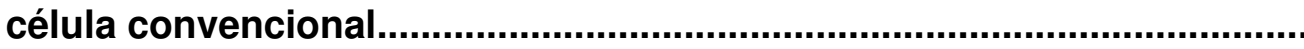

3.4.2 - Condições utilizadas nos experimentos de eletrólise com célula do tipo Filtro-prensa........................................................................ 26

3.4.3 - Análise dos produtos de eletrólise..................................... 27

3.5 - Experimentos utilizando técnica de Infra-Vermelho por Refletância com Transformada de Fourier in situ (FTIR in situ)..............

\section{CAPÍTULO IV}

4. Resultados e Discussão.

4.1 - Caracterização ex situ.

4.1.1 - Análise da morfologia e composição dos eletrodos contendo $\mathrm{SnO}_{2}$ e $\mathrm{IrO}_{2}$

4.1.2 - Análise estrutural dos eletrodos contendo $\mathrm{SnO}_{2}$ e $\mathrm{IrO}_{2} \ldots .$.

4.2 - Caracterização in situ.

4.2.1 - Caracterização por Voltametria Cíclica.

4.2.2 - Área eletroquimicamente ativa.

4.2.3 - Estudo da influência da adição de Ir aos eletrodos de $\mathrm{SnO}_{2}$ para a Reação de Desprendimento de Oxigênio.

4.2.4 - Estudo da estabilidade eletroquímica dos eletrodos de $\mathrm{Sn}_{(1-\mathrm{x})} \mid \mathrm{r}_{\mathrm{x}} \mathrm{O}_{2}$

4.3 - Estudo da atividade eletrocatalítica para a oxidação das 
moléculas orgânicas................................................................................ 59

4.3.1 - Estudo da eletrooxidação de ácido acético......................... 60

4.3.2 - Estudo da eletrooxidação de acetaldeído............................ 62

4.3.3 - Estudo da eletrooxidação de etanol....................................... 67

4.3.4 - Estudo da eletrooxidação por FTIR in situ.......................... 81

4.3.5 - Experimentos de eletrólise utilizando uma célula tipo

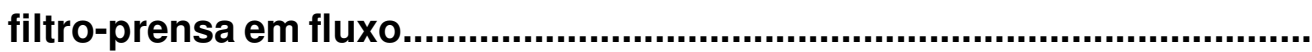

CAPÍTULO V



CAPÍTULO VI

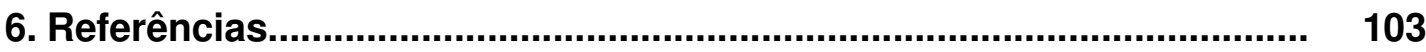




\section{ÍNDICE DE FIGURAS}

Figura 1 - Voltamograma cíclico de um eletrodo de $\mathrm{Ti} / \mathrm{rO}_{2}$ em $\mathrm{H}_{2} \mathrm{SO}_{4} \quad 0,5$ $\mathrm{mol} \mathrm{L}^{-1}$ a uma velocidade de varredura de $20 \mathrm{mVs}^{-1}$ [34]. O eletrodo foi obtido pelo método de Pechini calcinado a $600^{\circ} \mathrm{C}$ por $1 \mathrm{~h}$

Figura 2 - Voltamograma cíclico de um eletrodo de $\mathrm{Ti} / \mathrm{SnO}_{2}$ dopado com antimônio em $\mathrm{H}_{2} \mathrm{SO}_{4} \quad 0,5 \mathrm{~mol} \mathrm{~L}^{-1}$ a uma velocidade de varredura de 50 $\mathrm{mVs}^{-1}$ [28]. O eletrodo foi obtido pelo método de spray pirólise calcinado a

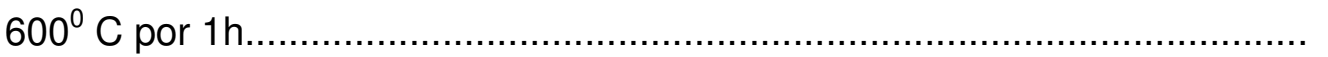

Figura 3 - Mecanismo proposto para a oxidação eletrocatalítica do etanol em platina lisa em meio ácido durante varredura de potencial positiva (todas as espécies com os nomes sublinhados foram detectadas por FTIR in situ, ou por CLAE, ou ambas as técnicas).

Figura 4 - Representação esquemática de um eletrodo recém preparado...

Figura 5 - Esquema da célula eletroquímica e eletrodos empregados nos experimentos de caracterização eletroquímica e eletrólises.

Figura 6 - Representação esquemática do sistema de eletrólise utilizando a célula do tipo Filtro-prensa. ET: Eletrodo de trabalho, CE: Contra eletrodo, ER: Eletrodo de referência, M: membrana. (1) Recipiente da solução do compartimento catódico e (2) Recipiente da solução do compartimento anódico

Figura 7 - Cromatograma da mistura de ácido fórmico, ácido acético, acetaldeído e etanol $20 \mathrm{mmol} \mathrm{L}^{-1} \mathrm{em} \mathrm{H}_{2} \mathrm{O}$ (a cima) e outro do carbonato de

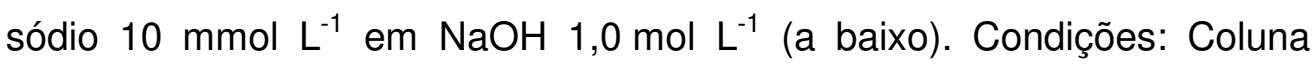
Phenomenex (300/ 7,8mm), Fase Móvel $\mathrm{H}_{2} \mathrm{SO}_{4} 3,33 \mathrm{mmol} \mathrm{L}^{-1}$, Fluxo: 0,6 $\mathrm{mL} \mathrm{min}^{-1}$, detector: índice de refração. 
Figura 8 - Célula eletroquímica e eletrodos empregados nos experimentos de espectroscopia no Infra-Vermelho in situ.

Figura 9 - Micrografias obtidas por MEV com ampliações de 500 vezes dos eletrodos de composições nominais: (A) $\mathrm{SnO}_{2}$ e (B) $\left.\mathrm{Sn}_{0,99}\right|_{0,01} \mathrm{O}_{2} \ldots \ldots \ldots$

Figura 10 - Micrografias obtidas por MEV com ampliações de 500 vezes dos eletrodos de composições nominais: (A) $\mathrm{Sn}_{0,95} \mid \mathrm{r}_{0,05} \mathrm{O}_{2}$ e (B) $\mathrm{Sn}_{0,90} \mathrm{Ir}_{0,10} \mathrm{O}_{2}$

Figura 11 - Micrografia obtida por MEV com ampliação de 500 (A) e 2000 (B) vezes do eletrodo de composição nominal $\mathrm{Sn}_{0,70} \mathrm{Ir}_{0,30} \mathrm{O}_{2}$

Figura 12 - Espectro de EDX representativo da composição global do eletrodo $\mathrm{Ti} / \mathrm{Sn}_{0,7} \mid \mathrm{r}_{0,3} \mathrm{O}_{2}$

Figura 13 - Micrografia obtida por MEV do corte transversal do eletrodo de composição nominal $\mathrm{Sn}_{0,90} \mathrm{Ir}_{0,10} \mathrm{O}_{2}$ com ampliação de 1000 vezes. Elétrons Secundários (A) e Elétrons Retro-Espalhados (B)

Figura 14 - Difratogramas de Raios-X das várias composições dos eletrodos de $\mathrm{Ti} / \mathrm{Sn}_{(1-x)} \mid \mathrm{r}_{\mathrm{x}} \mathrm{O}_{2}$. A figura $\mathbf{B}$ é a ampliação do primeiro pico da figura $A$. Os traços verticais indicam os seguintes padrões: vermelho $\mathrm{SnO}_{2}$, verde $\mathrm{IrO}_{2}$ e azul $\mathrm{Ti}^{\circ}$

Figura 15 - Voltamogramas cíclicos de todas as composições de eletrodo em solução de $\mathrm{H}_{2} \mathrm{SO}_{4} 0,5 \mathrm{~mol} \mathrm{~L}^{-1}$ a $20 \mathrm{mV} \mathrm{s}^{-1}$. 
Figura 17 - Voltamogramas cíclicos de dois eletrodos contendo $30 \%$ de $\mathrm{IrO}_{2}$ (os eletrodos A e B) em solução de $\mathrm{H}_{2} \mathrm{SO}_{4} 0,5 \mathrm{~mol} \mathrm{~L}^{-1}$ a $20 \mathrm{mV} \mathrm{s}^{-1} \ldots \ldots$.

Figura 18 - Gráfico de corrente capacitiva em função da velocidade de varredura, obtida no potencial de 1,3 $\vee(E R H)$, para todas as composições dos óxidos.

Figura 19 - Gráfico da capacitância da dupla camada elétrica e da carga anódica em função da $\%$ de $\quad \mathrm{IrO}_{2}$ na composição do eletrodo.

Figura 20 - Voltamogramas cíclicos do eletrodo $\mathrm{Ti} / \mathrm{SnO}_{2}$ em solução de $\mathrm{H}_{2} \mathrm{SO}_{4} 0,5 \mathrm{~mol} \mathrm{~L}^{-1}$ a $20 \mathrm{mV} \mathrm{s}^{-1}$

Figura 21 - Voltamogramas cíclicos do eletrodo contendo $1 \%$ de $\mathrm{IrO}_{2}$ em solução de $\mathrm{H}_{2} \mathrm{SO}_{4} 0,5 \mathrm{~mol} \mathrm{~L}^{-1}$ a $20 \mathrm{mV} \mathrm{s}^{-1}$

Figura 22 - Voltamogramas cíclicos dos primeiros 15 ciclos do eletrodo contendo $30 \%$ de $\mathrm{IrO}_{2}$ em solução de $\mathrm{H}_{2} \mathrm{SO}_{4} 0,5 \mathrm{~mol} \mathrm{~L}^{-1}$ a $20 \mathrm{mV} \mathrm{s}^{-1}$..

Figura 23 - Mecanismo da RDO em eletrodos de óxidos: (1) formação do radical hidroxila $\left({ }^{\circ} \mathrm{OH}\right)$ pela oxidação da água; (2) transferência do oxigênio do ${ }^{\circ} \mathrm{OH}$ para o retículo do óxido (formação de um sítio com estado de oxidação superior); (3) RDO por oxidação eletroquímica das espécies ${ }^{\circ} \mathrm{OH}$; (4) RDO por decomposição química dos sítio com estado de oxidação superior.

Figura 24 - Voltamogramas cíclicos dos eletrodos contendo de 0 a $30 \%$ de $\mathrm{IrO}_{2}$ na mistura dos óxidos em solução de $\mathrm{H}_{2} \mathrm{SO}_{4} 0,5 \mathrm{~mol} \mathrm{~L}^{-1}$ a $20 \mathrm{mV} \mathrm{s}^{-1} \ldots$. 
Figura 25 - Gráfico da densidade de corrente (i) e densidade de corrente dividida pela carga voltamétrica em função da concentração de $\mathrm{IrO}_{2}$. As i extraídas da Fig.24 em um potencial de 1,7 V (ERH). As cargas utilizadas na divisão são dos voltamogramas com varredura de potenciais entre 0,4 e 1,4 a $20 \mathrm{mV} \mathrm{s}^{-1}$ para cada respectiva composição.

Figura 26 - Curvas cronopotenciométricas obtidas em meio de $\mathrm{H}_{2} \mathrm{SO}_{4}$ $0,5 \mathrm{~mol} \mathrm{~L}^{-1}$ e corrente constante de $100 \mathrm{~mA} \mathrm{~cm}^{-2}$.

Figura 27 - Voltamogramas cíclicos do eletrodo contendo $1 \%$ do óxido de irídio em meio de $\mathrm{H}_{2} \mathrm{SO}_{4} \quad 0,5 \mathrm{~mol} \mathrm{~L}^{-1}$ a $20 \mathrm{mV} \mathrm{s}^{-1}$. Os Voltamogramas cíclicos foram obtidos antes, durante e após o experimento de cronopotenciometria.

Figura 28 - Voltamogramas cíclicos do eletrodo contendo 10\% do óxido de irídio em meio de $\mathrm{H}_{2} \mathrm{SO}_{4} \quad 0,5 \mathrm{~mol} \mathrm{~L}^{-1}$ a $20 \mathrm{mV} \mathrm{s}^{-1}$. Os Voltamogramas cíclicos foram obtidos antes, durante e após o experimento de cronopotenciometria

Figura 29 - Representação esquemática do mecanismo de interação entre grãos, responsável pela condutividade em sistemas do tipo $(\mathrm{Ti}) \mid \mathrm{rO} \mathrm{O}_{2}$ e (Ti) $\mid \mathrm{rO}_{2} / \mathrm{SnO}_{2}$. (1) Grão do óxido condutor; (2) Matriz de $\mathrm{SnO}_{2}$; (3) "Caminho" da condução eletrônica para composições com no mínimo de $30 \%$ do óxido condutor metálico $\left(\mathrm{IrO}_{2}\right)$; (4) "Caminho" da condução eletrônica para composições inferiores a 30\% do óxido condutor metálico $\left(\mathrm{IrO}_{2}\right)$

Figura 30 - Voltamogramas cíclicos do eletrodo contendo $5 \%$ do óxido de irídio em meio de $\mathrm{H}_{2} \mathrm{SO}_{4} \quad 0,5 \mathrm{~mol} \mathrm{~L}^{-1}$ a $20 \mathrm{mV} \mathrm{s}^{-1}$. Os Voltamogramas cíclicos foram obtidos antes, durante e após o experimento de cronopotenciometria.. 
Figura 31 - Voltamogramas cíclicos do eletrodo contendo $30 \%$ do óxido de irídio em meio de $\mathrm{H}_{2} \mathrm{SO}_{4} \quad 0,5 \mathrm{~mol} \mathrm{~L}^{-1}$ a $20 \mathrm{mV} \mathrm{s}^{-1}$. Os Voltamogramas cíclicos foram obtidos antes, durante e após o experimento de cronopotenciometria.

Figura 32 - Voltamogramas cíclicos em solução $\mathrm{H}_{2} \mathrm{SO}_{4} 0,5 \mathrm{~mol} \mathrm{~L}^{-1}$ a $20 \mathrm{mV}$ $\mathrm{s}^{-1}$ na presença e ausência de ácido acético $0,1 \mathrm{~mol} \mathrm{~L}^{-1}$ para eletrodos contendo: (A) $1 \%$ de $\mathrm{IrO}_{2}$, (B) $5 \%$ de $\mathrm{IrO}_{2}$, (C) $10 \%$ de $\mathrm{IrO}_{2}$, e (D) $30 \%$ de $\mathrm{IrO}_{2}$

Figura 33 - Voltamogramas cíclicos em solução de $\mathrm{H}_{2} \mathrm{SO}_{4} 0,5 \mathrm{~mol} \mathrm{~L}^{-1}$ a 20 $\mathrm{mV} \mathrm{s}^{-1}$ na presença e ausência do acetaldeído $0,1 \mathrm{~mol} \mathrm{~L}^{-1}$ para os eletrodos contendo: (A) $1 \%$ de $\mathrm{IrO}_{2}$, (B) $5 \%$ de $\mathrm{IrO}_{2}$, (C) $10 \%$ de $\mathrm{IrO}_{2} \mathrm{e}$ (D) $30 \%$ de $\mathrm{IrO}_{2}$

Figura 34 - Gráfico da densidade de carga de pico da eletrooxidação do acetaldeído ( $\mathbf{q}_{\text {oxi }}$ ) e $\mathbf{q}_{\text {oxi }} / \mathbf{q}_{\mathrm{a}}$ em função da quantidade de $\mathrm{IrO}_{2}$ contida no eletrodo.

Figura 35 - Gráficos do consumo do acetaldeído (A), seletividade para a formação do ácido acético (B) em função do tempo de eletrólise para todas as composições de eletrodos. Concentração inicial de acetaldeído = $5 \mathrm{mmol} \mathrm{L}^{-1}$, corrente aplicada $=20 \mathrm{~mA} \mathrm{~cm}^{-2}$.

Figura 36 - Voltamogramas cíclicos em solução de $\mathrm{H}_{2} \mathrm{SO}_{4} \quad 0,5 \mathrm{~mol} \mathrm{~L}^{-1}$ a $20 \mathrm{mV} \mathrm{s}^{-1}$ na presença e ausência de etanol $0,1 \mathrm{~mol} \mathrm{~L}^{-1}$ para os eletrodos contendo: (A) $1 \%$ de $\mathrm{IrO}_{2}$, (B) $5 \%$ de $\mathrm{IrO}_{2}$, (C) $10 \%$ de $\mathrm{IrO}_{2}$ e (D) $30 \%$ de $\mathrm{IrO}_{2}$.

Figura 37 - Curva da porção anódica dos voltamogramas cíclicos da oxidação de etanol subtraídos dos voltamogramas cíclicos dos eletrodos em eletrólito suporte, para os eletrodos contendo $1 \%, 5 \%, 10 \%$ e $30 \%$ de $\mathrm{IrO}_{2}$ 
Figura 38 - Gráfico da densidade de carga de pico da eletrooxidação do etanol ( $\mathbf{q}_{\text {oxi }}$ ) e $\mathbf{q}_{\text {oxi }} / \mathbf{q}_{\mathbf{a}}$ em função da quantidade de $\mathrm{IrO}_{2}$ contida no eletrodo.

Figura 39 - Ampliação dos cromatogramas obtidos em diferentes tempos de eletrólise com eletrodo contendo $1 \%$ de irídio realizada a $100 \mathrm{~mA} \mathrm{~cm} \mathrm{~cm}^{-2}$. Condições: Coluna: da Bio Rad mod. HPX-87H(250 mm/4,6 mm), T=30 ${ }^{0} \mathrm{C}$, Fase Móvel $\mathrm{H}_{2} \mathrm{SO}_{4} 3,33 \mathrm{mmol} \mathrm{L}^{-1}$, Fluxo: 0,4 $\mathrm{mL} \mathrm{min}^{-1}$, detector: índice de refração. Os picos são referentes ao (1) ácido acético, (2) acetaldeído e (3) etanol.

Figura 40 - Ampliação dos cromatogramas obtidos em diferentes tempos de eletrólise com eletrodo contendo $30 \%$ de irídio realizada a $100 \mathrm{~mA} \mathrm{~cm}$ 2. Condições: Coluna: da Bio Rad mod. HPX-87H(250 mm/4,6 mm), T=30 ${ }^{0} \mathrm{C}$, Fase Móvel $\mathrm{H}_{2} \mathrm{SO}_{4} 3,33 \mathrm{mmol} \mathrm{L}^{-1}$, Fluxo: 0,4 $\mathrm{mL} \mathrm{min}^{-1}$, detector: índice de refração. Os picos são referentes ao (1) ácido acético e (2) etanol

Figura 41 - Ampliação dos cromatogramas obtidos em diferentes tempos de eletrólise com eletrodo contendo $30 \%$ de irídio realizada a $100 \mathrm{~mA} \mathrm{~cm}$ 2. Condições: Coluna: da Bio Rad mod. HPX-87H(250 mm/4,6 mm), T=30 ${ }^{0} \mathrm{C}$, Fase Móvel $\mathrm{H}_{2} \mathrm{SO}_{4} 3,33 \mathrm{mmol} \mathrm{L}{ }^{-1}$, Fluxo: 0,4 $\mathrm{mL} \mathrm{min}^{-1}$, detector: U.V. $\lambda=210 \mathrm{~nm}$. O pico é referente a formação de ácido acético.

Figura 42 - Gráficos do consumo de etanol (A) e formação de ácido acético (B) em função do tempo de eletrólise para todas as composições de eletrodos. Concentração inicial de etanol $=5 \mathrm{mmol} \mathrm{L}^{-1}$, corrente aplicada $=100 \mathrm{~mA} \mathrm{~cm}^{-2}$

Figura 43 - Gráficos do consumo do etanol (A) e formação de ácido acético (B) em função do tempo de eletrólise para todas as composições de eletrodos. Concentração inicial de etanol $=5 \mathrm{mmol} \mathrm{L}^{-1}$, corrente aplicada $=20 \mathrm{~mA} \mathrm{~cm}^{-2}$ 
Figura 44 - Gráficos do consumo do etanol (A), formação do ácido acético (B) e formação do acetaldeído (C) em função do tempo de eletrólise para todas as composições de eletrodos. Concentração inicial de etanol $=20$ $\mathrm{mmol} \mathrm{L}{ }^{-1}$, corrente aplicada $=20 \mathrm{~mA} \mathrm{~cm}^{-2}$

Figura 45 - Voltamogramas cíclicos em solução de $\mathrm{HClO}_{4} 0,1 \mathrm{~mol} \mathrm{~L}^{-1}$ a $20 \mathrm{mV} \mathrm{s}^{-1}$ para o eletrodo contendo $1 \%$ de $\mathrm{IrO}_{2}$ preparado sobre ouro polido.

Figura 46 - Voltamogramas cíclicos em solução de $\mathrm{HClO}_{4} 0,1 \mathrm{~mol} \mathrm{~L}^{-1}$ a $5 \mathrm{mV} \mathrm{s}^{-1}$ na presença e ausência de etanol $0,1 \mathrm{~mol} \mathrm{~L}^{-1}$ para o eletrodo contendo $1 \%$ de $\mathrm{IrO}_{2}$

Figura 47 - Voltamogramas cíclicos em solução de $\mathrm{HClO}_{4} 0,1 \mathrm{~mol} \mathrm{~L}^{-1}$ a $5 \mathrm{mV} \mathrm{s}^{-1}$ na presença e ausência de etanol $1,0 \mathrm{~mol} \mathrm{~L}^{-1}$ para o eletrodo contendo $1 \%$ de $\mathrm{IrO}_{2}$

Figura 48 - Gráfico do rendimento do consumo de etanol e da seletividade dos produtos identificados (acetaldeído=AAld, ácido acético=HAC e $\mathrm{CO}_{2}$ ) em função da composição eletródica. Foram eletrolisadas $15 \mathrm{~mL}$ de etanol $0,1 \mathrm{~mol} \mathrm{~L}^{-1}$ em meio de $\mathrm{HClO}_{4} 0,1 \mathrm{~mol} \mathrm{~L}^{-1}$ e corrente constante de $20 \mathrm{~mA}$ $\mathrm{cm}^{-2}$ por 4 horas. As colunas que representam $\circ \mathrm{CO}_{2}$ formado foram multiplicadas por um fator de dez

Figura 49 - Espectros de FTIR in situ obtidos pelo método de SNIFITIRS com modulação de $300 \mathrm{mV}$ para todas as composições eletródicas durante a oxidação do etanol. Os potenciais de modulação foram entre: $[0,5-0,8 \mathrm{~V}],[0,7-1,0 \mathrm{~V}],[0,9-1,2 \mathrm{~V}],[1,1-1,4 \mathrm{~V}],[1,2-1,5 \mathrm{~V}],[1,3-1,6 \mathrm{~V}],[1,4-$ $1,7 \mathrm{~V}]$ e $[1,5-1,8 \mathrm{~V}]$ que estão representados pelos espectros em ordem decrescente nos gráficos 
Figura 50 - Espectros de FTIR in situ obtidos pelo método de SPAIRS entre 0,4 e 1,8 $\mathrm{V}$ em passos de $0,1 \mathrm{~V}$ para todas as composições eletródicas durante a oxidação do etanol

Figura 51 - Espectros de FTIR in situ obtidos pelo método de SPAIRS entre 0,4 e $1,8 \mathrm{~V}$ em passos de $0,1 \mathrm{~V}$ para todas as composições eletródicas durante a oxidação do acetaldeído

Figura 52 - Gráfico da intensidade das bandas de $\mathrm{CO}_{2}$ localizadas em $2345 \mathrm{~cm}^{-1}$ (extraídas da Figura 50) em função do potencial para todas as composições eletródicas.

Figura 53 - Gráfico do rendimento do consumo de etanol e da seletividade dos produtos identificados (acetaldeído=AAld e ácido acético=HAC) e $\mathrm{CO}_{2}$ em função da composição eletródica. Foram eletrolisadas $100 \mathrm{~mL}$ de etanol 0,1 mol L-1 em meio de $\mathrm{HClO}_{4}$ 0,1 $\mathrm{mol} \mathrm{L}^{-1}$ com um fluxo de $6,25 \mathrm{~mL}$ $\mathrm{min}^{-1}$ e corrente constante de $20 \mathrm{~mA} \mathrm{~cm}{ }^{-2}$ por 5 horas. As colunas que representam $\circ \mathrm{CO}_{2}$ formado foram multiplicadas por um fator de dez..........

Figura 54 -Gráfico do rendimento do consumo de etanol e da seletividade dos produtos identificados (acetaldeído=AAld e ácido acético=HAC) em função do fluxo da solução. Foram eletrolisadas $100 \mathrm{~mL}$ de etanol $0,1 \mathrm{~mol}$ $\mathrm{L}^{-1}$ em meio de $\mathrm{HClO}_{4}$ 0,1 mol L-1 com um fluxo de 6,25, 23,50 e 42,75 mL $\mathrm{min}^{-1}$ e corrente constante de $20 \mathrm{~mA} \mathrm{~cm}{ }^{-2}$ por 5 horas no eletrodo contendo $1 \%$ de $\mathrm{IrO}_{2}$. As colunas que representam $\circ \mathrm{CO}_{2}$ formado foram multiplicadas por um fator de dez

Figura 55 -Gráfico do rendimento da oxidação de etanol [A], da seletividade dos produtos identificados (acetaldeído=AAld [B] e ácido acético=HAc [C]) e AAld/AHc [D] em função do tempo de eletrólise. Foram eletrolisadas $100 \mathrm{~mL}$ de etanol em diferentes concentrações em meio de $\mathrm{HClO} 40,1 \mathrm{~mol} \mathrm{~L}-1$ com o eletrodo contendo $1 \%$ de $\mathrm{IrO} 2$ e corrente constante de $20 \mathrm{~mA} \mathrm{~cm}-2$ por 6 horas. 
Figura 56-Gráfico das seletividades para a formação de $\mathrm{CO}_{2}$ e acetaldeído ao final de 6 horas de eletrólise em função da concentração de etanol inicial...................................................................................... 97 


\section{ÍNDICE DE TABELAS}

Tabela I: Comparação entre a composição nominal das camadas de óxidos contendo $\mathrm{IrO}_{2} / \mathrm{SnO}_{2}$ e a composição real determinada por EDX.......

Tabela II: Resultados das análises pontuais da camada de óxido do eletrodo de composição $\mathrm{Sn}_{0,9} \mid \mathrm{r}_{0,1} \mathrm{O}_{2}$ determinada por EDX

Tabela III: Porcentagem de acetaldeído consumido e de produtos formados após 300 minutos de eletrólise em meio ácido para todas as composições dos eletrodos. Concentração inicial de acetaldeido $=5 \mathrm{mM}$, corrente aplicada $=20 \mathrm{~mA} \mathrm{~cm}^{-2}$

66

Tabela IV: Tabela das concentrações e rendimento do consumo de etanol e formação dos reagentes após 240 minutos de eletrólise em meio ácido para todas as composições dos eletrodos. Concentração inicial de etanol $=$ $5 \mathrm{mM}$, corrente aplicada $=100 \mathrm{~mA} \mathrm{~cm}^{-2}$.

Tabela V: Porcentagem de etanol consumido e de produtos formados após 240 minutos de eletrólise em meio ácido para todas as composições dos eletrodos. Concentração inicial de etanol $=5 \mathrm{mM}$, corrente aplicada $=20$ $\mathrm{mA} \mathrm{cm}{ }^{-2}$.

Tabela VI: Porcentagem de etanol consumido e de produtos formados após 240 minutos de eletrólise em meio ácido para todas as composições dos eletrodos. Concentração inicial de etanol $=20 \mathrm{mM}$, corrente aplicada $=$ $20 \mathrm{~mA} \mathrm{~cm}^{-2}$

Tabela VII - Relação entre acetaldeído e ácido acético formados após 4 horas de eletrólises para as diferentes composições de eletrodo. 


\section{Lista de Símbolos e Abreviaturas}

\begin{tabular}{|c|c|}
\hline MEV & Microscopia Eletrônica de Varredura \\
\hline EDX & Energia Dispersiva de Raios-X \\
\hline FTIR & Infravermalho com transformada de Fourier \\
\hline $\mathrm{RDO}$ & Reação de Desprendimento de Oxigênio \\
\hline $\mathrm{RDH}$ & Reação de Desprendimento de Hidrogênio \\
\hline VC & Voltametria Cíclica \\
\hline $\mathrm{q}_{\text {oxi }}$ & Carga de oxidação \\
\hline $\mathrm{EtOH}$ & Etanol \\
\hline AAld & Acetaldeído \\
\hline HAc & Ácido acético \\
\hline SNIFITIRS & $\begin{array}{l}\text { Espectroscopia no Infravermelho com transformada de } \\
\text { Fourier com reflexão externa e diferença de espectros em } \\
\text { dois potenciais }\end{array}$ \\
\hline SPAIRS & $\begin{array}{l}\text { Espectroscopia no Infravermelho durante uma variação } \\
\text { linear de potenciais }\end{array}$ \\
\hline CLAE & Cromatografia Líquida de Alta Eficiência \\
\hline$\tau$ & Rendimento \\
\hline$v$ & Velocidade de varredura de potenciais \\
\hline $\mathbf{i}$ & Densidade de corrente \\
\hline $\mathrm{i}_{E}$ & i em um dado potencial \\
\hline $\mathrm{C}_{\mathrm{dc}}$ & Capacitância da dupla camada elétrica \\
\hline$q$ & Carga voltamétrica \\
\hline $\mathrm{q}_{\mathrm{a}}$ & Carga voltamétrica anódica \\
\hline$q_{c}$ & Carga voltamétrica catódica \\
\hline
\end{tabular}




\section{RESUMO}

Neste trabalho foram investigados o efeito da adição de diferentes quantidades de $\mathrm{IrO}_{2}$ (entre 1 e $30 \%$ em mol) em eletrodos de $\mathrm{SnO}_{2}$ e suas atividades eletrocatalíticas para a reação de oxidação de etanol.

A inovação deste trabalho está na composição do eletrodo onde a concentração de $\mathrm{IrO}_{2}$ varia de níveis da ordem de dopante até concentrações típicas de ADE.

O método de preparação utilizado permitiu a obtenção de filmes homogêneos e com estequiometria controlada, comprovados pela técnica de Energia Dispersiva de Raios-X (EDX). A análise de Microscopia Eletrônica de Varredura (MEV) mostrou que os filmes possuem morfologia com trincas. $\mathrm{Na}$ análise por Difração de Raios-X (DRX) ficou evidente a formação de solução sólida. A caracterização por Voltametria Cíclica mostrou que a carga voltamétrica e a corrente relacionada a reação de desprendimento de oxigênio (RDO) aumentam com a concentração de $\mathrm{IrO}_{2}$ na composição do eletrodo. Adicionalmente, a ordem da estabilidade eletroquímica encontrada é a seguinte: $30>>1 \cong 10>5 \%$ em mol de $\mathrm{IrO}_{2}$.

Para avaliar a atividade eletrocatalítica destes eletrodos para a reação de oxidação de etanol foram utilizadas as técnicas de voltametria cíclica, eletrólise a corrente constante e Infravermelho com Transformada de Fourier (FTIR) in situ. Foram identificados como produtos acetaldeído, acido acético e $\mathrm{CO}_{2}$. Comprovouse que o ácido acético não é oxidado nas condições experimentais empregadas. Observou-se que os eletrodos contendo 5 e $10 \%$ em mol de $\mathrm{IrO}_{2}$ apresentaram as maiores velocidades de oxidação do etanol formando preferencialmente ácido acético. Os eletrodos contendo 1 e $30 \%$ em mol de $\mathrm{IrO}_{2}$ apresentaram maior seletividade para $\mathrm{CO}_{2}$ em relação as outras composições.

$\mathrm{A}$ adição de $1 \%$ em mol de $\mathrm{IrO}_{2}$ no $\mathrm{SnO}_{2}$ foi suficiente para promover uma estabilidade satisfatória para a aplicação deste eletrodo. Outra observação importante foi que este eletrodo apresentou a menor seletividade para a formação de ácido acético permitindo uma maior formação de $\mathrm{CO}_{2}$. 


\section{ABSTRACT}

In this work was investigated the effect of the $\mathrm{IrO}_{2}$ addition $(1-30$ mol\% contents) on $\mathrm{SnO}_{2}$ electrodes and its electrocatalytic activities towards ethanol oxidation.

The new approach of this work is related to the $\mathrm{IrO}_{2}$ contents on the electrodes compositions shifts between the dopant levels until Dimensionally Stable Anodes $\left(\mathrm{DSA}^{\circledR}\right)$ concentrations.

The preparation method used allowed to obtain homogeneous films with controlled stoichiometry, that was confirmed by Energy Dispersive X-ray (EDX) analysis. The Scanning Electron Microscopy (SEM) and X-ray diffraction (XRD) analysis showed a cracked morphology and the formation of solid solution, respectively. The voltammetric experiments showed an increase in the Oxygen Evolution Reaction (OER) currents and the voltammetric charges for the higher $\mathrm{IrO}_{2}$ contents. In addition, the stability order found is $30>1 \cong 10>5 \mathrm{~mol} \% \mathrm{IrO}_{2}$.

In order to investigate the electrodes activities towards ethanol oxidation, the cyclic voltammetry, electrolysis and Fourier Transform Infrared (FTIR) in situ techniques were used. The presence of products as acetaldehyde, acetic acid and $\mathrm{CO}_{2}$ was detected. Acetic acid was not oxided in the experimental conditions employed. The 5 and 10 mol\% $\mathrm{IrO}_{2}$ electrodes showed higher ethanol oxidation rates with the preferential acetic acid formation. The electrodes containing 1 and $30 \mathrm{~mol} \% \mathrm{IrO}_{2}$ are more selective to $\mathrm{CO}_{2}$ production than the others compositions.

The addition of $1 \mathrm{~mol} \% \mathrm{IrO} \mathrm{I}_{2}$ was enough to enhance the electrode stability, that make it applicable. Another interesting observation is that the $\mathrm{IrO}_{2} 1 \mathrm{~mol} \%$ electrode presented the smaller selectivity for the acid acetic formation allowing the complete oxidation of ethanol possible. 


\section{CAPÍTULO I}

\section{INTRODUÇÃO}

\section{Aspectos Gerais}

Verifica-se nas ultimas décadas uma intensa expansão da pesquisa na área de eletroquímica orgânica com objetivos mecanísticos e sintéticos. Recentemente o interesse nesta área tem crescido principalmente devido às exigências legais ambientais cada vez mais restritivas quanto aos efluentes industriais.

Além disso, também há um grande interesse no desenvolvimento de eletrocatalisadores que atuem com eficiência na oxidação de pequenas moléculas orgânicas como, por exemplo, ácido fórmico, metanol e formaldeído [1, 2]. Tal interesse é justificado pela intensa procura de substâncias que possam substituir o hidrogênio gasoso utilizado como combustível em dispositivos eletroquímicos chamados células a combustível [3, 4]. As moléculas orgânicas pequenas podem ser utilizadas como modelo para a compreensão dos mecanismos reacionais de eletrooxidação de moléculas maiores, as quais podem ser encontradas como poluentes em efluentes industriais.

A eficiência eletrocatalítica depende de diversos fatores como valor da densidade de corrente e, principalmente, a natureza do material do eletrodo [5], os quais devem ser estáveis química e estruturalmente em presença de soluções ácidas e/ou básicas, e resistentes a processos de corrosão. No caso de moléculas orgânicas, a oxidação direta pode ser alcançada utilizando eletrodos de metais nobres como, por exemplo, a platina, o paládio, entre outros. Porém, estes eletrodos de metais nobres podem sofrer um fenômeno de envenenamento da superfície, onde produtos intermediários da reação de oxidação, difíceis de serem oxidados, adsorvem-se fortemente sobre a superfície do eletrodo ocupando sítios 
ativos, impedindo, assim, que outras espécies, mais facilmente oxidáveis, se adsorvam e sejam oxidadas, o que leva a uma perda progressiva da atividade catalítica do eletrodo.

Um dos materiais de eletrodo que podem ser utilizados são os eletrodos formados por óxidos metálicos eletronicamente condutores chamados de Ânodos Dimensionalmente Estáveis (ADE), tais como $\mathrm{RuO}_{2}, \mathrm{IrO}_{2}, \mathrm{RhO}_{2}$, entre outros. $A$ utilização de eletrodos recobertos com óxidos metálicos pode ser uma estratégia para evitar o fenômeno de envenenamento da superfície, pois acredita-se que os óxidos de cátions metálicos possuam vários estados de oxidação podendo adsorver grandes quantidades de espécies $\mathrm{OH}$ e $\mathrm{O}$ os quais serão agentes oxidantes efetivos durante a reação [6].

Eletrodos do tipo ADEs, introduzidos por Beer [7] na década de 60, têm sido usados por muitos anos como ânodos estáveis na industria cloro-soda. Os ADEs combinam alta resistência mecânica com excelentes propriedades eletrocatalíticas. Basicamente os ADEs são constituídos por um suporte metálico, freqüentemente titânio, sobre o qual é depositado, por deposição térmica, os sais precursores dissolvidos em solvente apropriado. A forte adesão da mistura dos óxidos ao suporte metálico é assegurada pela formação, a partir do Ti metálico, de uma camada de $\mathrm{TiO}_{2}$ durante a calcinação da mistura precursora [8].

Apesar das propriedades altamente desejáveis dos ADEs, as suas aplicações como material eletródicos em eletrossíntese orgânica é um campo pouco explorado. Um dos primeiros trabalhos foi publicado em meados da década de 70 por Galizzioli et al. [9]. No entanto, somente na década de 90 estes materiais passaram a ser utilizados mais intensamente na investigação da eletrooxidação de compostos orgânicos passando a receber considerável atenção no campo da eletrossíntese orgânica [10-13] e tratamento de efluentes [14-18].

Um dos primeiros trabalhos descritos na literatura envolvendo a oxidação de moléculas orgânicas com eletrodos de óxidos metálicos foi de Burke e Murphy [6], os quais estudaram a eletrooxidação de metanol em meio ácido sobre eletrodos de $\mathrm{Pt}$ modificados com $\mathrm{RuO}_{2}$ preparados termicamente. Os autores verificaram boa eficiência deste material na oxidação do metanol.

Katayama [19] estudou a eletrooxidação do metanol utilizando eletrocatalisadores formados por óxido de estanho e platina comprovando uma 
maior atividade catalítica para este material do que para platina pura e do que 0 sistema binário Pt-Sn. O autor observou que a platina contida no sistema óxido de Pt-Sn foi fixada em sua forma iônica pelo óxido de estanho, dificultando, assim, a adsorção das espécies que envenenam a superfície do eletrodo.

Aramata et al. [20] estudaram a eletrooxidação do metanol utilizando óxido de Rh-Sn, óxido de Pt- Sn e óxido de Ir-Sn comparando-os com a Pt metálica. Os autores verificaram uma maior atividade catalítica para o óxido de Pt-Sn atribuindo este fato a existência de vários estados de oxidação da Pt tais como, $\mathrm{Pt}^{0}, \mathrm{Pt}^{2+}$ e $\mathrm{Pt}^{4+}$ os quais são estabilizados pelo óxido de estanho.

Outra molécula que também está presente em muitos processos tecnológicos, tal como, nas industrias têxteis, e a qual normalmente é descartada sem um tratamento prévio, é o formaldeído. Motheo et al. [5] estudaram a eletrooxidação de formaldeído em três diferentes eletrodos de óxidos tipo ADEs, $\mathrm{Ti} / \mathrm{Ir}_{0,3} \mathrm{Ti}_{0,7} \mathrm{O}_{2}$, Ti/Ru $\mathrm{Ru}_{0,3} \mathrm{Ti}_{0,7} \mathrm{O}_{2}$ e $\mathrm{Ti} / \mathrm{Ir}_{0,2} \mathrm{Ru}_{0,2} \mathrm{Ti}_{0,6} \mathrm{O}_{2}$. O óxido ternário foi o que apresentou a maior atividade eletrocatalítica.

De Andrade et al. [13] investigaram a oxidação de etanol em eletrodos de $\mathrm{Ti} / \mathrm{RuO}_{2}$ em meio de $\mathrm{HClO}_{4}$ 1,0 mol L-1. Os resultados revelaram uma alta seletividade do sistema, formando como principal produto acetaldeído em eletrólise a potencial controlado.

Kim et al. [21] investigaram a eletrooxidação de etanol em eletrodos de níquel descoberto, titânio recoberto com $\mathrm{RuO}_{2}\left(\mathrm{Ti}_{\mathrm{RuO}}\right)$ e níquel recoberto com $\mathrm{RuO}_{2}\left(\mathrm{Ni} / \mathrm{RuO}_{2}\right)$ em meio alcalino. Foi observado que o eletrodo $\mathrm{Ni} / \mathrm{RuO}_{2}$ oxidou etanol com maior eficiência.

Muitos processos industriais são fontes de poluentes fenólicos, incluindo refinarias de óleo, produção de carvão mineral, industrias químicas e de plásticos. Muitos tratamentos estão sendo usados ou têm sido propostos, para a recuperação ou destruição do fenol, incluindo adsorção em carbono ativado e extração com solvente para a recuperação, e para a destruição, os tratamentos biológicos, químicos e oxidação eletroquímica. Comninellis et al. [14, 15, 22] investigaram a oxidação anódica do fenol em ânodo de $\mathrm{Pt}, \mathrm{Ti} / \mathrm{SnO}_{2}$ e $\mathrm{Ti} / \mathrm{IrO}_{2}$.

As medidas de eficiência de corrente e as análises de intermediários de reações têm mostrado que ânodos tradicionais $\left(\mathrm{Pt}, \mathrm{Ti} / \mathrm{IrO}, \mathrm{Ti} / \mathrm{RuO}_{2}, \mathrm{Ti} / \mathrm{PbO}_{2}\right.$ ) fornecem uma baixa eficiência de corrente em comparação ao ânodo de $\mathrm{Ti} / \mathrm{SnO}_{2}$, 
o qual não somente fornece alta eficiência de corrente, mas também permite eliminação quase completa de carbono orgânico total [15].

Alguns autores têm mostrado que, em alguns ânodos, a oxidação de orgânicos pode ocorrer somente sob condições de evolução de $\mathrm{O}_{2}$ simultânea. Um mecanismo generalizado tem também sido proposto no qual a oxidação completa do orgânico a $\mathrm{CO}_{2}$ é alcançada no eletrodo "não ativo" (eletrodos, os quais não participam na oxidação) devido à formação de radicais hidroxilas (por exemplo, ânodos de $\mathrm{SnO}_{2}, \mathrm{PbO}_{2}$ ) e que ocorre oxidação seletiva em eletrodos "ativos" (eletrodos, os quais participam na oxidação) devido à formação de um estado de oxidação superiores (por exemplo, ânodos de $\mathrm{IrO}_{2}$ ) [23].

Durante a reação de eletrooxidação do fenol sempre há formação de benzoquinona, quer seja como um intermediário reacional ou até mesmo como produto final. Estudos de oxidação de benzoquinona foram realizados por Santos [24] com eletrodos $\mathrm{Ti} / \mathrm{SnO}_{2}-\mathrm{RuO}_{2}$ e Takeuchi [25] com eletrodos $\mathrm{Ti} / \mathrm{SnO}_{2}-\mathrm{IrO}_{2}-$ $\mathrm{RuO}_{2}$ e verificou-se que durante as eletrólises não se formaram produtos aromáticos, assim, a primeira etapa da eletrooxidação da benzoquinona parece envolver a ruptura do anel aromático nestes eletrodos.

\section{2 - A importância em se estudar o $\mathrm{SnO}_{2}$}

Como descrito acima o dióxido de estanho possui a capacidade de promover eficientemente a oxidação completa de compostos orgânicos e esta característica faz deste óxido um material eletródico promissor para a remoção de espécies orgânicas de efluentes industriais. No entanto, o $\mathrm{SnO}_{2}$ apresenta baixo tempo de vida útil, ou seja, o eletrodo perde rapidamente sua atividade, isto porque este óxido é um semicondutor tipo-n, tendo sua condutividade baseada em vacâncias de oxigênio [26]. A rápida desativação do $\mathrm{SnO}_{2}$ ocorre devido à incorporação de oxigênio a camada de óxido quando esta é submetida a potenciais anódicos, o que torna o óxido de estanho mais estequiométrico e conseqüentemente menos condutor. Geralmente, adiciona-se antimônio como dopante na camada de $\mathrm{SnO}_{2}$, com o objetivo de aumentar sua condutividade e estabilidade. $\mathrm{O}$ antimônio é o dopante mais utilizado, pois sua presença não altera 
significantemente a estrutura cristalina do $\mathrm{SnO}_{2}$, isto devido à similaridade entre os raios iônicos do $\mathrm{Sb}^{5+}(0,71 \AA)$ e do $\mathrm{Sn}^{4+}(0,69 \AA)$.

Correa-Lozano et al. [27] prepararam ânodos de dióxido de estanho dopados com pentóxido de antimônio $\left(\mathrm{SnO}_{2}-\mathrm{Sb}_{2} \mathrm{O}_{5}\right)$ em substratos de Ti e Ti//rO para estudo do tempo de vida útil destes ânodos sob condições galvanostáticas (100 mA cm ${ }^{-2}$ em de $\mathrm{H}_{2} \mathrm{SO}_{4} 1,0 \mathrm{~mol} \mathrm{~L}^{-1}$ a $25^{\circ} \mathrm{C}$ ). Estes autores observaram que a presença de uma intercamada de $\mathrm{IrO}_{2}$ entre o substrato de $\mathrm{Ti}$ e $0 \mathrm{SnO}_{2}-\mathrm{Sb}_{2} \mathrm{O}_{5}$ $\left(\mathrm{Ti} / \mathrm{IrO}_{2} / \mathrm{SnO}_{2}-\mathrm{Sb}_{2} \mathrm{O}_{5}\right)$ aumenta consideravelmente o tempo de vida útil do ânodo. Esta atuação benéfica da intercamada de $\mathrm{IrO}_{2}$ foi atribuída a sua alta estabilidade anódica e a sua estrutura isomorfa com o $\mathrm{TiO}_{2}$ e $\mathrm{SnO}_{2}$.

Em outro trabalho Vicent et al. [28] prepararam eletrodos de $\mathrm{SnO}_{2}$ dopados com antimônio e platina pelo método de "spray" pirólise. Estes autores estudaram a influência do método de preparo dos eletrodos sobre seu tempo de vida útil e constataram que este não aumenta com o número de "spray", mas sim com o aumento da espessura da camada de óxido. Foi observado também, que a presença da platina promove um aumento do tempo de vida útil do eletrodo de $\mathrm{SnO}_{2}$-Sb. Neste trabalho foram obtidos eletrodos com tempo de vida útil de até $750 \mathrm{~h}$ em de $\mathrm{K}_{2} \mathrm{SO}_{4} \quad 0,5 \mathrm{~mol} \mathrm{~L}^{-1}$ a $40 \mathrm{~mA} \mathrm{~cm}^{-2}$ com o aumento da quantidade de platina no eletrodo. Estes eletrodos foram preparados a partir de uma mistura etanol/ $\mathrm{HCl}$ contendo $10 \%(\mathrm{~m} / \mathrm{v})$ de $\mathrm{SnCl}_{4} .5 \mathrm{H}_{2} \mathrm{O}+1 \%(\mathrm{~m} / \mathrm{v})$ de $\mathrm{SbCl}_{3}+2,1 \%(\mathrm{~m} / \mathrm{v})$ de $\mathrm{H}_{2} \mathrm{PtCl}_{6}$ em uma seqüência de quinze "spray" sobre um substrato de Ti.

Além da dopagem com antimônio, a introdução de um segundo óxido ao $\mathrm{SnO}_{2}$ pode modular as propriedades físicas e/ou eletroquímicas deste, proporcionando também um aumento na estabilidade do eletrodo de $\mathrm{SnO}_{2}$. A mistura binária de óxidos $\mathrm{RuO}_{2}-\mathrm{SnO}_{2}$ é particularmente atrativa, isto porque 0 óxido de rutênio é reconhecidamente muito estável e apresenta elevada atividade eletrocatalítica, sendo amplamente empregado na indústria de cloro - soda. Tais características sugerem que o óxido de rutênio seja um excelente modulador das propriedades físicas e/ou eletroquímicas do dióxido de estanho. As características morfológicas e eletroquímicas dos eletrodos de óxidos de rutênio e estanho têm sido estudadas por diversos autores.

Ito M. et al. [29] caracterizaram eletrodos de $\mathrm{RuO}_{2}-\mathrm{SnO}_{2}$ preparados por decomposição térmica de n-butanol contendo sais dos dois metais. A caracterização morfológica dos eletrodos de $\mathrm{RuO}_{2}-\mathrm{SnO}_{2}$ foi realizada através 
das técnicas de microscopia eletrônica de varredura e microscopia de força atômica. As micrografias mostraram, para os eletrodos $\mathrm{RuO}_{2}(80 \%)-\mathrm{SnO}_{2}(20 \%)$,

a existência de depósitos de cristalitos sobre planos que são macroscopicamente lisos, o que é característico para eletrodos do tipo ADEs ricos em rutênio. A microscopia de força atômica confirmou a presença tanto dos depósitos de microcristalitos quanto dos planos macroscopicamente lisos, sendo observado que estes são, na verdade, constituídos por partículas ultrafinas. Para os eletrodos $\mathrm{RuO}_{2}(20 \%)$ - $\mathrm{SnO}_{2}(80 \%)$ começam a aparecer rachaduras no plano macroscopicamente liso do óxido de rutênio o que é típico dos ADEs com baixa porcentagem de rutênio. Estudos por voltametria cíclica, realizados em meio de $\mathrm{H}_{2} \mathrm{SO}_{4} 0,5 \mathrm{~mol} \mathrm{~L}^{-1}$, demonstraram que a carga voltamétrica depende fortemente da composição do eletrodo e atinge um valor máximo para os eletrodos contendo de 20 a $40 \%$ de $\mathrm{RuO}_{2}$.

Em outro trabalho, Murakami et al [30] estes mesmos autores estudaram o comportamento da carga voltamétrica em função da porcentagem de $\mathrm{RuO}_{2}$ em meio ácido e alcalino. Neste trabalho também se observou que os eletrodos contendo de 20 a $40 \%$ de $\mathrm{RuO}_{2}$ possuem maior carga voltamétrica.

Nanni et al. [31] estudaram a morfologia e propriedades eletrocatalíticas para a reação de desprendimento de cloro dos eletrodos de $\mathrm{RuO}_{2}-\mathrm{SnO}_{2}$ preparados pela decomposição térmica de seus cloretos. Estes autores observaram que a atividade eletrocatalítica destes eletrodos era fortemente influenciada pela morfologia dos eletrodos, e que esta sofria grande dependência das porcentagens relativas de rutênio e estanho no eletrodo, uma vez que foi observada a formação de solução sólida entre os dois óxidos dependendo da quantidade de estanho presente nos eletrodos.

\subsection{1- Métodos de preparação de eletrodos recobertos por óxidos metálicos}

De forma geral a preparação dos eletrodos revestidos de óxidos condutores baseia-se na deposição de uma solução contendo os sais precursores sobre um substrato metálico que é aquecido. Este aquecimento provoca a evaporação do solvente e a formação do óxido. 
Geralmente o sal precursor utilizado é um cloreto, como, por exemplo, na obtenção do $\mathrm{ADE}$ comercial de $\mathrm{RuO}_{2}+\mathrm{TiO}_{2}$, onde utiliza-se o cloreto de $\mathrm{Ru}$ e $\mathrm{o}$ cloreto de Ti. A utilização de cloretos dos metais como precursores é intensa devido a disponibilidade dos mesmos.

Camara e Trasatti [32] prepararam eletrodos de composição binária de óxidos de rutênio e zircônio com diferentes combinações de precursores para selecionar o precursor mais apropriado. Foram utilizados como precursores $\mathrm{RuCl}_{3}, \mathrm{Ru}\left(\mathrm{NO}_{3}\right)_{3}, \mathrm{ZrCl}_{4}, \mathrm{ZrOCl}_{2}, \mathrm{ZrO}\left(\mathrm{NO}_{3}\right)_{2}$. Os autores concluíram que o eletrodo preparado com sais de nitratos contendo $50 \%$ em mol de $\mathrm{RuO}_{2}$ foi a combinação de precursores mais apropriada por ser o eletrodo com a maior carga voltamétrica.

O método de preparação utilizado é importante para se obter óxidos com características desejadas. Os filmes de $\mathrm{SnO}_{2}$ podem ser obtidos por diferentes métodos como, por exemplo, deposição de vapor químico e "spray" pirólise [33], decomposição térmica de cloretos e sol-gel [34], e método de "electromagnetic induction heating" [35]

Um método que tem sido largamente utilizado nos filmes de óxido de estanho puro [36] e dopados com antimônio [37-39] é o sol-gel. A deposição nos filmes finos pode ser obtida a partir de precursores alcóxidos e não alcóxidos como cloretos, acetatos, nitratos e carbonatos. Os precursores alcóxidos oferecem filmes com alta qualidade e sua microestrutura pode ser precisamente controlada apesar de serem caros e difíceis de manusear. Os precursores inorgânicos são relativamente baratos e podem ser manuseados convenientemente mas, a composição desejada e a qualidade do filme formado dependem das condições do processo [39].

A decomposição térmica de cloretos de estanho e platina não permite que se controle com eficiência a estequiometria do filme devido a evaporação do $\mathrm{SnCl}_{4}$, geralmente utilizado como precursor, fazendo com que durante o processo de calcinação ocorra uma perda considerável de estanho [40].

Outro método de preparo que tem sido bastante utilizado para a obtenção de eletrodos constituídos por filmes finos de óxidos é o método de decomposição térmica de precursores poliméricos, também chamado de método Pechini [41-43], O método Pechini inicialmente foi desenvolvido para a obtenção de pós cerâmicos e filmes finos. Este método é baseado na habilidade dos ácidos orgânicos 
hidroxicarboxílicos em formar quelatos com diversos cátions metálicos. Inicialmente, o cátion do metal de interesse é complexado pelo ácido hidrocarboxílico. Posteriormente, adiciona-se, sob aquecimento, o quelato do metal de interesse a um álcool polihidroxilado; nestas condições, ocorre uma reação de poliesterificação. Após esta reação, forma-se uma rede polimérica na qual os cátions metálicos ficam homogeneamente distribuídos e fortemente incorporados, o que dificulta sua evaporação e conseqüente perda. Desta forma, o método Pechini permite a obtenção de filmes uniformes, com superfícies homogêneas, além de permitir o controle da estequiometria do filme de óxido. No método Pechini, geralmente a matriz polimérica é obtida através da poliesterificação entre o ácido cítrico e o etilenoglicol [42]. A formação do quelato entre o ácido cítrico e o metal ocorre através da dissolução do sal do metal de interesse em uma mistura de ácido cítrico e etilenoglicol a aproximadamente $90^{\circ} \mathrm{C}$. A etapa seguinte consiste na reação de poliesterificação entre os grupos hidroxil do etilenoglicol e os grupos carboxílicos do ácido, esta etapa ocorre em temperaturas superiores a $120^{\circ} \mathrm{C}$ e dá origem a rede polimérica.

O método Pechini apresenta grandes vantagens para o preparo de eletrodos de filmes de óxidos, principalmente para se preparar eletrodos de $\mathrm{SnO}_{2}$.

A metodologia de preparo do filme de óxido desempenha um papel crucial nas propriedades eletroquímicas do eletrodo. Oliveira-Sousa et al. [34] prepararam eletrodos de $\mathrm{IrO}_{2}$ através de três métodos de preparo: decomposição térmica de cloretos, sol-gel e Pechini. Foi observado que os eletrodos obtidos pelos diferentes métodos apresentaram diferentes morfologias, comportamentos eletroquímicos e tempos de vida útil, sendo estas diferenças bastante significativas. Lassali et al. [44] prepararam eletrodos de composição nominal $\mathrm{Sn}_{0,70} \mathrm{Ir}_{0,30} \mathrm{O}_{2}$ através do processo sol-gel e de decomposição térmica de cloretos. Os autores verificaram que o tipo de precursor de Sn afeta a velocidade e o mecanismo de decomposição da mistura precursora. Baseado em análises realizadas com as técnicas de Microscopia Eletrônica de Varredura (MEV) e Voltametria Cíclica (VC) eles sugerem que pelo menos uma fração do $\mathrm{IrO}_{2}$ presente na superfície da camada do óxido está no estado amorfo e o uso de $\mathrm{SnCl}_{2}$ como precursor produziu um eletrodo com uma maior área superficial. 


\subsubsection{Morfologia, Estrutura e Composição Química}

A composição do eletrodo tem uma influencia muito forte na morfologia, na estrutura (por exemplo: formação de solução sólida), a atividade, o tempo de vida útil e o comportamento eletroquímico do eletrodo. Estes fatores também podem sofrer forte influência das condições de preparação, tais como, tipo de precursor utilizado, espessura da camada, temperatura e tempo de calcinação e da técnica empregada na deposição do filme $[45,46]$. Portanto, é de fundamental importância conhecer estes parâmetros para que se posa fazer uma correlação entre eles e a eficiência do eletrodo.

A morfologia barro-rachado do sistema binário $\mathrm{IrO}_{2} / \mathrm{TiO}_{2}$ [47] apresenta grandes cristalitos tendo um alto grau de microporosidade, e separada por fendas e rachaduras. A presença de fendas e rachaduras é um aspecto peculiar da camadas de óxidos obtidos por decomposição térmica. $O$ aspecto de barrorrachado surge como resultado de choque térmico e tensões mecânicas dentro da camada de óxido durante o estágio de calcinação [48]

Oliveira-Sousa et al.[34] prepararam eletrodos de óxido de irídio sobre titânio metálico em três métodos diferentes: método tradicional (decomposição térmica dos cloretos), sol-gel inorgânico e Pechini. As micrografias da camada de óxido obtida pelo método tradicional revelaram uma superfície craqueada como freqüentemente é obtida com este método. A camada preparada pelo método solgel inorgânico apresentou uma morfologia superficial uniforme, com a presença de grãos bem definidos enquanto que a morfologia da camada obtida pelo método Pechini apresentou craques e placas.

Vários trabalhos [37-39, 49] mostraram, através dos difratogramas de raios$X$ dos óxidos de estanho dopados com antimônio, uma estrutura característica do $\mathrm{SnO}_{2}$ (estrutura tetragonal tipo rutila). A não identificação de picos de óxido de antimônio sugere a possibilidade de formação de uma solução sólida, na qual os átomos de antimônio ficariam incorporados na rede cristalina do $\mathrm{SnO}_{2}$. Lin e $\mathrm{Wu}$ [37] observou, com o aumento da concentração do dopante, que os picos de difração diminuíam, indicando que a cristalinidade da estrutura do $\mathrm{SnO}_{2}$ era modificada pela presença do $\mathrm{Sb}$ na estrutura. Segundo este autor o $\mathrm{Sb}$ pode existir como $\mathrm{Sb}^{3+}$ ou $\mathrm{Sb}^{5+}$ nesta solução sólida. A substituição do $\mathrm{Sn}^{4+}$ por $\mathrm{Sb}^{3+}$ ou $\mathrm{Sb}^{5+}$ pode gerar vacâncias e distúrbios locais rearranjando a estrutura do cristal. 
Eletrodos de óxidos de Ir ou Ru consistem de uma fase cristalina de $\mathrm{IrO}_{2}$ ou $\mathrm{RuO}_{2}$, juntamente com as formas hidratadas dos respectivos óxidos [50]. Esses resultados contradizem a opinião existente nos anos 80 , de que a camada de óxido era composta de produto microcristalino com estequiometria próxima de $\mathrm{RuO}_{2}$ ou $\mathrm{IrO}_{2}$, mas com alguns defeitos na microestrutura. Baseados nesses defeitos é que a influência das condições de preparação (tempo, temperatura) nas propriedades eletroquímicas dos ânodos tem sido explicada.

Investigações por Difração de Raios-X (DRX) mostram que filmes de óxidos de irídio-titânio apresentam um caráter multifásico: duas fases rutilo. Uma delas, a fase hidratada de óxido de Ir, não muda os parâmetros de célula em filmes de diferentes composições. Entretanto, os parâmetros de célula $(a$ e $c$ ) da Segunda fase rutilo variam com a composição do filme, cuja variação é muito próxima daquela descrita pela lei de Veghard para soluções sólidas verdadeiras. A Segunda fase é estável até $800^{\circ} \mathrm{C}$. Esses aspectos indicam formação de uma solução sólida verdadeira com substituição de Ir e Ti a nível atômico, diferente da solução sólida com ordem de curto alcance, a qual é formada para filmes de rutênio-titânio [50].

A causa das diferenças na composição e microestrutura de soluções sólidas em filmes de irídio-titânio e rutênio-titânio se encontram na região dos componentes no estágio de hidrólise (em solução). No sistema Ir-Ti a interação de uma parte do $\left[\mathrm{IrCl}_{6}\right]^{-2}$ não-hidrolisado com a superfície de formas coloidais do óxido de titânio hidratado conduz a uma dispersão muito fina de Ir no componente titânio e conseqüentemente à formação de uma fase (solução sólida) de $(\mathrm{Ti}, \mathrm{Ir}) \mathrm{O}_{2}$, com substituição a nível atômico. Os íons hexacloroirídio (IV) que não estão em contato com a superfície do óxido hidrolisado de $\mathrm{TiO}_{2}$ sofrem decomposição térmica isolada dando origem à fase 2 , de $\mathrm{IrO}_{2}$ praticamente puro.

Em eletrodos compostos por óxidos mistos pode ocorrer um enriquecimento superficial de um dos compostos da camada ativa. Isso ocorre devido a efeitos cinéticos durante a formação dos diferentes óxidos. Eletrodo de $\mathrm{RuO}_{2}+\mathrm{TiO}_{2}$ apresenta superfície enriquecida em Ti, fato que está associado a um processo de difusão preferencial de Ti para superfície durante a calcinação. Já, para eletrodos contendo $\mathrm{RuO}_{2}+\mathrm{IrO}_{2}$ observa-se a segregação superficial de $\operatorname{Ir}[51]$. 


\subsubsection{Caracterização eletroquímica}

A caracterização eletroquímica de eletrodos de óxidos condutores é geralmente realizada com o auxílio da técnica de voltametria cíclica. Esta técnica é considerada como um poderoso meio de caracterização in situ da superfície eletródica, já que seu comportamento quantitativo e qualitativo está relacionado com as condições superficiais do eletrodo.

As curvas voltamétricas de eletrodos de óxidos condutores são geralmente registradas dentro do maior intervalo de potencial onde é possível observar suas transições redox, limitado no lado catódico pelo processo de desprendimento de $\mathrm{H}_{2}$ e no lado anódico pelo processo de desprendimento de $\mathrm{O}_{2}$. No caso de eletrodos contendo $\mathrm{RuO}_{2}$ e $\mathrm{IrO}_{2}$ este intervalo encontra-se, em meio ácido, entre 0,4 e $1,4 \mathrm{~V}(\mathrm{ERH})$.

A Figura 1 mostra um voltamograma cíclico de um eletrodo de $\mathrm{Ti} / / \mathrm{rO}_{2}$ obtido pelo método de Pechini, registrado em solução de em $\mathrm{H}_{2} \mathrm{SO}_{4} \quad 0,5 \mathrm{~mol} \mathrm{~L}^{-1}$ em uma velocidade de varredura de $20 \mathrm{mVs}^{-1}$, onde podemos observar picos poucos definidos relacionados aos processos redox superficiais[34]. 


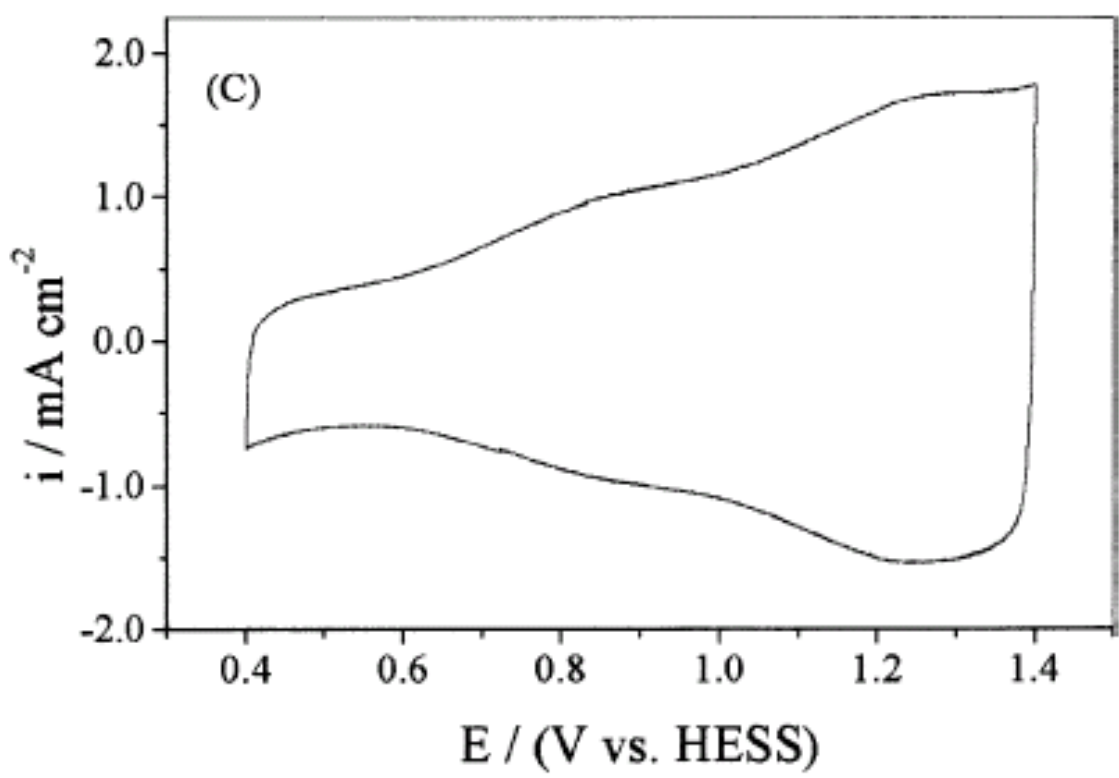

Figura 1 - Voltamograma cíclico de um eletrodo de $\mathrm{Ti} / \mathrm{IrO}_{2}$ em $\mathrm{H}_{2} \mathrm{SO}_{4} 0,5 \mathrm{~mol} \mathrm{~L}^{-1}$ a uma velocidade de varredura de $20 \mathrm{mVs}^{-1}$ [34]. O eletrodo foi obtido pelo método de Pechini calcinado a $600^{\circ} \mathrm{C}$ por $1 \mathrm{~h}$.

Tais picos observados no voltamograma cíclico foram interpretados como conseqüentes de uma variação no estado de oxidação do irídio de acordo com as equações:

$$
\begin{aligned}
& \operatorname{Ir}(\mathrm{III}) \rightarrow \operatorname{Ir}(\mathrm{IV}) \quad(0,6-1,1 \mathrm{~V} \text { vs } \mathrm{ERH}) \\
& \operatorname{Ir}(\mathrm{IV}) \rightarrow \operatorname{Ir}(\mathrm{VI}) \quad(1,1-1,3 \mathrm{~V} \text { vs ERH })
\end{aligned}
$$

A Figura 2 mostra um voltamograma cíclico de um eletrodo de $\mathrm{Ti} / \mathrm{SnO}_{2}$ dopado com antimônio obtido pelo método de spray pirólise, registrado em solução de $\mathrm{H}_{2} \mathrm{SO}_{4} \quad 0,5 \mathrm{~mol} \mathrm{~L}^{-1}$ [28]. $\mathrm{O}$ voltamograma não apresenta nenhum processo redox característico nesta região de potenciais e poucas informações são obtidas sobre a composição e comportamento da superfície do eletrodo. Em potenciais abaixo de $0,3 \mathrm{~V}(\mathrm{ERH})$ o começo de um processo catódico torna-se evidente. A corrente associada com este processo aumenta com a diminuição do potencial e eventualmente se sobrepõem com a corrente de desprendimento de hidrogênio. Nenhum pico ou onda foi observado antes do desprendimento de oxigênio, o qual começa em aproximadamente em 2,2 V(ERH). 


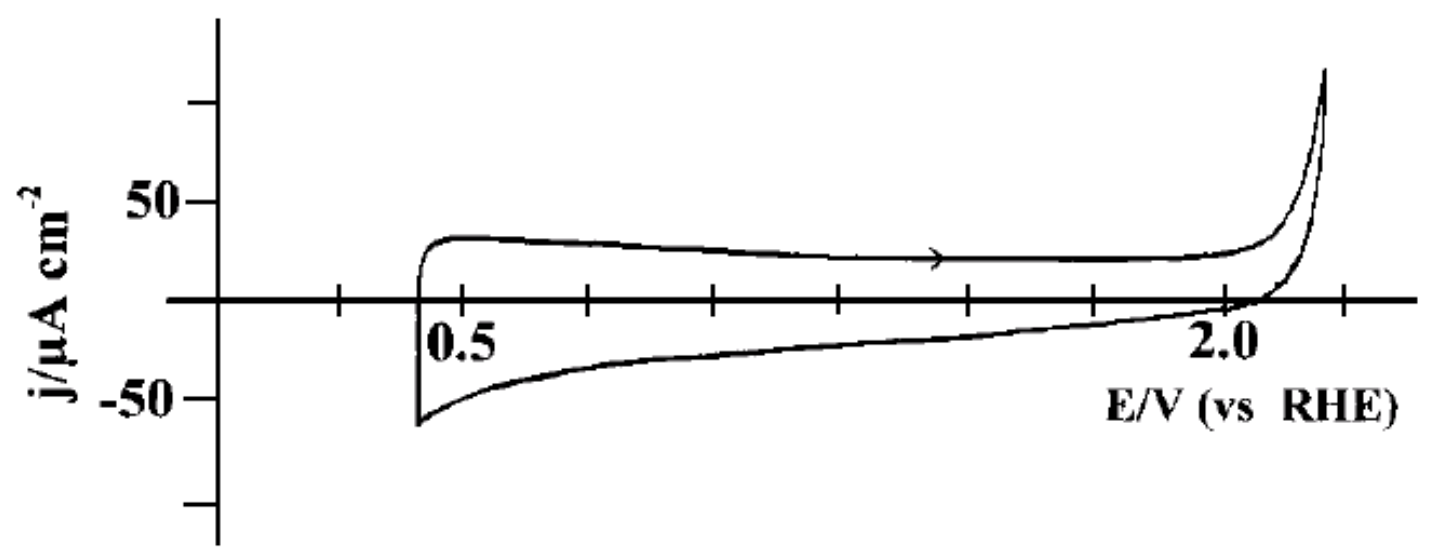

Figura 2 - Voltamograma cíclico de um eletrodo de $\mathrm{Ti} / \mathrm{SnO}_{2}$ dopado com antimônio em $\mathrm{H}_{2} \mathrm{SO}_{4} \quad 0,5 \mathrm{~mol} \mathrm{~L}^{-1}$ a uma velocidade de varredura de $50 \mathrm{mVs}^{-1}$ [28]. O eletrodo foi obtido pelo método de spray pirólise calcinado a $600^{\circ} \mathrm{C}$ por $1 \mathrm{~h}$.

\subsubsection{Determinação da área eletroquimicamente ativa}

O processo mais comumente utilizado para avaliar a área eletroquimicamente ativa de eletrodos de óxidos de metais nobres é a medida da carga voltamétrica $(\mathbf{q})$, obtida através da integração do voltamograma cíclico característico do eletrodo. A carga voltamétrica é proporcional ao número de sítios superficiais, denominados sítios ativos. Assim, a medida da carga voltamétrica pode ser utilizada como uma medida relativa da área eletroquimicamente ativa [52].

Há uma dependência da carga voltamétrica com a velocidade de varredura para eletrodos de $\mathrm{IrO}_{2}-\mathrm{Ta}_{2} \mathrm{O}_{5}$ [53] indicando uma contribuição da carga voltamétrica devido aos sítios ativos mais internos da camada de óxido. Em velocidades de varredura maiores há uma limitação na difusão de prótons para sítios reativos situados na parte mais interna da camada de óxido, o que acarreta em uma diminuição da carga voltamétrica para velocidades de varredura maiores. Medidas de carga voltamétrica em velocidades de varredura superiores a 100 $\mathrm{mVs}^{-1}$ envolvem troca de prótons somente na superfície mais externa da camada, 
portanto, estes valores não podem ser utilizados para a determinação da área superficial real dos eletrodos de óxidos.

Diferente da determinação da carga eletroquimicamente ativa através da carga voltamétrica, é a determinação através de valores de capacitância da dupla camada elétrica. Este método consiste em obter valores de corrente em um dado potencial $\left(\mathbf{i}_{E}\right)$ em diferentes velocidades de varredura $(\boldsymbol{v})$, em regiões do voltamograma cíclico, onde existe somente corrente capacitiva, ou seja, em regiões onde não ocorrem transições redox superficiais.

A relação entre a corrente capacitiva e a velocidade de varredura deve ser linear. A partir do coeficiente angular da curva $\mathbf{i}_{E}$ vs. $\mathbf{v}$, é possível obter a capacitância da dupla camada elétrica, $\mathbf{C}_{\mathbf{d c}}$, e usá-la para avaliar a área superficial.

A principal diferença entre a determinação da área eletroquimicamente ativa através da carga voltamétrica ou através da capacitância da dupla camada elétrica é que a primeira inclui as transições redox superficiais, considerando, portanto, a natureza química e geométrica do óxido. Já a capacitância da dupla camada elétrica é a medida de uma região do voltamograma cíclico onde não há processos redox envolvidos, sendo sensível somente a extensão geométrica da superfície do filme de óxido, independentemente da sua composição química.

Porém, Trasatti et al. [54-56] enfatizam que a determinação da porosidade dos óxidos baseada na dependência da $\mathbf{q}$ em função da $\mathbf{v}$ pode ser afetada por alguns fatores tais como: irreversibilidade de transições redox de estado sólido e resistência não compensada. Ambos os fatores podem causar distorções nos dados de carga voltamétrica.

Recentemente Da Silva et al. [57] propuseram um método alternativo de determinação de área superficial chamado de Determinação do Fator de Morfologia, o qual é definido como a razão da capacitância interna e a capacitância diferencial total. A vantagem deste método é que não é necessária a utilização de valores teóricos de capacitância usados como referência. Estes valores teóricos são difíceis de serem calculados no caso de composições binárias ou mais complexas, requerendo o conhecimento exato da composição superficial e a contribuição teórica de cada fase deve ser considerada. 


\subsection{Estudo do mecanismo de oxidação de etanol}

Com o crescente interesse na pesquisa em busca de eletrocatalisadores eficiente para as reações de oxidação de moléculas orgânicas, torna-se relevante a utilização de técnicas espectroscópicas in situ, como, por exemplo, Infravermelho com Transformada de Fourier in situ (FTIR). Técnicas como esta podem auxiliar na elucidação de mecanismos de reação.

O desenvolvimento da espectroscopia Infravermelho in-situ no início dos anos 80 forneceu uma nova ferramenta para estudar o caráter da adsorção de moléculas orgânicas em superfície metálica e para identificação de intermediários e produtos das reações de eletrodo, auxiliando na investigação dos mecanismos de eletrooxidação. A eletrooxidação de pequenas moléculas orgânicas pode ser investigada em um nível molecular usando técnica modernas de espectroscopia in-situ. Dentre as técnicas podem-se destacar a EMIRS (Espectroscopia de Infravermelho por Modulação Eletroquímica), SNIFTIRS (Espectroscopia de Infravermelho com Transformada de Fourier Interfacial Subtrativamente Normalizada) e SPAIRS (Espectroscopia de Infravermelho com Transformada de Fourier com Variação Linear de Potencial), bem como técnicas espectroscópicas de massas, tais como, EMS (Espectroscopia de Massa Eletroquímica), DEMS (Espectroscopia de Massa Eletroquímica Diferencial), ECTDMS (Espectroscopia de Massa por Termodessorção Acoplada a Eletroquímica) [58].

Pode-se destacar alguns trabalhos encontrados na literatura sobre a utilização de técnicas de FTIR aplicadas à eletrooxidação de etanol.

Tacconi et al. [59] compararam a atividade eletrocatalítica de eletrodos de Ir e Rh policristalino para a eletrooxidação de etanol. Neste estudo foi utilizada a técnica de FTIR in situ (SPAIRS) o que permitiu analisar a eletroadsorção e eletrooxidação do etanol dependente do potencial durante a varredura de potenciais. Os autores propuseram um mecanismo de eletrooxidação de etanol que pode ser dividido em três caminhos reacionais que competem produzindo acetaldeído, ácido acético e $\mathrm{CO}_{2}$ :

$$
\begin{aligned}
& \mathrm{C}_{2} \mathrm{H}_{5} \mathrm{OH} \rightarrow \mathrm{CH}_{3} \mathrm{CHO}+2 \mathrm{H}^{+}+2 \mathrm{e}^{-} \\
& \mathrm{C}_{2} \mathrm{H}_{5} \mathrm{OH}+\mathrm{H}_{2} \mathrm{O} \rightarrow \mathrm{CH}_{3} \mathrm{COOH}+4 \mathrm{H}^{+}+4 \mathrm{e}^{-}
\end{aligned}
$$




$$
\mathrm{C}_{2} \mathrm{H}_{5} \mathrm{OH}+3 \mathrm{H}_{2} \mathrm{O} \rightarrow 2 \mathrm{CO}_{2}+12 \mathrm{H}^{+}+12 \mathrm{e}^{-}
$$

Os dois últimos processos ocorrem em potenciais onde a superfície do eletrodo começa a ser recoberta por uma camada reversível de óxido de espessura menor que uma monocamada, e esta condição superficial influencia o mecanismo de eletrooxidação de etanol. Foi encontrado que a eficiência da oxidação depende do material do eletrodo; se o objetivo a ser alcançado é a oxidação completa do etanol a $\mathrm{CO}_{2}$, então $\mathrm{Rh}$ é um melhor catalisador que o Ir, isto é, mais eficiente. Contudo, se a seletividade é o objetivo mais importante, Ir é bem mais interessante que Rh para dada reação eletroquímica, na qual ele pode levar seletivamente tanto para acetaldeído quanto para ácido acético, essencialmente sem $\mathrm{CO}_{2}$ como produto, dependendo da escolha do potencial.

Em um outro trabalho, Hitmi et al. [60] estudam com a técnica de FTIR a eletrooxidação em meio ácido com eletrodos de Pt e propuseram o mecanismo que está esquematizado na Figura 3. 


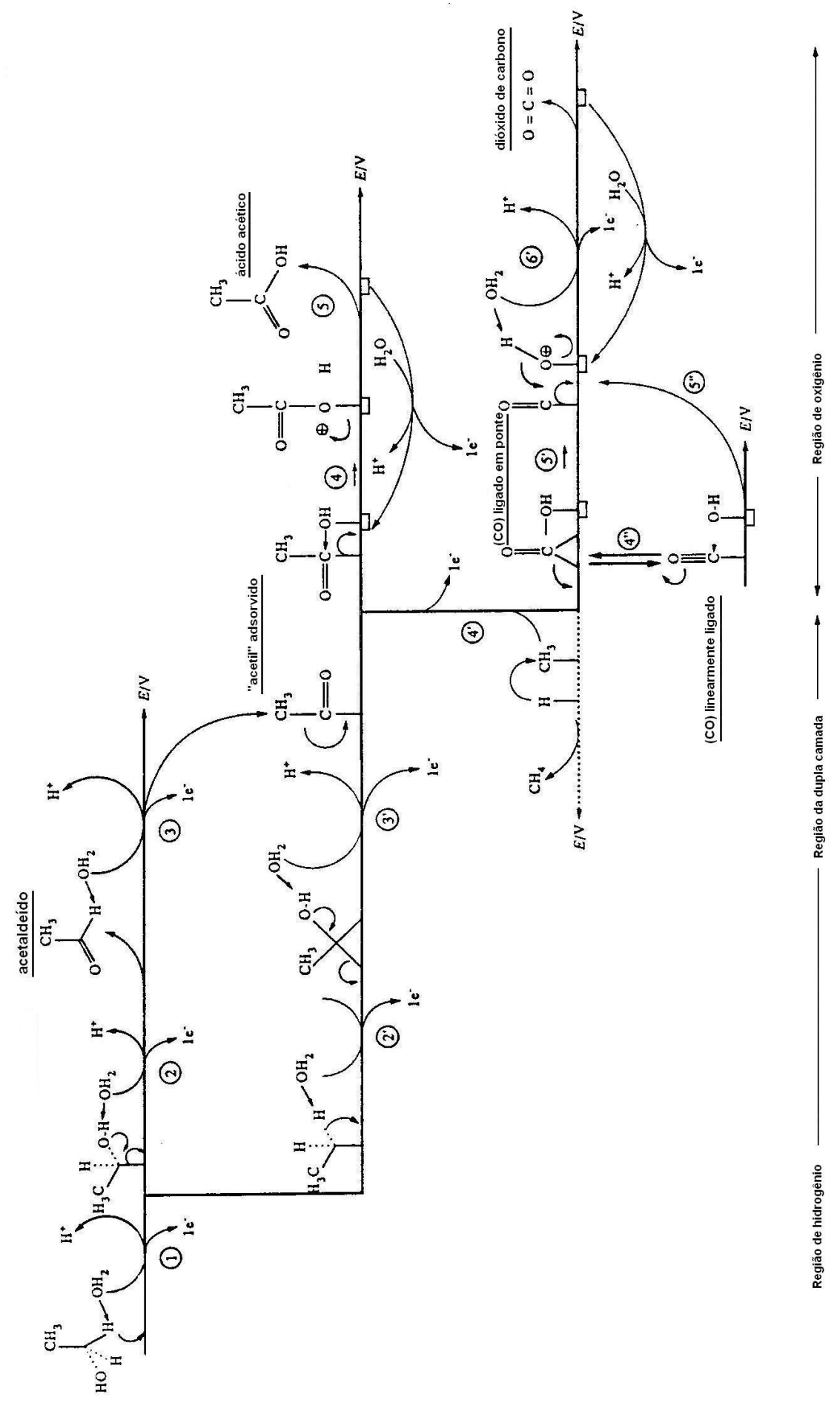

Figura 3 - Mecanismo proposto para a oxidação eletrocatalítica do etanol em platina lisa em meio ácido durante varredura de potencial positiva (todas as espécies com os nomes sublinhados foram detectadas por FTIR in situ, ou por CLAE, ou ambas as técnicas) [60]. 
Este mecanismo de reação global para o eletrodo de platina pode ser descrito como dependente do potencial do eletrodo $E$ :

- Para $E<0,8$ V / ERH: a adsorção de etanol ocorre na Pt pelo carbono do grupo funcional álcool. Esta adsorção envolve uma dissociação de CH com a transferência de 1 elétron (passo 1). O intermediário adsorvido pode dessorver e resultar em acetaldeído com a transferência de um outro elétron (passo 2). Alternativamente, um segundo hidrogênio pode ser eliminado (passo 2') e a espécie resultante é um acetil adsorvido, o qual pode levar (passo 4') ao intermediário $\mathrm{CO}_{\text {ads }}$ e a um metil adsorvido $\left(\mathrm{CH}_{3}\right)_{\text {ads }}$, o qual é um intermediário reativo durante a varredura negativa, e dessorverá como $\mathrm{CH}_{4}$ em forma de gás.

- Para $E>0,8 \mathrm{~V} / \mathrm{ERH}$ : os autores estabeleceram que quando o potencial de eletrólise foi mantido em valores na região do oxigênio, a seletividade para a produção de ácido acético foi aumentada. $\mathrm{O}$ acetil adsorvido é precursor do ácido acético livre (passos 4 e 5) e as espécies $\mathrm{CO}_{\text {ads }}$ levam a $\mathrm{CO}_{2}$ (passos 5', 5" e 6'). Contudo, os autores lembram que durante a varredura positiva do potencial $(0,60<E<1,15 \mathrm{~V} / \mathrm{ERH})$ os principais caminhos serão os passos 1 e 2 para a produção de acetaldeído e passos 1, 2, 3, 4 e 5, ou passos 1, 2', 3', 4 e 5 para a produção de ácido acético. A atividade do eletrodo e a seletividade da reação (orientação cinética) dependem da estrutura da superfície e do potencial aplicado.

Recentemente de Souza et. al. [61] estudaram a eletrooxidação de etanol em eletrodos de platina, ródio e platina/ródio usando as técnicas de espectroscopia de massa eletroquímica diferencial em linha (DEMS) e espectroscopia de infravermelho in situ (FTIR). Três produtos foram detectados, $\mathrm{CO}_{2}$ e acetaldeído (detectado por DEMS) e ácido acético (detectado por FTIR). As combinações de platina e ródio em eletrodos bimetálicos para a oxidação do etanol mostraram que o ródio leva a uma forte diminuição na formação do acetaldeído, comparado ao eletrodo de platina pura. O rendimento de $\mathrm{CO}_{2}$ é maior nos eletrodos $\mathrm{Pt}_{73} \mathrm{Rh}_{27}$ e $\mathrm{Pt}_{55} \mathrm{Rh}_{45}$ que em platina pura, sendo que o melhor desempenho foi obtido pela composição $\mathrm{Pt}_{73} \mathrm{Rh}_{27}$. Embora a seletividade aumente para a produção de $\mathrm{CO}_{2}$ preferencialmente ao acetaldeído, somente o $\mathrm{Pt}_{90} \mathrm{Rh}_{10}$ apresenta uma corrente total similar àquela do eletrodo de platina. Contudo, o aumento na seletividade para formação preferencial de $\mathrm{CO}_{2}$ mostra que eletrodos bimetálicos de PtRh são candidatos promissores para a oxidação de etanol. 


\section{CAPÍTULO II}

\section{OBJETIVO}

O objetivo deste trabalho foi a preparação de eletrodos de composição $\left.\mathrm{Sn}_{(1-\mathrm{x})}\right) \mathrm{r}_{(\mathrm{X})} \mathrm{O}_{2}$ (com Ir entre 1 e $30 \%$ em mol) com o intuito de avaliar as características morfológicas, estruturais, eletroquímicas e o tempo de vida útil destes eletrodos, e também investigar a atividade eletrocatalítica destes materiais para a reação de oxidação do etanol. $O$ etanol foi escolhido como uma molécula modelo para se estudar a quebra da ligação C-C e também porque a oxidação do etanol pode levar a formação de ácido acético impedindo a oxidação completa que leva a $\mathrm{CO}_{2}$ como produto final. Assim, buscou-se encontrar uma composição de eletrodo que apresentasse um mecanismo de oxidação que evitasse a formação de ácido acético. 


\section{CAPÍTULO III}

\section{PARTE EXPERIMENTAL}

Neste trabalho foi utilizado o método de decomposição térmica de precursores poliméricos também conhecido como método de Pechini e Adams [41], para obtenção do óxido de estanho e decomposição térmica de cloretos para obtenção do óxido de irídio.

\section{1 - Preparação e padronização das soluções precursoras}

\subsection{1 - Síntese do Precursor de Sn (Citrato de Estanho)}

$\mathrm{O}$ citrato de estanho, cuja fórmula molecular é $\mathrm{C}_{6} \mathrm{H}_{8} \mathrm{O}_{8} \mathrm{Sn}_{2}$ $(\mathrm{M}=445,44 \mathrm{~g} / \mathrm{mol})$, foi obtido partindo-se do ácido cítrico $\left(\mathrm{C}_{6} \mathrm{H}_{8} \mathrm{O}_{7} \cdot \mathrm{H}_{2} \mathrm{O}\right.$ MERCK) e cloreto de estanho $\left(\mathrm{SnCl}_{2} \cdot 2 \mathrm{H}_{2} \mathrm{O}-\mathrm{MERCK}\right)$ na proporção de $1: 2 \mathrm{~mol}$. A massa de cloreto foi dissolvida na solução do ácido cítrico $\left(0,25 \mathrm{~mol} \mathrm{l}^{-1}\right) \mathrm{e}$, em seguida, adicionou-se $\mathrm{NH}_{4} \mathrm{OH}$ (MERCK) 2,0 mol l$^{-1}$ gota a gota, com agitação e controle de $\mathrm{pH}$ até valores próximos de 3,0, havendo a formação de um precipitado branco. Atingindo-se $\mathrm{opH}$ desejado, a mistura foi filtrada a vácuo obtendo-se o citrato de estanho como filtrado; este foi mantido em estufa a $70^{\circ} \mathrm{C}$ por 24 horas para a secagem completa do sal.

\subsection{2 - Preparação da resina precursora de estanho}

A resina precursora de estanho foi obtida através da dissolução de ácido cítrico em etilenoglicol (MERCK) em quantidades de $50 \%$ - $50 \%$ em massa a $65^{\circ} \mathrm{C}$. Após a dissolução do ácido, a temperatura foi elevada a $90-95^{\circ} \mathrm{C}$, neste 
ponto o citrato de estanho foi adicionado lentamente em proporção com o ácido cítrico de $1: 3$ em mol. Em seguida, adicionou-se $\mathrm{HNO}_{3}$ (MERCK) concentrado gota a gota até a dissolução completa do sal. Nesta etapa foi observado intenso desprendimento de $\mathrm{NO}_{2}$ e acentuado aumento da viscosidade da solução, sendo obtida, então, uma resina de coloração amarelada.

\subsection{3 - Gravimetria da resina precursora de estanho}

A determinação da concentração de estanho na resina precursora foi realizada através de gravimetria. Uma massa conhecida da resina foi submetida à calcinação a $550^{\circ} \mathrm{C}$ por $1 \mathrm{~h}$ com fluxo de $\mathrm{O}_{2}$ de $5 \mathrm{~L} \mathrm{~min}^{-1}$, em seguida o produto da calcinação foi pesado e o procedimento repetido até a obtenção de massa constante, em média $2 \mathrm{~h}$ de calcinação foram suficientes. Para a determinação da concentração de estanho na resina foi assumido como único produto de calcinação $\mathrm{SnO}_{2}$ e através da relação entre o número de mols de estanho no óxido obtido e a massa de resina utilizada na análise pôde-se obter a concentração real de estanho presente na resina. As determinações gravimétricas foram realizadas em triplicata.

\subsection{4 - Dopagem da resina de estanho com antimônio}

A resina de estanho foi dopada com 2,0 \% em mol de antimônio em relação ao número de mols de estanho presente na resina. A dopagem foi realizada dissolvendo-se $\mathrm{Sb}_{2} \mathrm{O}_{3}$ (Riedel-de Haën) na resina de estanho a temperatura de aproximadamente $60^{\circ} \mathrm{C}$ sob agitação constante e adição de algumas gotas de $\mathrm{HNO}_{3}$ (MERCK) concentrado.

\subsubsection{Preparação da solução de cloreto de irídio}

A solução de cloreto de irídio foi obtida através do seguinte procedimento: Adicionou-se $1 \mathrm{~g}$ de $\mathrm{IrCl}_{3}$ hidratado (Aldrich) em $10 \mathrm{~mL}$ de $\mathrm{HCl}$ (MERCK) (1v:1v), em seguida, devido a insolubilidade do $\mathrm{IrCl}_{3}$, foram adicionadas cerca de 10 gotas de $\mathrm{H}_{2} \mathrm{O}_{2} 30 \%$. Após esta etapa, adicionou-se mais $\mathrm{HCl}$ (1v:1v) até um volume de aproximadamente $60 \mathrm{~mL}$. Posteriormente, a solução foi concentrada por 
aquecimento até a obtenção de um volume final de aproximadamente $20 \mathrm{~mL}$. Após esta etapa obteve-se a solução precursora de cloreto de irídio utilizada para a preparação dos eletrodos.

\subsubsection{Gravimetria da solução precursora de irídio}

A determinação da concentração de irídio na solução precursora de cloreto de irídio foi realizada através de gravimetria. Um volume conhecido da solução foi submetido à calcinação a $550^{\circ} \mathrm{C}$ por 1 hora com fluxo de $\mathrm{O}_{2}$ de $5 \mathrm{~L} \mathrm{~min}^{-1}$, em seguida o produto da calcinação foi pesado e o procedimento repetido até a obtenção de massa constante. A massa de óxido de irídio obtido após este processo foi determinada. Pela relação do número de mols de irídio no óxido obtido e o volume de solução precursora utilizado pôde-se obter a concentração real de irídio presente na solução. As determinações gravimétricas foram realizadas em triplicata.

\subsection{Preparação dos eletrodos $\mathrm{Sn}_{(1-\mathrm{x})} \mid \mathrm{r}_{\mathrm{x}} \mathrm{O}_{2}$}

Os suportes utilizados para o preparo dos eletrodos foram placas de titânio metálico com dimensões de $1 \times 1 \mathrm{~cm}$. As placas de Ti utilizadas como suporte foram previamente jateadas com granalha de aço e em seguida submetidas ao seguinte pré-tratamento:

1. Imersão em água em ebulição durante $30 \mathrm{~min}$;

2. Ultrasonificação em isopropanol (Merck) durante 30 min para a eliminação de gordura e impurezas orgânicas;

3. Imersão em solução $\mathrm{HCl}$ (Merck) $20 \%$ (v) em ebulição durante 30 min;

4. Imersão em solução de ácido oxálico (Synth) 10\% (m) em ebulição durante $20 \mathrm{~min}$;

Para o preparo dos eletrodos $\mathrm{Sn}_{(1-\mathrm{x})} \mid \mathrm{Ir}_{\mathrm{x}} \mathrm{O}_{2}(\operatorname{com} \mathrm{x}=0 ; 0,01 ; 0,05 ; 0,1$ e 0,3$)$ misturou-se as soluções precursoras em proporções adequadas para se preparar as camadas de óxido nas composições nominais desejadas.

As misturas precursoras foram pinceladas sobre um suporte de $\mathrm{Ti}$, o qual, após o pincelamento, é levado a uma estufa pré-aquecida a $100^{\circ} \mathrm{C}$ durante 5 
minutos para evaporar o solvente. Após esta etapa, o suporte de Ti pincelado é calcinado a $550^{\circ} \mathrm{C}$ por 5 minutos. O pincelamento e posterior calcinação das soluções foram realizados repetidamente até a obtenção da massa de óxido desejada. Após atingir a massa, o eletrodo foi calcinado a $550^{\circ} \mathrm{C}$ por 1 hora.

A massa de óxido a ser depositada sobre o substrato foi calculada de modo a ser obtido um filme de espessura nominal de $2 \mu \mathrm{m}$. Dispondo-se da área geométrica do suporte, das densidades dos óxidos formados $\left(\mathrm{SnO}_{2}\right.$ e $\left.\mathrm{IrO}_{2}\right)$ e da fração molar de cada óxido, pôde-se calcular a massa a ser depositada através da seguinte equação:

$$
\mathrm{m}=\mathrm{V}\left[\mathbf{x}_{i} \cdot \mathbf{d}_{i}+\mathbf{x}_{i i} \cdot \mathbf{d}_{i i}\right]
$$

onde, $\mathbf{m}$ é a massa a ser depositada, $\mathbf{V}$ é o volume do filme (área do suporte multiplicada pela espessura desejeda), $\boldsymbol{i}$ e $\boldsymbol{i} \boldsymbol{i}$ designam os respectivos óxidos, $\boldsymbol{x}_{\boldsymbol{i}} \mathrm{e}$ $\boldsymbol{x}_{i i}$ as suas respectivas frações molares e $\mathbf{d}_{i}$ e $\mathbf{d}_{i i}$ as suas respectivas densidades.

\subsection{1 - Confecção final do eletrodo}

Após a calcinação por 1h, a haste do substrato foi lixada para se retirar a camada de óxido de titânio formada durante o processo de calcinação. Após a remoção da camada de $\mathrm{TiO}_{2}$, foram feitos os contatos elétricos através de um fio de cobre, o qual foi preso a haste do suporte através de solda-ponto. O suporte contendo a camada de óxidos e com os contatos elétricos já realizados foi, então, embutido em um tubo de vidro de modo que apenas a camada de óxidos ficasse exposta. Posteriormente, a extremidade do tubo foi vedada utilizando-se cola de silicone. A Figura 4 apresenta uma ilustração esquemática de um eletrodo. 


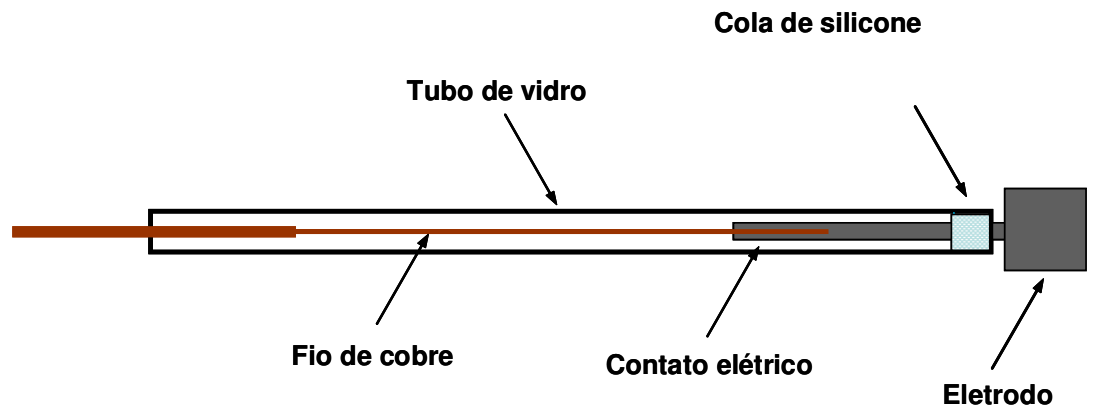

Figura 4 - Representação esquemática de um eletrodo recém preparado.

Foram preparados pelo menos dois eletrodos de cada composição estudada, de modo que os dados eletroquímicos obtidos correspondem a uma média de diferentes eletrodos. Tal procedimento permite a obtenção de dados realmente representativos para cada composição, uma vez que discrepâncias específicas de algum eletrodo são facilmente detectadas por comparação.

\section{3 - Equipamentos utilizados na caracterização física e química dos eletrodos}

A composição e a morfologia da camada de óxido foram analisadas por microscopia eletrônica de varredura (MEV) e energia dispersiva de raios-X (EDX) utilizando um microscópio eletrônico de varredura da Zeiss DSM 940 acoplado a um microanalisador de raios-X Link Analytical QX 2000. A estrutura cristalina dos óxidos suportados em placas de titânio foi estudada por difração de raios-X (DRX) obtidos através de um difratômetro SIEMENS D5005 com radiação $\mathrm{Cu}(\mathrm{K} \alpha)=1,5406 \AA$, monocromador de grafite e equipado com um acessório de ângulo de incidência rasante.

\section{4 - Equipamentos eletroquímicos}

Todos os experimentos eletroquímicos foram feitos utilizando como eletrólito de suporte uma solução de $\mathrm{H}_{2} \mathrm{SO}_{4}$ (Merck) $0,5 \mathrm{~mol} \mathrm{~L}^{-1}$ ou em $\mathrm{HClO}_{4}$ (Merck) 0,1 $\mathrm{mol} \mathrm{L}^{-1}$ empregando-se um potenciostato/galvanostato da Ecochemie modelo Autolab PGSTAT20 interfaceado a um microcomputador. 
Foi utilizado como eletrodo de trabalho nos estudos eletroquímicos eletrodos de composição nominal Ti / $\mathrm{Sn}_{(1-\mathrm{x})} \mid \mathrm{r}_{\mathrm{x}} \mathrm{O}_{2}$ onde os valores de x são 0; 0,01; 0,$05 ; 0,1$ e 0,3 , com $2 \mathrm{~cm}^{2}$ de área geométrica.

\subsection{1 - Condições utilizadas nos experimentos de eletrólise com célula convencional}

Foi utilizada uma célula universal de $50 \mathrm{~mL}$ de capacidade (Figura 5). Como contra eletrodo utilizou-se um fio de platina com $0,5 \mathrm{~mm}$ de diâmetro e 10 $\mathrm{cm}$ de comprimento. Um eletrodo reversível de hidrogênio $(\mathrm{ERH})$ colocado dentro de um compartimento do tipo Luggin contendo a solução de eletrólito suporte, foi utilizado como eletrodo de referência. Este sistema foi utilizado também para os experimentos de voltametria cíclica.

As eletrólises foram realizadas em $20 \mathrm{~mL}$ de soluções das moléculas orgânicas nas concentrações de 5 e $20 \mathrm{mmol} \mathrm{L}^{-1}$ em meio de $\mathrm{H}_{2} \mathrm{SO}_{4}$ (Merck) 0,5 mol L $\mathrm{L}^{-1}$, aplicando-se corrente constante de $100 \mathrm{~mA} \mathrm{~cm}{ }^{-2}$ ou $20 \mathrm{~mA} \mathrm{~cm}^{-2}$, mantendo-se a temperatura constante em $25{ }^{\circ} \mathrm{C}$. As soluções eletrolisadas foram mantidas sob constante agitação (com um agitador magnético) duram as eletrólises realizadas em célula convencional.

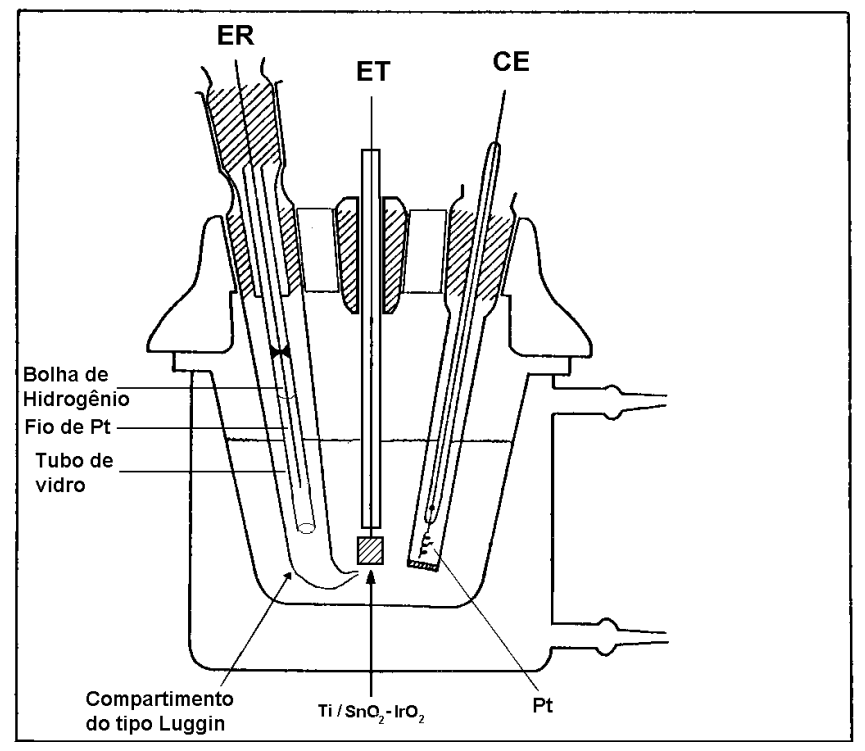

Figura 5 - Esquema da célula eletroquímica e eletrodos empregados nos experimentos de caracterização eletroquímica e eletrólises. 


\subsection{2 - Condições utilizadas nos experimentos de eletrólise com célula do tipo Filtro-prensa}

Os experimentos de eletrólises foram feitos utilizando como eletrólito de suporte uma solução de $\mathrm{HClO}_{4}$ (Merck) $0,1 \mathrm{~mol} \mathrm{~L}^{-1}$ e etanol (Merck) $0,1 \mathrm{~mol} \mathrm{~L}^{-1}$ (com um volume total de $100 \mathrm{~mL}$ ) empregando-se um potenciostato/galvanostato da PAR mod. 362. A célula utilizada foi uma célula tipo Filtro-prensa com fluxo contínuo. Esta célula é composta de dois compartimentos, um contendo o eletrodo de trabalho (área útil geométrica de $14 \mathrm{~cm}^{2}$ ) preparado com o mesmo procedimento descrito na seção 3.2 (exceto pelas dimensões do eletrodo) e outro contendo uma placa de aço inoxidável também com $14 \mathrm{~cm}^{2}$ de área geométrica. A circulação destas soluções foi mantida por uma bomba peristáltica Masterflex ${ }^{\circledR}$. Um controlador de rotação, conectado ao motor da bomba, foi usado para ajustar o fluxo desejado. Uma representação esquemática deste sistema pode ser visto na Figura 6.

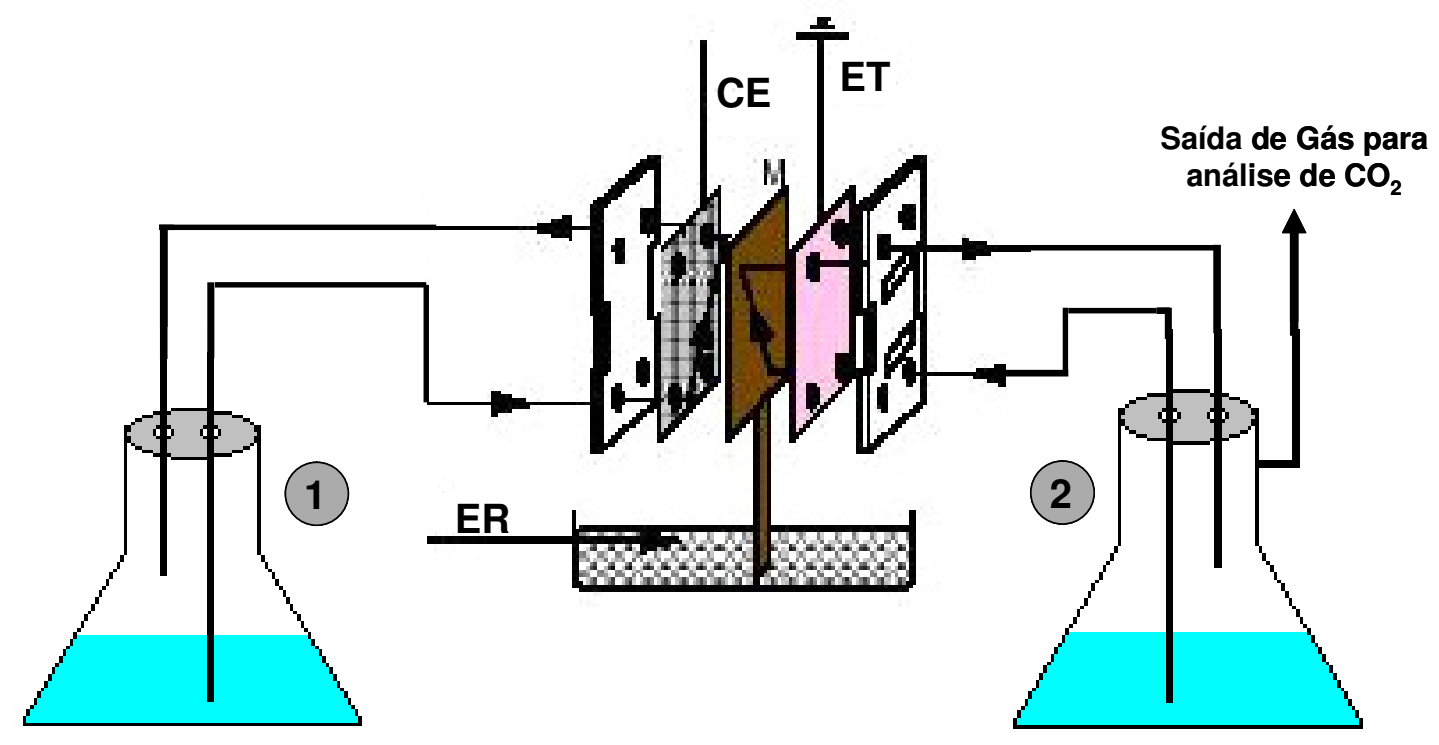

Figura 6 - Representação esquemática do sistema de eletrólise utilizando a célula do tipo Filtro-prensa. ET: Eletrodo de trabalho, CE: Contra eletrodo, ER: Eletrodo de referência, M: membrana. (1) Recipiente da solução do compartimento catódico e (2) Recipiente da solução do compartimento anódico. 


\subsection{3 - Análise dos produtos de eletrólise}

A análise dos produtos formados durante a eletrólise foi feita por Cromatografia Líquida de Alta Eficiência (CLAE) em um equipamento da Shimadzu composto de uma central controladora do sistema mod. SCL-10Avp, uma bomba mod. LC-10Atvp acoplada a uma válvula controladora de fluxo de gradiente de baixa pressão mod. FCV-10ALvp, um forno de coluna $\left(30^{\circ} \mathrm{C}\right) \mathrm{mod}$. CTO-10ASvp e dois detectores dispostos em série: um detector UV-visível (210 $\mathrm{nm})$ mod. SPD-10Avp e um refratômetro diferencial mod. RID-10A. Os cromatogramas foram registrados e integrados pelo software Class-vp. Foi utilizado como fase móvel uma solução de $\mathrm{H}_{2} \mathrm{SO}_{4} 3,33.10^{-3} \mathrm{~mol} \mathrm{~L}^{-1} \mathrm{com}$ um fluxo de 0,6 mL $\min ^{-1}$ e uma coluna da Bio Rad mod. HPX-87H(300 mm/7,8 mm).

Os gases formados durante a eletrólise foram coletados borbulhando-os

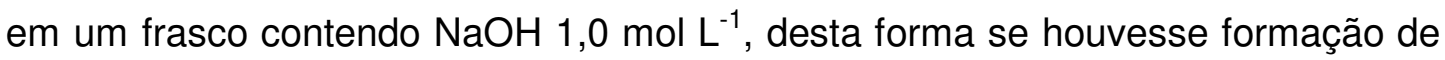
$\mathrm{CO}_{2}$ durante a eletrólise ele seria convertido em $\mathrm{CO}_{3}{ }^{2-}$ o que permite que ele seja quantificado por CLAE.

A Figura 7 apresenta os cromatogramas do etanol e dos possíveis intermediários e produtos de sua oxidação. Nestas figuras pode-se observar que o método utilizado foi adequado, uma vez que a uma boa separação entre os picos de cada composto permitindo assim acompanhar o consumo do etanol e a formação dos produtos de reação com o tempo de eletrólise. 



Figura 7 - Cromatograma da mistura de ácido fórmico, ácido acético, acetaldeído e etanol em $\mathrm{H}_{2} \mathrm{O}$ (A) e outro do carbonato de sódio em $\mathrm{NaOH} 1,0 \mathrm{~mol} \mathrm{~L}^{-1}$ (B). Condições: Coluna: da Bio Rad mod. HPX-87H $(300 \mathrm{~mm} / 7,8 \mathrm{~mm}), \mathrm{T}=30{ }^{\circ} \mathrm{C}$, Fase Móvel $\mathrm{H}_{2} \mathrm{SO}_{4} 3,33 \mathrm{mmol} \mathrm{L}^{-1}$, Fluxo: 0,6 $\mathrm{mL} \mathrm{min}^{-1}$, detector: índice de refração. 


\section{5 - Experimentos utilizando técnica de Infra-Vermelho por Refletância com Transformada de Fourier in situ (FTIR in situ)}

A célula de Infra-Vermelho foi equipada com uma janela de $\mathrm{CaF}_{2}$ e o eletrodo de trabalho colado em um tubo de vidro foi ajustado através do topo da célula (permitindo que ele seja pressionado contra a janela de $\mathrm{CaF}_{2}$ ). Uma placa de carbono vítreo foi usada como contra eletrodo, e um ERH foi usado como referência. Na Figura 8 representação esquemática da célula eletroquímica e eletrodos empregados nos experimentos de espectroscopia no Infra-Vermelho in situ.

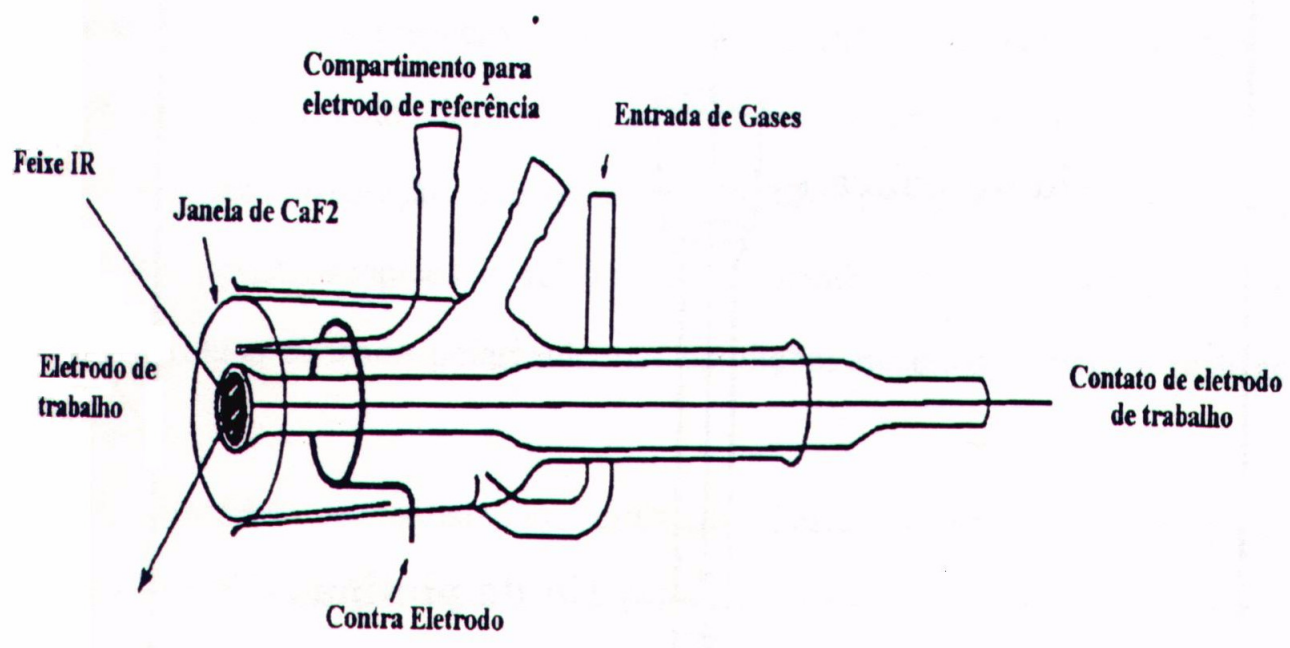

Figura 8 - Célula eletroquímica e eletrodos empregados nos experimentos de espectroscopia no Infra-Vermelho in situ.

As medidas foram realizadas utilizando como eletrólito de suporte uma solução de $\mathrm{HClO}_{4}$ (Merck) 0,1 mol L-1 e etanol ou acetaldeído (Merck) 0,1 mol L-1. O potencial da célula foi controlado com um potenciostato Wenking mod. LB 81 e um gerador de forma de onda Hi-tek, conectado a um registrador XY mod. BD 90. Um espectrômetro de Infra-Vermelho com Transformada de Fourier da Bruker mod. IFS 66v foi modificado para uma reflexão do feixe com angulo de incidência de $65^{\circ}$ na superfície do eletrodo. Para remover interferência do $\mathrm{CO}_{2}$ e da $\mathrm{H}_{2} \mathrm{O}$ atmosférica, o caminho do feixe ficou sob vácuo durante o experimento. 0 
detector utilizado foi de $\mathrm{HgCdTe}$ refrigerado com $\mathrm{N}_{2}$ líquido. A precisão do número de onda foi de $4 \mathrm{~cm}^{-1}$.

Os eletrodos utilizados nos experimentos de Infra-Vermelho por Refletância foram basicamente preparados da mesma forma que os para as eletrólises, porém, a deposição do filme de óxido foi sobre uma placa de ouro polido. Foram dadas somente duas pinceladas da solução precursora, o suficiente para cobrir homogeneamente a superfície do disco de ouro (diâmetro de $8 \mathrm{~mm}$ ) com um filme liso. Desta forma os eletrodos apresentaram uma boa refletividade.

Com a técnica de SPAIRS a refletividade do eletrodo foi registrada a cada $50 \mathrm{mV}$ durante uma varredura voltamétrica a $1 \mathrm{mV} \mathrm{s}{ }^{-1}$ em potencial entre $400 \mathrm{e}$ $1800 \mathrm{mV}$. Cada espectro é resultado da adição de 128 interferogramas. Os espectros finais foram normalizados como:

$$
\Delta R / R=\left(R_{E i}-R_{E r e f}\right) / R_{E r e f}
$$

onde $\mathbf{R}_{\mathrm{Ei}}$ é a refletividade registrada durante a varredura voltamétrica e $\mathbf{R}_{\mathrm{Eref}}$ é a refletividade registrada no potencial de $400 \mathrm{mV}(\mathrm{ERH})$ que foi usado como potencial de referência.

Com a técnica de SNIFTIRS o potencial do eletrodo de trabalho foi modulado entre dois valores de potencial (Ei e Ef) conforme um sinal de onda quadrada. Os espectros finais foram calculados como:

$$
\Delta R / R=\left(R_{E f}-R_{E i}\right) / R_{E i}
$$

onde Ei é o potencial inicial e Ef o potencial final da modulação e $\Delta \mathrm{E}=\mathrm{Ef}-\mathrm{Ei}=$ constante.

Para ambas as técnicas, uma banda negativa indica a produção de espécies e uma banda positiva indica o consumo de espécies na superfície do eletrodo. 


\section{CAPÍTULO IV}

\section{RESULTADOS E DISCUSSÃO}

Em eletrocatálise é de fundamental importância o conhecimento das características químicas e físicas do material para que se possa fazer uma correlação entre estes fatores e a atividade eletrocatalítica para a reação de interesse. Sendo assim, numa primeira etapa deste trabalho foram preparadas diferentes composições eletródicas e caracterizadas quanto as suas composições químicas, seus aspectos estruturais e morfológicos e seu comportamento eletroquímico. Em uma segunda etapa foi verificada a atividade eletrocatalítica destes eletrodos para a reação de oxidação do etanol e seus subprodutos, o acetaldeído e o ácido acético.

\section{1 - Caracterização ex situ}

\subsection{1 - Análise da morfologia e composição dos eletrodos contendo $\mathrm{SnO}_{2}$ e $\mathrm{IrO}_{2}$.}

A introdução de $\mathrm{IrO}_{2}$ no $\mathrm{SnO}_{2}$, formando as diferentes composições eletródicas, deve causar mudanças significativas em suas morfologias. Sendo assim, os filmes de óxido foram caracterizados quanto ao aspecto morfológico empregando a técnica de Microscopia Eletrônica de Varredura (MEV). As

micrografias foram obtidas para todas as concentrações de irídio e estanho utilizadas na preparação dos filmes.

$\mathrm{Na}$ Figuras 9 estão mostradas duas micrografias dos eletrodos contendo $\mathrm{SnO}_{2} 100 \%$ e $\mathrm{Sn}_{0,99} \mathrm{Ir}_{0,01} \mathrm{O}_{2}$, as quais possuem uma morfologia de "barro-rachado". Este tipo de morfologia tem sido encontrada em trabalhos anteriores realizados 
em nosso laboratório no preparo de eletrodos de óxidos de estanho obtidos por decomposição térmica dos precursores poliméricos [62]. A região dentro das rachaduras revela uma matriz altamente rugosa. Este aspecto morfológico, com trincas e rachaduras formando ilhas isoladas, surge como resultado de choque térmico e tensões mecânicas na camada de óxido durante o processo de calcinação o que confere ao eletrodo uma elevada área superficial [48].

Já na Figura 10 estão demonstradas as micrografias dos eletrodos contendo 5 e 10\% de irídio na mistura dos óxidos. Nestas figuras podemos observar em algumas regiões trincas ou rachaduras e um aspecto "barrorachado", porém, com uma morfologia mais compacta predominando.

Na micrografia do eletrodo contendo $30 \%$ de irídio (Figura 11) o número de microrachaduras aumenta expressivamente, as ilhas isoladas pelas rachaduras tornam-se cada vez menores e a camada torna-se finamente dividida.
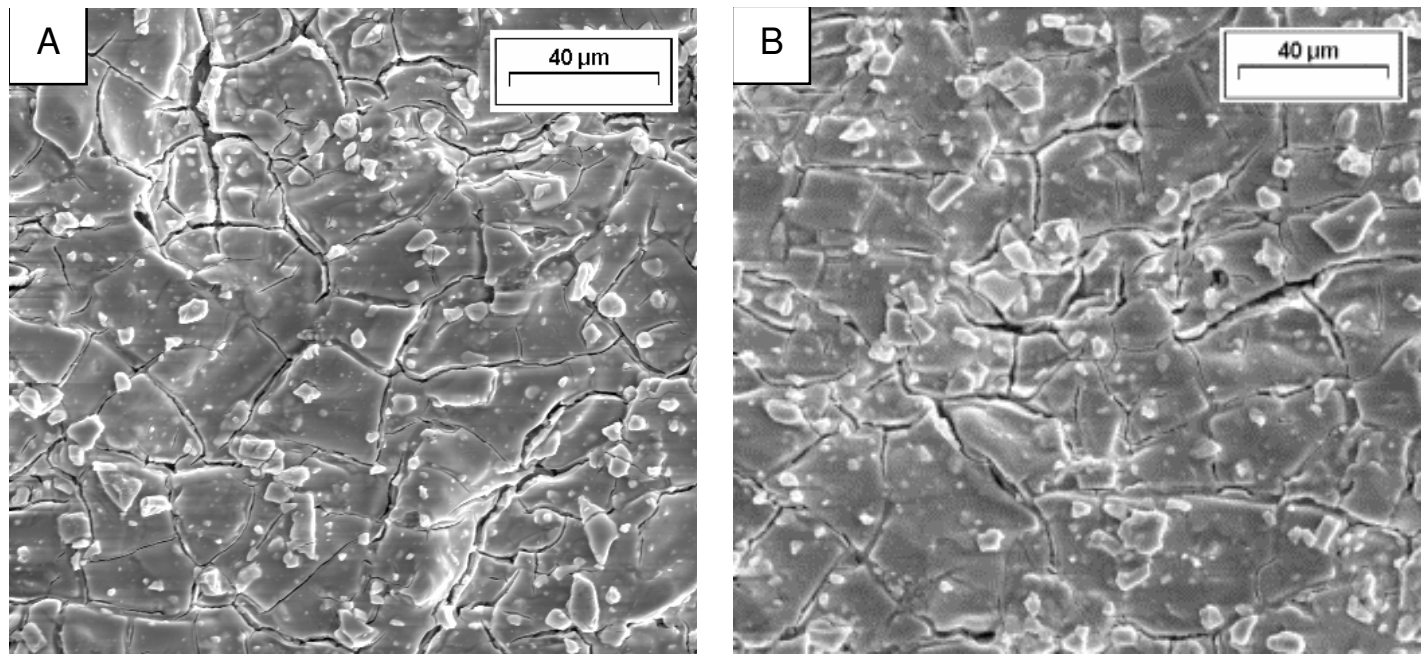

Figura 9 - Micrografias obtidas por MEV com ampliações de 500 vezes dos eletrodos de composições nominais: (A) $\mathrm{SnO}_{2}$ e (B) $\mathrm{Sn}_{0,99} \mathrm{Ir}_{0,01} \mathrm{O}_{2}$. 

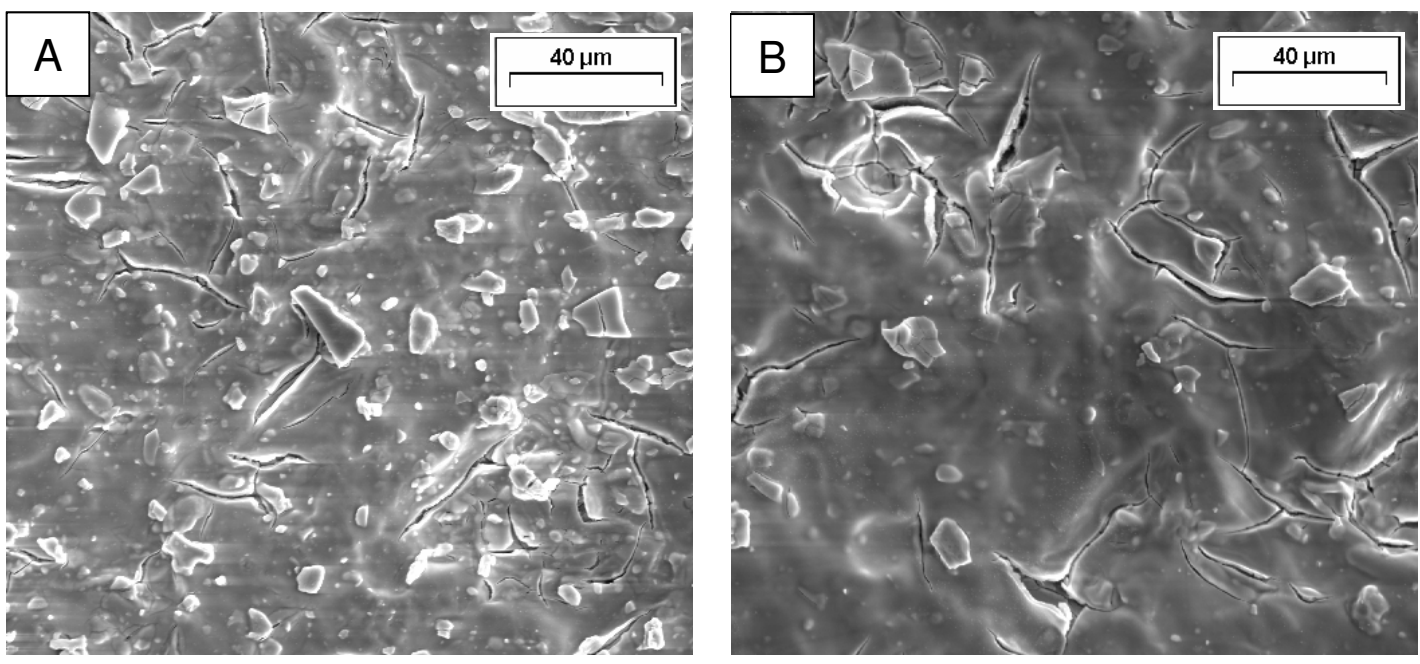

Figura 10 - Micrografias obtidas por MEV com ampliações de 500 vezes dos eletrodos de composições nominais: (A) $\mathrm{Sn}_{0,95} \mid \mathrm{r}_{0,05} \mathrm{O}_{2}$ e (B) $\mathrm{Sn}_{0,90} \mathrm{r}_{0,10} \mathrm{O}_{2}$.
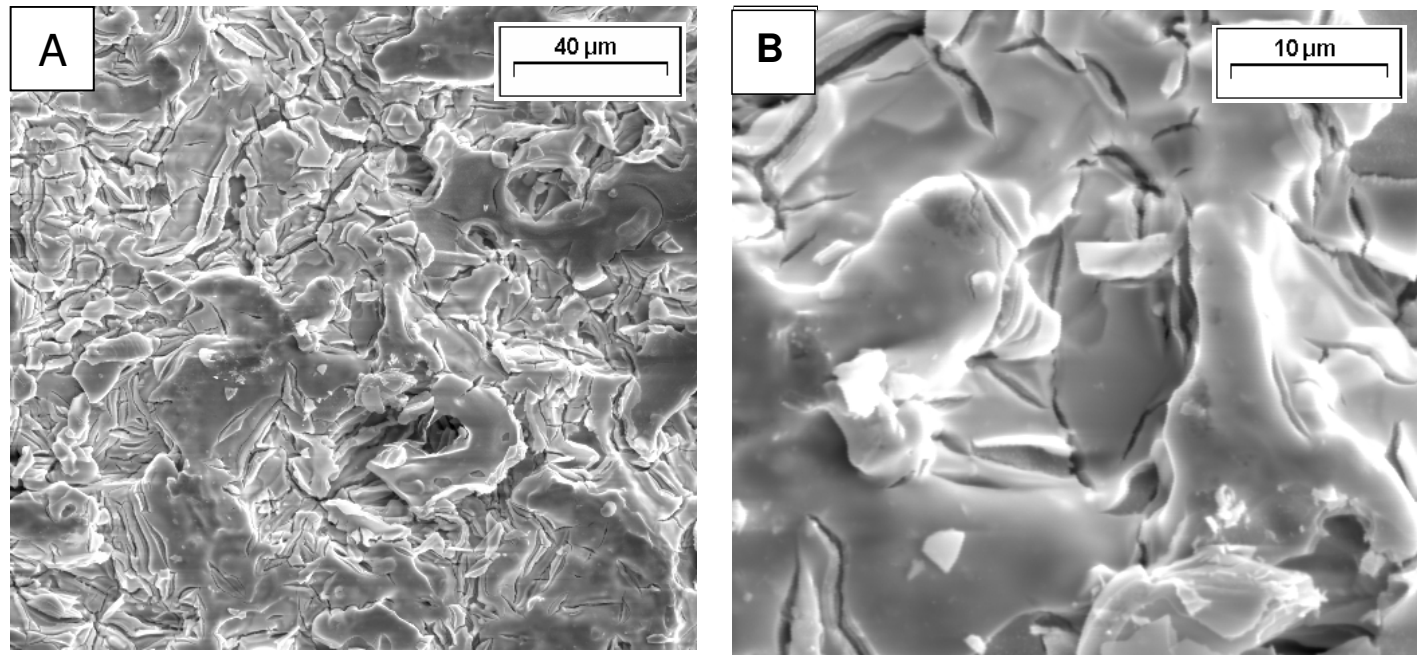

Figura 11 - Micrografia obtida por MEV com ampliação de 500 (A) e 2000 (B) vezes do eletrodo de composição nominal $\mathrm{Sn}_{0,70} \mathrm{Ir}_{0,30} \mathrm{O}_{2}$.

A composição dos filmes de óxido foram determinadas a partir da análise qualitativa e semi-quantitativa dos espectros utilizando a técnica de Energia Dispersiva de Raios-X (EDX) obtidos para todos os eletrodos de composição binária. Esta análise pode ser tomada como representativa da composição global da camada de óxido, uma vez que, foi realizada sobre uma área de $0,9 \mathrm{~mm} \times 0,9 \mathrm{~mm}$ da superfície do eletrodo. Desta forma, em termos qualitativos, foi possível identificar 
os picos referentes aos elementos irídio e estanho, conforme demonstra a Figura 12.

Analisando a Figura 12 pode-se observar também picos de titânio. É preciso mencionar que EDX não é uma técnica de análise de superfície, uma vez que ocorre uma penetração significativa da irradiação na amostra. A presença destes picos de titânio pode ser explicada em virtude da estrutura tipo barro rachado verificada por MEV, ou seja, esta intensidade deve ser devido ao feixe de incidência ter atingido a região das trincas onde o filme de óxido deve estar ausente ou presente com uma espessura muito fina. Outra hipótese provável descrita na literatura $[63,64]$ é o Ti ter sido incorporado na camada de óxido devido ao ataque do suporte metálico de Ti pela solução muito ácida $(\mathrm{HCl} 1: 1)$ do precursor de Ir resultando em uma contaminação no filme com $\mathrm{TiO}_{2}$

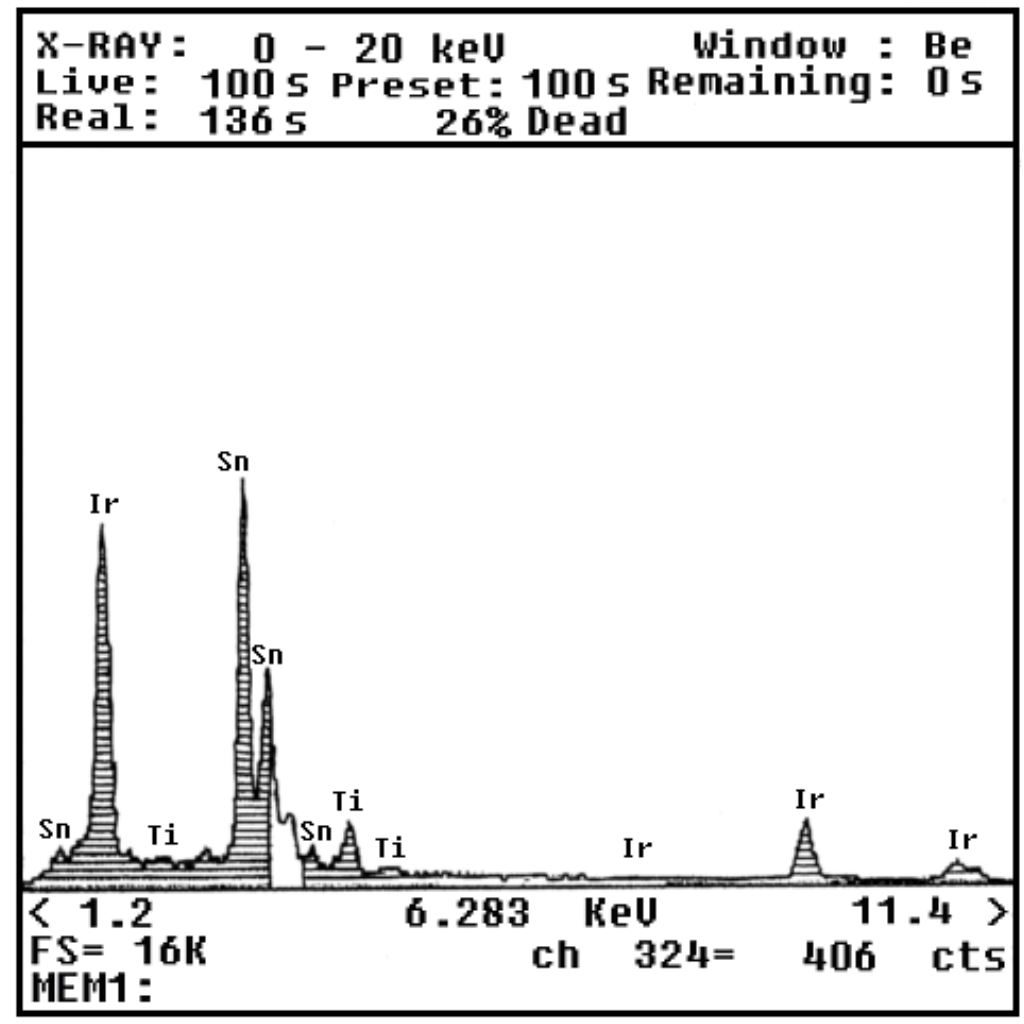

Figura 12 - Espectro de EDX representativo da composição global do eletrodo $\mathrm{Ti} / \mathrm{Sn}_{0,7} \mathrm{Ir}_{0,3} \mathrm{O}_{2}$. 
As porcentagens atômicas obtidas pelas análises de EDX estão demonstradas na Tabela I e foram próximas da composição nominal em todas as regiões, sugerindo a formação de uma camada bastante homogênea.

Tabela I: Comparação entre a composição nominal das camadas de óxidos contendo $\mathrm{IrO}_{2} / \mathrm{SnO}_{2}$ e a composição real determinada por EDX.

\begin{tabular}{cc|c|c}
\hline \multicolumn{4}{c}{ Porcentagens Atômicas / \% at } \\
\hline \multicolumn{3}{c|}{ Sn } & \multicolumn{2}{c}{ Ir } \\
\hline Nominal & Experimental & Nominal & Experimental \\
\hline 99 & 99,1 & 1 & 0,9 \\
95 & 94,1 & 5 & 5,9 \\
90 & 87,9 & 10 & 12,1 \\
70 & 65,8 & 30 & 34,2 \\
\hline
\end{tabular}

Também foi realizada MEV e análises pontuais EDX na seção transversal do eletrodo de composição $\mathrm{Ti} / \mathrm{Sn}_{0,9} \mathrm{Ir}_{0,1} \mathrm{O}_{2}$. Na Figura 13 pode ser observada a micrografia deste eletrodo em dois modos diferentes de aquisição:elétrons secundários na Fig.13-A e elétrons retro espalhados na Fig.13-B.

Para realizar esta análise o substrato de titânio com o filme de óxido previamente depositado, foi mergulhado em uma resina acrílica, e após sua secagem foi lixado e polido. Desta forma, a Figura 13 é constituida pela camada de óxido entre a resina acrílica e o substrato de titânio metálico.

Pode ser observado nesta micrografia que a camada de óxido é formada por partículas empacotadas em toda a sua espessura, e que a espessura real é de aproximadamente $20 \mu \mathrm{m}$. 

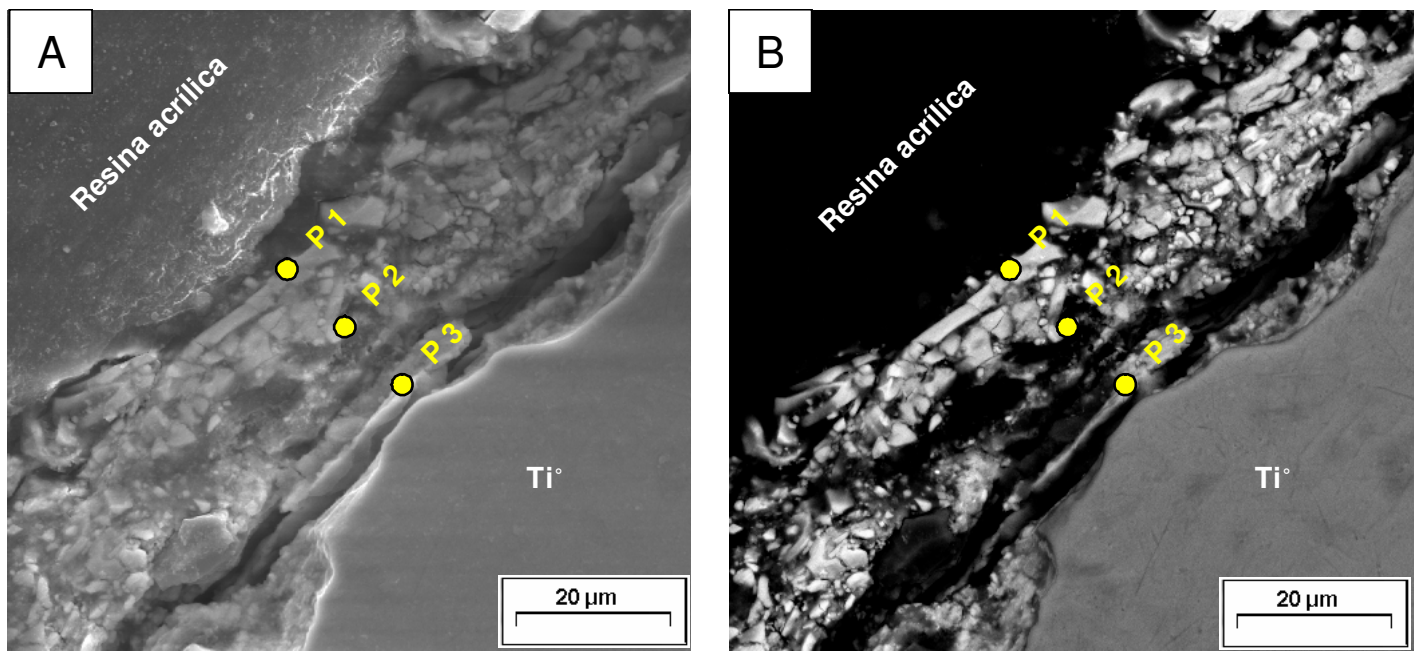

Figura 13 - Micrografia obtida por MEV do corte transversal do eletrodo de composição nominal $\mathrm{Sn}_{0,90} \mathrm{Ir}_{0,10} \mathrm{O}_{2}$ com ampliação de 1000 vezes. Elétrons Secundários (A) e Elétrons Retro-Espalhados (B).

Uma análise pontual de EDX (realizada sobre uma área de 0,94 $\mu \mathrm{m} X$ 0,94 $\mu \mathrm{m}$ da superfície do eletrodo) em pontos distintos da seção transversal, permitiu obter a composição em regiões selecionadas ( $\mathrm{P} 1$, região na superfície da camada; P2 região no centro da camada; P3, região próxima à base de Ti).

A Tabela II apresenta a média das porcentagens atômicas das análises pontuais da camada de óxido para o eletrodo de composição $S_{n_{0,9}} \mid r_{0,1} \mathrm{O}_{2}$ nos diferentes pontos analisados.

As porcentagens atômicas obtidas pelas análises de EDX (demonstradas na Tabela II) foram próximas da composição nominal em todas as regiões, sugerindo a formação de uma camada bastante homogênea. Diferentes misturas de óxidos tem sido relatada na literatura em sistemas como $1 \mathrm{IO}_{2} / \mathrm{Ta}_{2} \mathrm{O}_{5}$ [65], $\mathrm{IrO}_{2} / \mathrm{RuO}_{2}$ [66], $\mathrm{IrO}_{2} / \mathrm{SnO}_{2}$ [55], $\mathrm{IrO}_{2} / \mathrm{TiO}_{2} / \mathrm{PtO}_{\mathrm{x}}[63,67,68]$ onde foi comprovado (em alguns trabalhos utilizando a Técnica de Espectroscopia Fotoeletrónica de Raios-X) que ocorre uma segregação do Ir na superfície da camada de óxido, sendo o Ir encontrado na superfície em maiores quantidades que a composição nominal. Este fenômeno que, em geral, está relacionado a diferenças na cinética de decomposição térmica dos componentes [48].

Esta segregação pode ser evitada utilizando o método de decomposição térmica de precursores poliméricos, provavelmente, devido aos metais que 
constituem os óxidos permanecerem entre as cadeias poliméricas, evitando assim, a sua difusão até a superfície.

Tabela II: Resultados das análises pontuais da camada de óxido do eletrodo de composição $\mathrm{Sn}_{0,9} \mathrm{Ir}_{0,1} \mathrm{O}_{2}$ determinada por EDX.

\section{Porcentagens Atômicas / \% at}

\begin{tabular}{ccc}
\hline Região & Sn & Ir \\
P1 & 88,3 & 11,7 \\
P2 & 88,7 & 11,3 \\
P3 & 88,2 & 11,8 \\
\hline
\end{tabular}

\subsection{2 - Análise estrutural dos eletrodos contendo $\mathrm{SnO}_{2}$ e $\mathrm{IrO}_{2}$.}

A Figura 14 apresenta os difratogramas de raio-X das várias composições dos eletrodos de $\mathrm{Ti} / \mathrm{Sn}_{(1-x)} \mid r_{x} \mathrm{O}_{2}$. As linhas verticais nestas figuras indicam os padrões para $\mathrm{IrO}_{2}, \mathrm{SnO}_{2}$ e $\mathrm{Ti}^{\circ}$. Observando-se os difratogramas pode-se comprovar através dos picos em $2 \theta$ igual a $26,6^{\circ}$ e $33,9^{\circ}$ (referentes aos planos 110 e 101 respectivamente) a presença de um material cristalino com fase rutílica (tetragonal) do $\mathrm{SnO}_{2}$ e nos picos em $2 \theta$ igual a $28^{\circ}$ e $34,7^{\circ}$ a presença de uma fase cristalina do $\mathrm{IrO}_{2}$. Pode-se observar também a diminuição na intensidade dos picos referentes ao $\mathrm{SnO}_{2}$ com o aumento das quantidades $\mathrm{IrO}_{2}$ na composição dos eletrodos. Houve, além de um alargamento, um deslocamento dos picos de $\mathrm{SnO}_{2}$ para ângulos maiores comparado ao $\mathrm{SnO}_{2}$ puro. Maiores ângulos, isto é, menores parâmetros de rede indicam a formação de solução sólida da mistura dos óxidos devido a contração da rede pela substituição de alguns átomos de $\mathrm{Sn}$ por átomos menores de $\operatorname{Ir}\left(r_{S n}{ }^{4+}=0,069 \mathrm{~nm}\right.$ e $\left.r_{l r}{ }^{4+}=0,063 \mathrm{~nm}\right)$ com o aumento da quantidade de $\mathrm{IrO}_{2}$ na mistura.

Não existe diagrama de fase destes óxidos disponível na literatura, porém, ambos os óxidos de irídio e estanho têm uma estrutura tetragonal, os raios iônicos dos dois metais diferem somente cerca de $8 \%$ e eles possuem a mesma valência, o que satisfaz a condição de formação de solução sólida por substituição [31]. 
Apesar dos difratogramas serem obtidos com um acessório de ângulo rasante em todos os difratogramas existe um sinal de Ti que é provavelmente proveniente do suporte metálico.
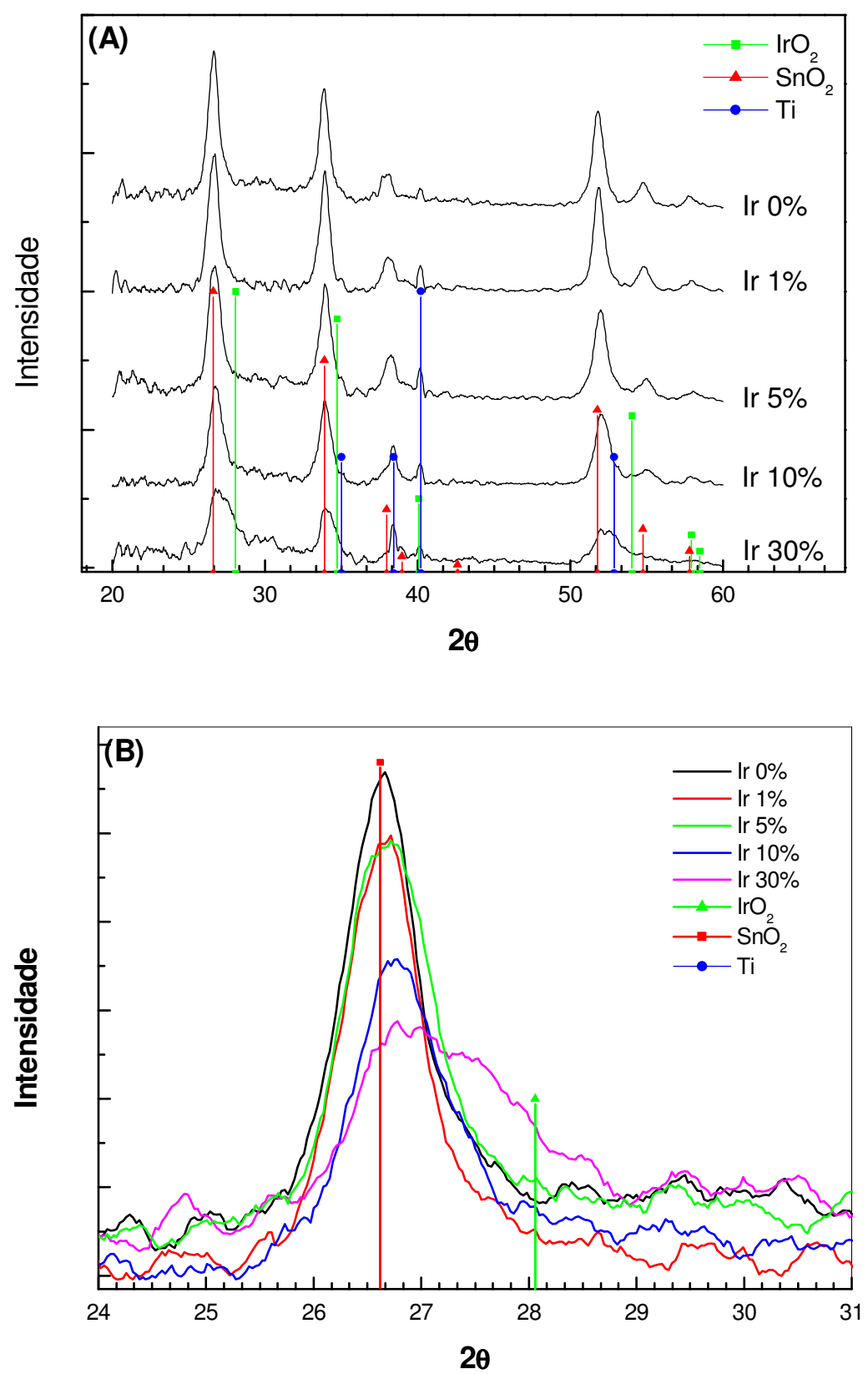

Figura 14 - Difratogramas de Raios-X das várias composições dos eletrodos de $\mathrm{Ti} / \mathrm{Sn}_{(1-x)} \mid \mathrm{r}_{\mathrm{x}} \mathrm{O}_{2}$. A figura $\mathbf{B}$ é a ampliação do primeiro pico da figura $\mathbf{A}$. Os traços verticais indicam os seguintes padrões: vermelho $\mathrm{SnO}_{2}$, verde $\mathrm{IrO}_{2}$ e azul $\mathrm{Ti}^{\circ}$. 


\section{2 - Caracterização in situ}

\subsection{1 - Caracterização por Voltametria Cíclica}

A caracterização eletroquímica dos eletrodos foi realizada através da técnica voltametria cíclica. Os voltamogramas cíclicos foram obtidos em solução de eletrólito suporte, $0,5 \mathrm{~mol} \mathrm{~L}^{-1} \mathrm{H}_{2} \mathrm{SO}_{4}$, em um intervalo de potencial de 0,4 a 1,4 $\mathrm{V}(\mathrm{ERH})$ a uma velocidade de varredura de $20 \mathrm{mVs}^{-1}$. Antes de realizar os estudos voltamétricos, os eletrodos foram submetidos a 30 ciclos de varredura de potenciais a uma velocidade de varredura de $20 \mathrm{mVs}^{-1}$, com a finalidade hidratar os sítios superficiais. Esta hidratação é necessária para que os sítios de difícil acesso existentes em eletrodo recém preparado entre em contato com o eletrólito.

Na Figura 15 podemos observar os voltamogramas cíclicos obtidos para os eletrodos de $\mathrm{Sn}_{(1-\mathrm{x})} \mid \mathrm{r}_{\mathrm{x}} \mathrm{O}_{2}$. O voltamograma cíclico do $\mathrm{SnO}_{2}$ na Figura $15 \mathrm{~A}$, representado pela linha preta, não apresentou transições redox no intervalo de potenciais utilizado, mostrando um comportamento semelhante aos resultados obtidos para filmes preparados por outras técnicas $[27,28]$.

$\mathrm{O}$ voltamograma cíclico do eletrodo contendo $1 \%$ de $\mathrm{IrO}_{2}$ na Figura $15 \mathrm{~A}$, representado pela linha vermelho, caracteriza-se por apresentar um par de picos redox em torno de $1,2 \mathrm{~V}(\mathrm{ERH})$.

A Figura 15B mostra os voltamogramas cíclicos dos eletrodos com a mistura dos óxidos contendo 5, 10 e $30 \%$ de $\mathrm{IrO}_{2}$, onde podemos observar um comportamento bem característico do óxido de irídio e que os picos redox são bastante discretos, contudo, isto é muito comum neste tipo eletrodo. Nestes voltamogramas cíclicos pode-se observar dois pares de picos redox, um em aproximadamente 0,8 e 1,1 $\mathrm{V}(\mathrm{ERH})$ que se assemelham com os resultados encontrados na literatura $[27,34]$ para eletrodo $\mathrm{Ti} / \mathrm{IrO}_{2}$.

Oliveira-Sousa et al. [34] atribuiu o pico observado em 0,8V a transição redox Ir (III)/Ir (IV) e outro em aproximadamente 1,1V como sendo a transição Ir (IV)/Ir (VI), em eletrodo de $\mathrm{Ti} / \mathrm{IO}_{2}$. Foi encontrado na literatura que a transição Ir (IV)/Ir (VI) ocorreria em um potencial de 1,35 V vs. ERH [33,35].

Outra possibilidade é que ambos os pares de picos estejam associados à transição Ir (III)/Ir (IV). Uma explicação para estes picos, seria que devido ao eletrodo possuir uma superfície muito rugosa, haveria uma distribuição do potencial em sua superfície e, conseqüentemente, ocorrendo um desdobramento da transição redox Ir (III)/Ir (IV) em dois pares de picos [69]. 

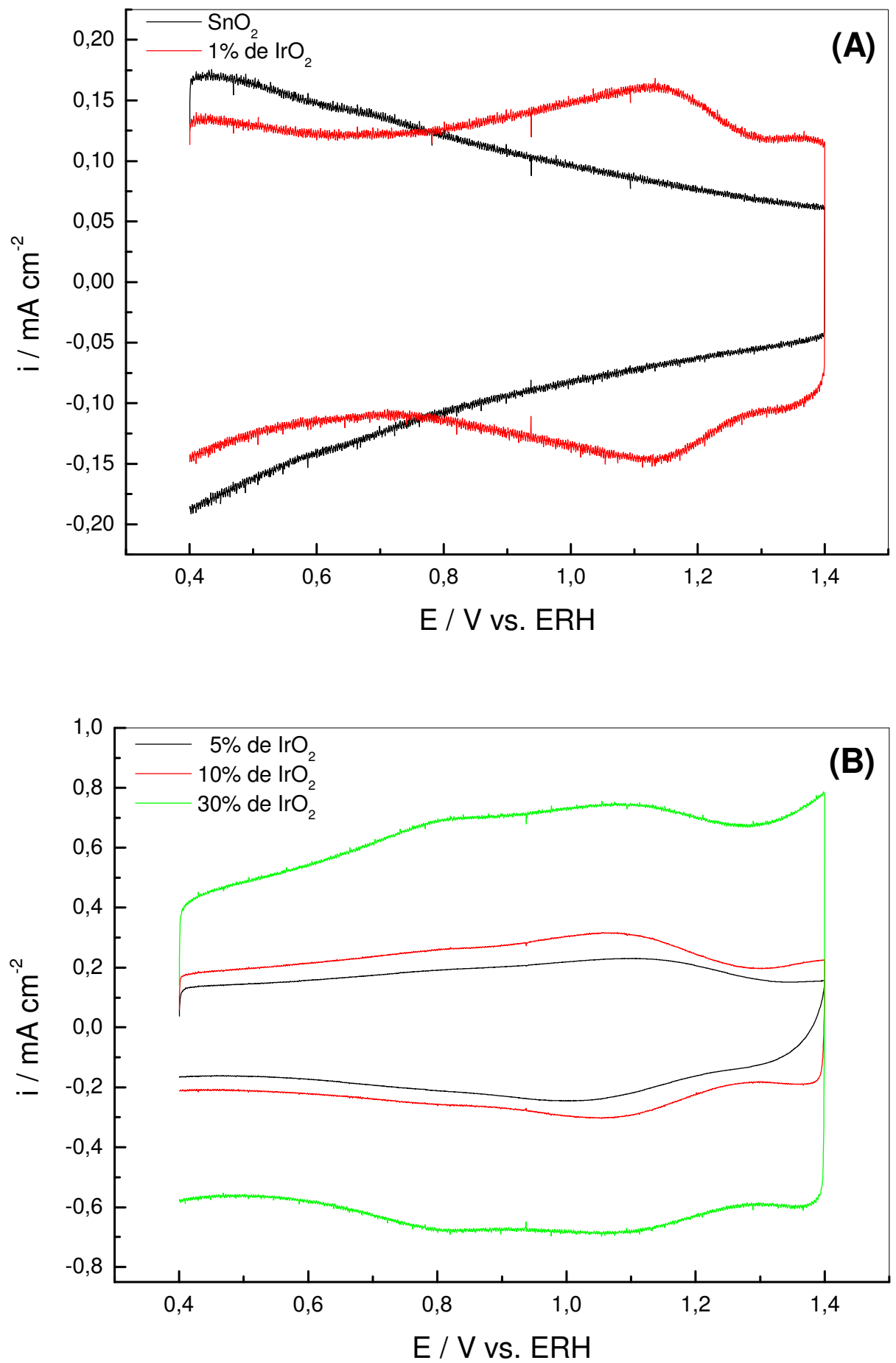

Figura 15 - Voltamogramas cíclicos de todas as composições de eletrodo em solução de $\mathrm{H}_{2} \mathrm{SO}_{4} 0,5 \mathrm{~mol} \mathrm{~L}^{-1}$ a $20 \mathrm{mV} \mathrm{s}^{-1}$.

Para se obter informações sobre a reversibilidade dos processos redox na Figura 16 está apresentado um gráfico da razão carga anódica / carga catódica, $\mathrm{q}_{a} / \mathrm{q}_{\mathrm{c}}$, em função da composição dos eletrodos. As cargas voltamétricas anódicas 
e/ou catódicas foram obtida por integração da parte anódica e/ou catódica da curva voltamétrica.

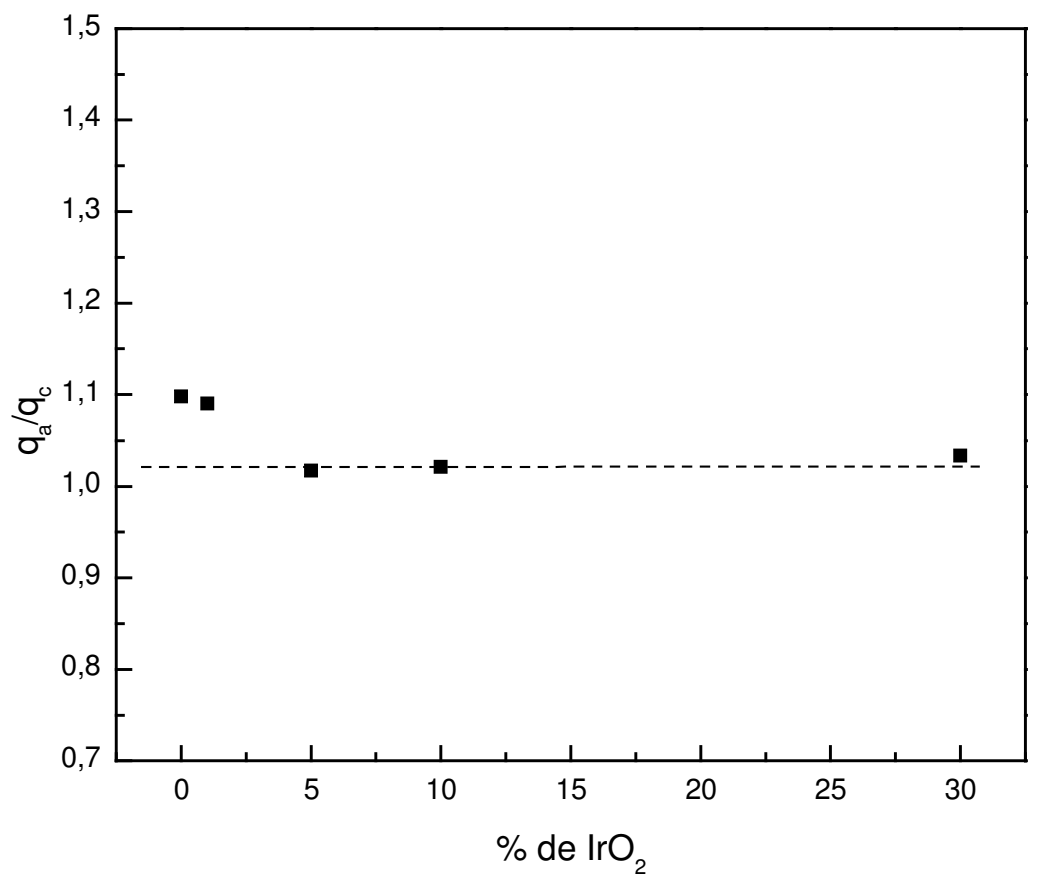

Figura 16 - Dependência da razão carga anódica / catódica, qa/qc, em função da composição dos eletrodos.

As razões carga anódica / catódica para as composições eletródicas são próximas de um. Este comportamento repete-se para todas as composições, sugerindo transições redox superficiais reversíveis para todos os eletrodos.

Os eletrodos foram preparados em duplicata para cada composição, e como podemos observar na Figura 17, onde estão demonstrados os voltamogramas cíclicos dos eletrodos de mesma composição, existe uma mínima diferença entre as cargas voltamétricas dos eletrodos de mesma composição, indicando que o método empregado na preparação dos óxidos proporcionou o controle e a reprodutibilidade dos eletrodos. 


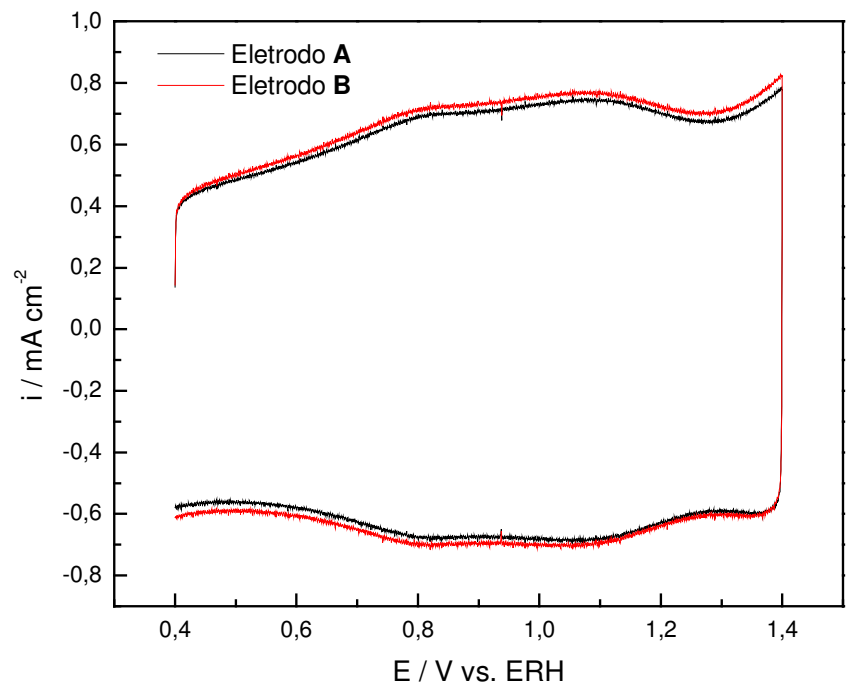

Figura 17 - Voltamogramas cíclicos de dois eletrodos contendo $30 \%$ de $\mathrm{IrO}_{2}$ (os eletrodos $\mathrm{A}$ e B) em solução de $\mathrm{H}_{2} \mathrm{SO}_{4} 0,5 \mathrm{~mol} \mathrm{~L}^{-1}$ a $20 \mathrm{mV} \mathrm{s}^{-1}$.

\subsection{2 - Área eletroquimicamente ativa}

Através dos voltamogramas cíclicos das composições de eletrodo estudadas fica evidente um aumento na carga voltamétrica com o aumento da quantidade de $\mathrm{IrO}_{2}$ na composição. A carga voltamétrica, tanto anódica como catódica, é um parâmetro que pode ser tomado como medida relativa da área eletroquimicamente ativa [70].

Uma outra forma de medida relativa da área eletroquimicamente ativa é a determinação através de valores de capacitância da dupla camada elétrica. Este método consiste em obter valores de corrente, em um dado potencial, em voltamogramas cíclicos em diferentes velocidades de varredura. Este potencial deve estar em regiões do voltamograma cíclico, onde existe somente corrente capacitiva, ou seja, em regiões onde não ocorrem transições redox superficiais.

A partir dos coeficientes angulares das retas $\mathrm{i}_{\mathrm{E}} \mathrm{vs}$. Velocidade de varredura, é possível obter a capacitância da dupla camada elétrica, $\mathrm{C}_{\mathrm{dc}}$, e usá-las para avaliar as mudanças relativas de área em função da composição da camada de óxido. 


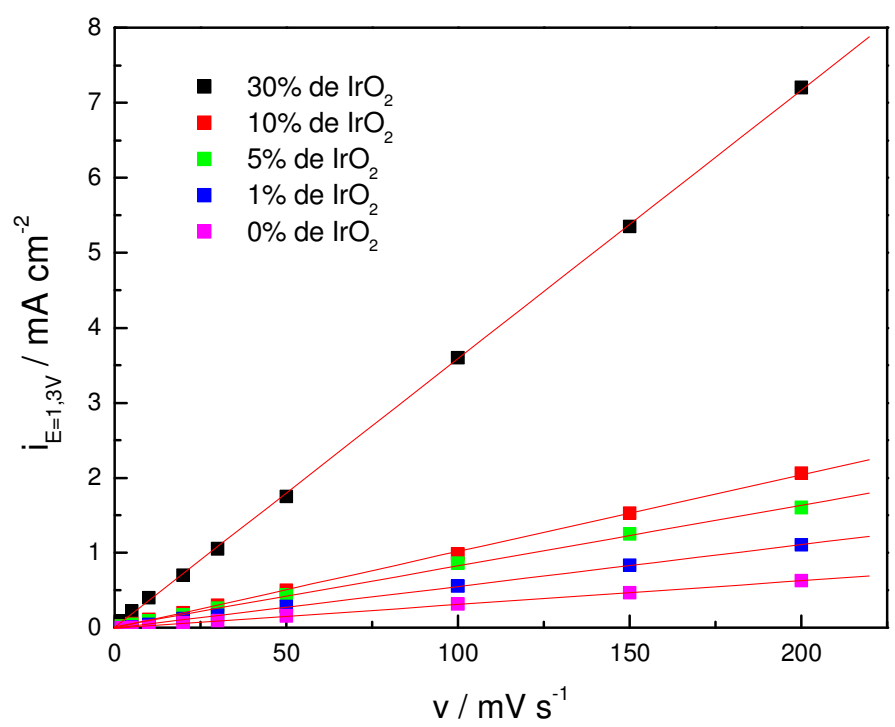

Figura 18 - Gráfico de corrente capacitiva em função da velocidade de varredura, obtida no potencial de 1,3 V (ERH), para todas as composições dos óxidos.

Contudo nos voltamogramas cíclicos dos eletrodos $\mathrm{Sn}_{(1-x)} \mid \mathrm{r}_{x} \mathrm{O}_{2}$ não existe uma região puramente capacitiva. Isto se deve a alta rugosidade deste tipo de eletrodo, causando uma distribuição do potencial dos processos redox ao longo da superfície. Desta forma, a área superficial dos eletrodos foi determinada através de medidas de corrente em regiões do voltamograma cíclico onde os processos redox são menos pronunciados, ou seja, onde a uma menor contribuição da corrente faradáica, no potencial de 1,3 V (i $\mathrm{i}_{\mathrm{E}}$. Este potencial se encontra em uma região entre o processo redox em 1,1V e a RDO, e deve ser considerada uma região pseudocapacitiva. As correntes pseudocapacitivas foram extraídas dos voltamogramas cíclicos em velocidade de varredura variando de 2 a $200 \mathrm{mVs}^{-1}$ e posteriormente foi feito um gráfico de corrente capacitiva vs. velocidade de varredura para todas as composições, o que pode ser observado na Figura 18.

Na Figura 19 esta apresentada a dependência da $\mathbf{C}_{\mathrm{dc}}$, determinada a partir da Figura 18, e da carga anódica $\left(\mathbf{q}_{\mathrm{a}}\right)$ em função da composição, e pode ser observado que elas tem um comportamento muito semelhante.

Como a dependência da $\mathbf{C}_{d c}$ e da carga anódica, $\mathbf{q}_{a}$, em função da composição, apresentaram um comportamento muito semelhante, pode-se dizer 
que tanto $\mathbf{C}_{\mathrm{dc}}$ quanto $\mathbf{q}_{\mathrm{a}}$ podem ser utilizados como uma medida relativa da área eletroquimicamente ativa nos eletrodos investigados.



Figura 19 - Gráfico da capacitância da dupla camada elétrica e da carga anódica em função da \% de $\mathrm{IrO}_{2}$ na composição do eletrodo.

Apesar das micrografias (Fig. 10 e 9B) apresentarem uma morfologia mais compacta para os eletrodos contendo 5 e $10 \%$ de $\mathrm{IrO}_{2}$ que para o contendo $1 \%$, na Figura 19 a $\mathbf{C}_{\mathrm{dc}}$ e $\mathbf{q}_{\mathbf{a}}$ aumentam com o aumento de $\mathrm{IrO}_{2}$ na composição do eletrodo. Esta aparente discordância de resultados pode ser explicada baseado em um trabalho sistemático de substituição de $\mathrm{RuO}_{2}$ por $\mathrm{SnO}_{2}$ desenvolvido por Ito et al. [29]. Estes autores caracterizaram morfologicamente eletrodos de $\mathrm{SnO}_{2}$ $\mathrm{RuO}_{2}$ através das técnicas de Microscopia de Força Atômica e Microscopia Eletrônica de Varredura de Alta Resolução. Os autores puderam observar que os eletrodos com altos conteúdos de rutênio apresentavam em sua microestrutura planos lisos, aos quais os autores chamaram de "macroscopicamente lisos". Através das micrografias obtidas, os autores verificaram que estes planos são, na verdade, constituídos por partículas ultrafinas, da ordem de $30 \mathrm{~nm}$ de diâmetro e de $10 \mathrm{~nm}$ de altura, tais partículas conferem ao eletrodo elevada área eletroquimicamente ativa. Provavelmente, os eletrodos desenvolvidos no presente trabalho, apresentam uma microestrutura semelhante à dos eletrodos desenvolvidos por lto et al. [29]. Assim, o aspecto liso e aparentemente mais 
compacto observado nas micrografias dos eletrodos contendo 5 e $10 \%$ de $\mathrm{IrO}_{2}$, provavelmente, deve-se a partículas com dimensões bem menores que aquelas observadas no eletrodo contendo $1 \%$ de $\mathrm{IrO}_{2}$. Nas ampliações utilizadas nas micrografias, tais partículas são vistas como planos lisos. Assim, a possível diminuição do tamanho das partículas deve aumentar de maneira significativa a área eletroquimicamente ativa dos eletrodos com maiores porcentagens de Ir.

\subsection{3 - Estudo da influência da adição de Ir aos eletrodos de $\mathrm{SnO}_{2}$ para a Reação de Desprendimento de Oxigênio.}

Com a finalidade de se estudar o comportamento dos eletrodos em regiões de potenciais mais anódicas foram registrados voltamogramas cíclicos entre 0,4 V (potencial inicial) e 1,8 a 3,0 V (potencial de inversão).

No gráfico da Figura 20 estão apresentados os voltamogramas cíclicos de 15 ciclos de um eletrodo $\mathrm{Ti} / \mathrm{SnO}_{2}$ entre 0,4 e 2,5 V. Neste experimento verificou-se que próximo ao potencial de inversão há um aumento da corrente atribuída ao início da reação de desprendimento de oxigênio (RDO). Esta corrente diminui gradativamente com o número de ciclos, como pode-se observar após 15 ciclos. Após essa queda de corrente da RDO, o potencial de inversão do voltamograma cíclico foi aumentado para um valor mais anódico $(3,0 \mathrm{~V})$ e a corrente da RDO voltou a ter um aumento, e com sucessivos ciclos foi diminuindo novamente. 




Figura 20 - Voltamogramas cíclicos do eletrodo $\mathrm{Ti} / \mathrm{SnO}_{2}$ em solução de $\mathrm{H}_{2} \mathrm{SO}_{4} 0,5$ $\mathrm{mol} \mathrm{L}^{-1}$ a $20 \mathrm{mV} \mathrm{s}^{-1}$.

Segundo Correa-Lozano et al. [71], o mecanismo de desativação do eletrodo de $\mathrm{SnO}_{2}$ pode ser explicado com relação ao mecanismo de formação de oxigênio. Este mecanismo envolveria um certo grau de não-estequiometria do $\mathrm{SnO}_{2}$ (defeitos na rede cristalina com deficiência de oxigênio) que poderia ser escrito como $\mathrm{SnO}_{(2-x)}$. Estes defeitos no $\mathrm{SnO}_{2}$ é que proporcionariam uma maior condutividade ao óxido, e conseqüentemente a perda destes defeitos o tornaria menos condutor levando a sua desativação.

Estes defeitos iniciais envolveriam uma grande concentração de defeitos estequiométricos, que levariam a formação de radicais hidroxilas adsorvidos $\left({ }^{\circ} \mathrm{OH}\right)$.

$$
\left.\mathrm{SnO}_{(2-x)}+\mathrm{H}_{2} \mathrm{O} \rightarrow \mathrm{SnO}_{(2-x)}{ }^{\circ} \mathrm{OH}\right)+\mathrm{H}^{+}+\mathrm{e}^{-}
$$

Posteriormente ocorreria uma oxidação que acarretaria em um aumento da estequiometria do óxido em relação ao oxigênio. 


$$
\mathrm{SnO}_{(2-x)}\left({ }^{\circ} \mathrm{OH}\right) \rightarrow \mathrm{SnO}_{(2-x+y)}+y \mathrm{H}^{+}+\mathrm{ye}^{-}
$$

A decomposição das espécies $\mathrm{SnO}_{(2-x+y)}$ pode levar à formação de $\mathrm{O}_{2}$ através da seguinte etapa abaixo, onde $\mathrm{SnO}_{(2-x)}$ seria regenerado:

$$
\mathrm{SnO}_{(2-x+y)} \rightarrow \mathrm{SnO}_{(2-x)}+1 / 2 \mathrm{O}_{2}
$$

Entretanto, sob polarização anódica e/ou ciclagem entre RDH e RDO, poderia ocorrer a incorporação de oxigênio na superfície do filme de óxido, e conseqüentemente a perda dos defeitos, gerando $\mathrm{SnO}_{2}$, com o aumento progressivo do valor de $y$ em relação a $x$. Neste caso o mecanismo para a RDO seria:

$$
\begin{aligned}
& \mathrm{SnO}_{2}+\mathrm{H}_{2} \mathrm{O} \rightarrow \mathrm{SnO}_{2}\left({ }^{\circ} \mathrm{OH}\right)+\mathrm{H}^{+}+\mathrm{e}^{-} \\
& \mathrm{SnO}_{2}\left({ }^{\circ} \mathrm{OH}\right) \rightarrow \mathrm{SnO}_{2}+1 / 2 \mathrm{O}_{2}+\mathrm{H}^{+}+\mathrm{e}^{-}
\end{aligned}
$$

Além do eletrodo de $\mathrm{SnO}_{2}$, também nos eletrodos contendo as misturas dos óxidos houve uma queda da corrente da RDO, porém proporcionalmente menos acentuada. Isto pode ser devido a que os eletrodos contendo as misturas dos óxidos apresentam um comportamento característico do $\mathrm{IrO}_{2}$, o qual torna os eletrodos mais estáveis como pode ser visto nas Figuras 21 e 22 . 


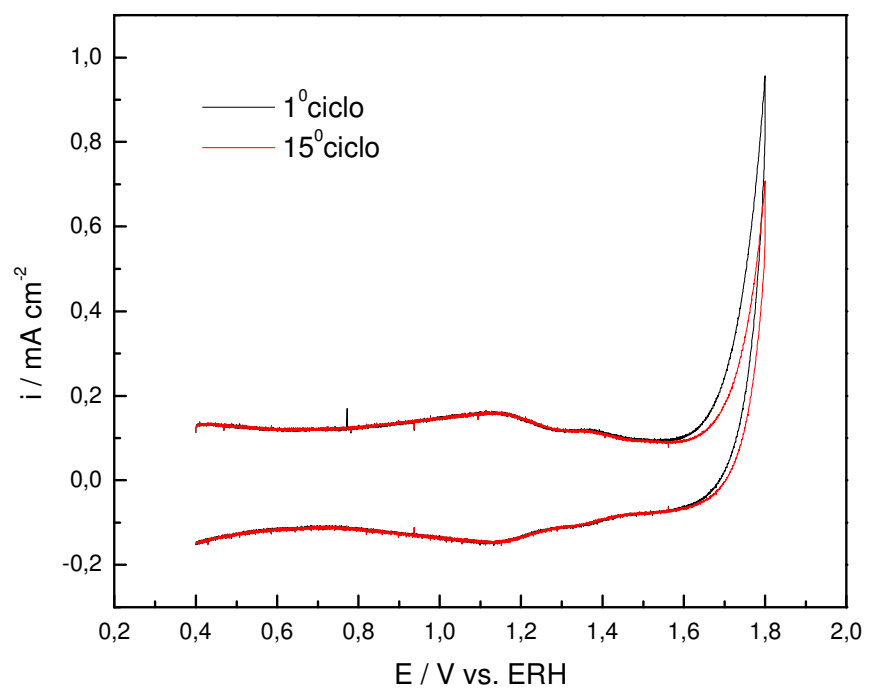

Figura 21 - Voltamogramas cíclicos do eletrodo contendo $1 \%$ de $\mathrm{IrO}_{2}$ em solução de $\mathrm{H}_{2} \mathrm{SO}_{4} 0,5 \mathrm{~mol} \mathrm{~L}^{-1}$ a $20 \mathrm{mV} \mathrm{s}^{-1}$.

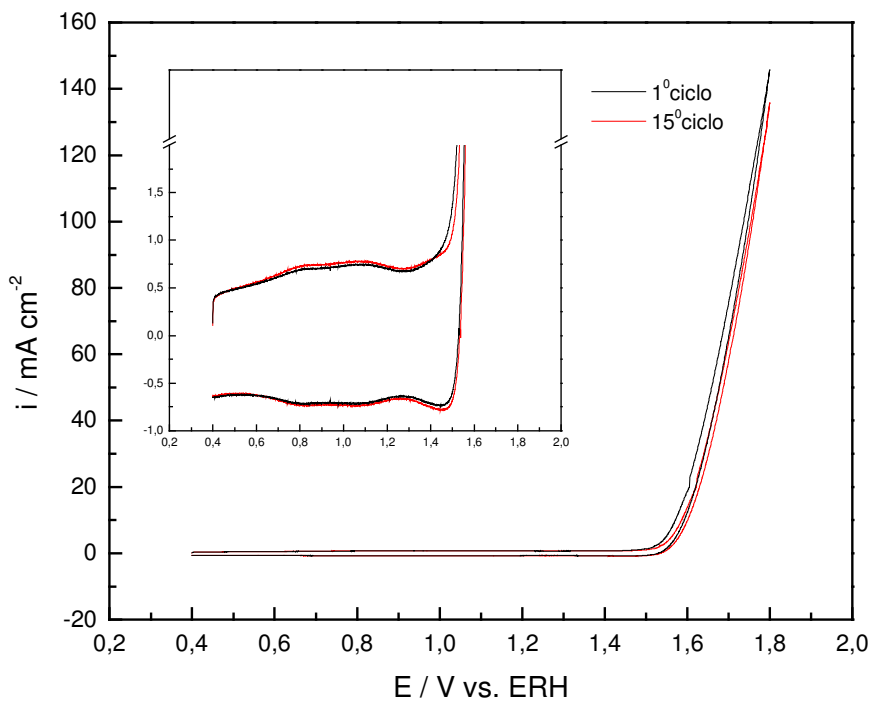

Figura 22 - Voltamogramas cíclicos dos primeiros 15 ciclos do eletrodo contendo $30 \%$ de $\mathrm{IrO}_{2}$ em solução de $\mathrm{H}_{2} \mathrm{SO}_{4} 0,5 \mathrm{~mol} \mathrm{~L}^{-1}$ a $20 \mathrm{mV} \mathrm{s}^{-1}$.

Nos voltamogramas cíclicos pode-se observar também que o potencial de início da RDO é de aproximadamente $1,8 \mathrm{~V}$ para o eletrodo de $\mathrm{SnO}_{2}$ e de aproximadamente $1,4 \mathrm{~V}$ para o eletrodo contendo $\mathrm{IrO}_{2}$. No caso do eletrodo de $\mathrm{SnO}_{2}$ o potencial é bastante próximo ao potencial redox $\mathrm{H}_{2} \mathrm{O} / \mathrm{H}_{2} \mathrm{O}_{2}$ (equação 6) e 
para as composições contendo $\mathrm{IrO}_{2}$ é próximo a formação de estados de oxidação superiores do Ir (equação 7).

$$
\begin{gathered}
2 \mathrm{H}_{2} \mathrm{O} \leftrightharpoons \mathrm{H}_{2} \mathrm{O}_{2}+2 \mathrm{H}^{+}+2 \mathrm{e}^{-} \\
\mathrm{IrO}_{2}+\mathrm{H}_{2} \mathrm{O} \leftrightharpoons \mathrm{IrO}_{3}+2 \mathrm{H}^{+}+2 \mathrm{e}^{-}
\end{gathered}
$$

Baseando-se nas discussões acima Correa-Losano et al. [71] propuseram um mecanismo generalizado para a RDO nos eletrodos de óxidos em meio ácido, que está esquematizado na Figura 23.

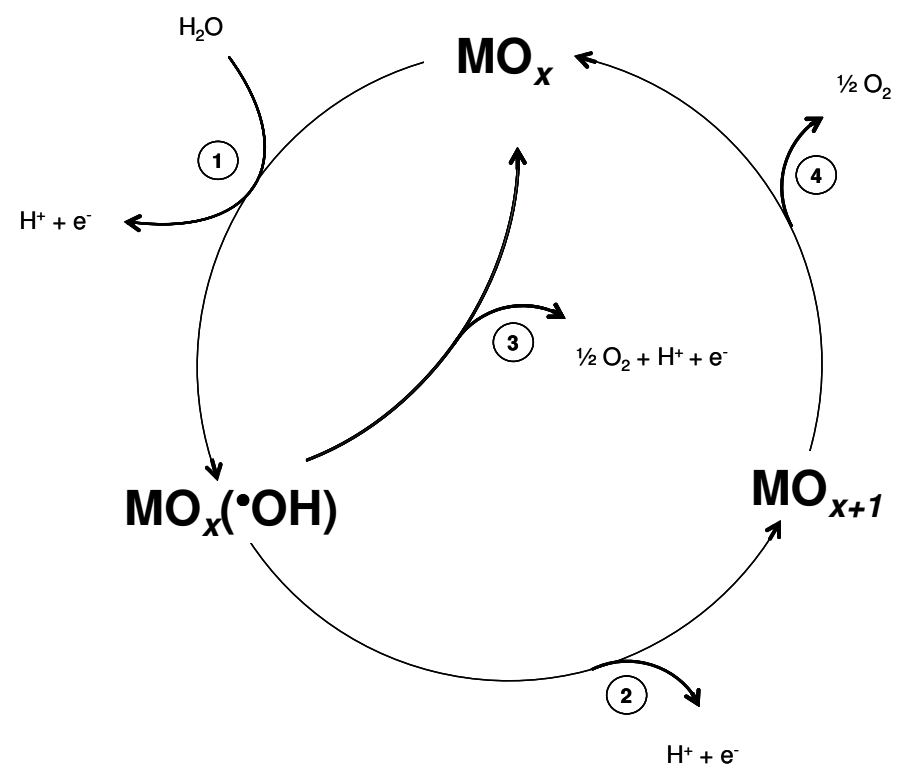

Figura 23 - Mecanismo da RDO em eletrodos de óxidos: (1) formação do radical hidroxila $\left({ }^{\circ} \mathrm{OH}\right)$ pela oxidação da água; (2) transferência do oxigênio do ${ }^{\circ} \mathrm{OH}$ para o retículo do óxido (formação de um sítio com estado de oxidação superior); (3) RDO por oxidação eletroquímica das espécies ${ }^{\bullet} \mathrm{OH}$; (4) RDO por decomposição química dos sítio com estado de oxidação superior [71].

Em um primeiro passo radicais hidroxilas $\left({ }^{\circ} \mathrm{OH}\right)$ são adsorvidos. 


$$
\mathrm{MO}_{x}+\mathrm{H}_{2} \mathrm{O} \rightarrow \mathrm{MO}_{x}\left({ }^{\circ} \mathrm{OH}\right)+\mathrm{H}^{+}+\mathrm{e}^{-}
$$

No caso de óxidos "não ativos" os radicais hidroxilas adsorvidos fracamente são oxidados para formar $\mathrm{O}_{2}$, pelo então chamado mecanismo do peróxido (peróxido de hidrogênio é provavelmente um intermediário):

$$
M O_{x}\left({ }^{\circ} \mathrm{OH}\right) \rightarrow 1 / 2 \mathrm{O}_{2}+\mathrm{H}^{+}+\mathrm{e}^{-}+\mathrm{MO}_{x}
$$

Aparentemente o eletrodo de $\mathrm{SnO}_{2}$ quando polarizado anodicamente, a RDO ocorre através das equações (8)-(9).

Para os óxidos "ativos" (óxido de metais nobres como $\mathrm{RuO}_{2}$ e $\mathrm{IrO}_{2}$ ), os quais são cataliticamente ativos para a RDO, os radicais hidroxilas podem ser estabilizados pela interação com o cátion metálico no retículo do óxido, causando um aumento do seu estado de oxidação:

$$
\mathrm{MO}_{x}\left({ }^{\circ} \mathrm{OH}\right) \rightarrow \mathrm{MO}_{x+1}+\mathrm{H}^{+}+\mathrm{e}^{-}
$$

A decomposição desta espécie instável da origem ao $\mathrm{O}_{2}$ :

$$
\mathrm{MO}_{x+1} \rightarrow \mathrm{MO}_{x}+1 / 2 \mathrm{O}_{2}
$$

É conhecido que o Ir é um material catalítico para a RDO, por isso, o potencial para esta reação é cada vez menos positivo com o aumento da concentração de Ir na mistura. A Figura 24 mostra os voltamogramas cíclicos dos eletrodos de todas as composições utilizadas até o potencial final de 1,8 $\mathrm{V}(\mathrm{ERH})$. Nesta figura é possível observar a diferença do efeito catalítico para a RDO em função da composição, o qual aumenta com o aumento da concentração de $\mathrm{IrO}_{2}$ na mistura dos óxidos.

Deve-se destacar que quanto maior a composição de $\mathrm{IrO}_{2}$ nos eletrodos, maior é a carga voltamétrica obtida, o que indica que os eletrodos mais ricos em Ir apresentam área eletroquimicamente ativa maior. Assim, ao se comparar eletrodos com diferentes composições através de valores de densidades de 
corrente em um determinado potencial, estará sendo avaliada uma soma dos efeitos catalítico e de área eletroquimicamente ativa.



Figura 24 - Voltamogramas cíclicos dos eletrodos contendo de 0 a $30 \%$ de $\mathrm{IrO}_{2}$ na mistura dos óxidos em solução de $\mathrm{H}_{2} \mathrm{SO}_{4} 0,5 \mathrm{~mol} \mathrm{~L}^{-1}$ a $20 \mathrm{mV} \mathrm{s}^{-1}$.

Na Figura 25 está apresentado um gráfico da densidade de corrente e densidade de corrente dividida pela carga voltamétrica em função da concentração de $\mathrm{IrO}_{2}$. As densidades de corrente foram extraídas dos voltamogramas da figura anterior no potencial de $1,7 \mathrm{~V}(\mathrm{ERH})$. As cargas voltamétricas utilizadas para normalizar a corrente em 1,7 V foram determinadas a partir dos voltamogramas cíclicos com varredura de potenciais entre 0,4 e 1,4 V $(\mathrm{ERH})$ a $20 \mathrm{mV} \mathrm{s}^{-1}$ para cada composição. Esta normalização foi realizada para eliminar a contribuição da área de cada eletrodo na densidade de corrente.

Nesta figura fica mais visível a dependência da densidade de corrente para a RDO em função da composição do eletrodo. Além disso pode-se observar que a densidade de corrente dividida pela carga voltamétrica de cada eletrodo também aumenta com a concentração de $\mathrm{IrO}_{2}$, sugerindo que há um aumento catalítico para a RDO com a adição de irídio na composição, independentemente da área real de cada eletrodo. 


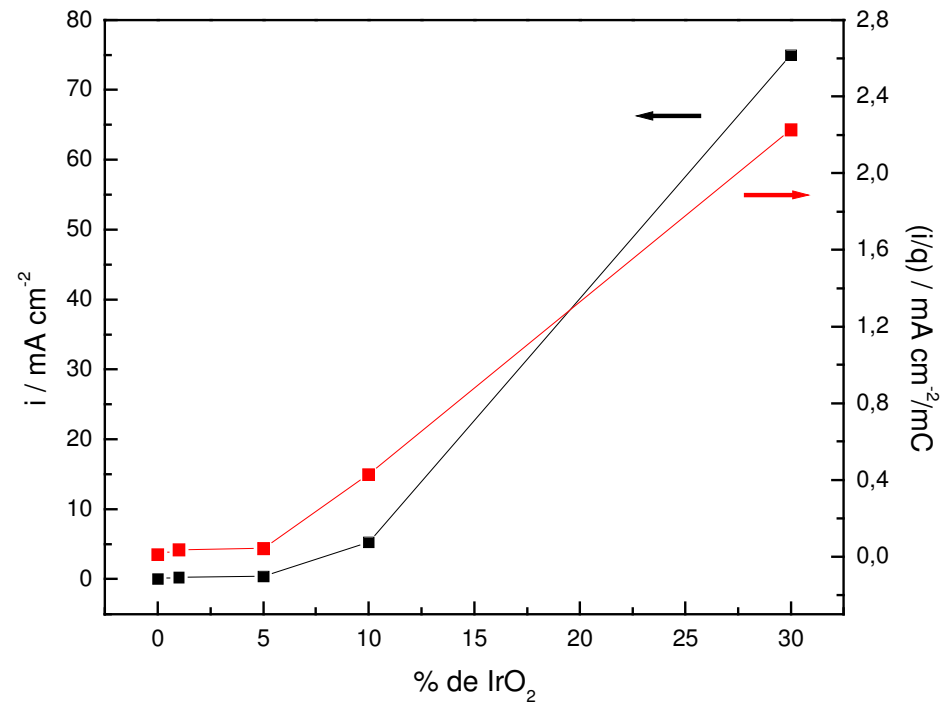

Figura 25 - Gráfico da densidade de corrente (i) e densidade de corrente dividida pela carga voltamétrica em função da concentração de $\mathrm{IrO}_{2}$. As correntes foram extraídas da Fig.24 em um potencial de 1,7 V (ERH). As cargas utilizadas na divisão são dos voltamogramas com varredura de potenciais entre 0,4 e 1,4 a $20 \mathrm{mV} \mathrm{s}^{-1}$ para cada respectiva composição.

\subsection{4 - Estudo da estabilidade eletroquímica dos eletrodos de $\mathrm{Sn}_{(1-\mathrm{x})} \mid \mathrm{r}_{\mathrm{x}} \mathrm{O}_{2}$}

Os eletrodos de $\mathrm{SnO}_{2}$ normalmente possuem um baixo tempo de vida útil, quando estão operando na RDO, o que inviabiliza a sua aplicação na oxidação de moléculas orgânicas. Em estudos de tempo de vida útil de eletrodos de $\mathrm{Ti} / \mathrm{SnO}_{2}$ encontrados na literatura obtiveram tempos de 5 a 9 horas com corrente de $10 \mathrm{~mA} \mathrm{~cm}^{-2}$ [28] e 4 horas com corrente de $100 \mathrm{~mA} \mathrm{~cm}^{-2}$ [27], porém, nestes trabalhos os eletrodos foram preparados pelo método de "spray-pyrolysis".

Em um outro trabalho realizado por Rodrigues [62], o qual utilizou o mesmo método de preparação dos eletrodos utilizado neste trabalho, encontrou tempos de vida útil da ordem de alguns segundos.

Desta forma neste trabalho nem o estudo de estabilidade e nem a oxidação das moléculas orgânicas foram realizados com o eletrodo de $\mathrm{SnO}_{2}$.

$\mathrm{O}$ estudo da estabilidade eletroquímica dos eletrodos $S n_{(1-x)} I_{x} O_{2}$ foi realizado utilizando a técnica de cronopotenciometria em meio de uma solução de $\mathrm{H}_{2} \mathrm{SO}_{4} \quad 0,5 \mathrm{~mol} \mathrm{~L}^{-1}$. Foi aplicada uma densidade de corrente constante de 
$100 \mathrm{~mA} \mathrm{~cm}^{-2}$ por um período de 100 horas ou até que o potencial atingisse $6 \mathrm{~V}$ vs. ERH. Sob estas condições os eletrodos operam como ânodo na reação de desprendimento de oxigênio. No potencial de $6 \mathrm{~V}$, assume-se que a camada de óxido foi completamente desativada, sendo que o tempo necessário para atingir este potencial foi definido como o tempo de vida útil do eletrodo.

Os eletrodos constituídos por filmes de óxidos do tipo ADE normalmente se desativam devido a formação de uma intercamada isolante de $\mathrm{TiO}_{2}$ entre o suporte metálico e a camada de óxido ou devido a um desgaste da própria camada, seja por dissolução (corrosão) ou desgaste mecânico (erosão). No caso da formação da intercamada isolante observa-se normalmente que o potencial permanece constante com o tempo, sofrendo posteriormente um brusco aumento. Além disso, o aspecto voltamétrico após o eletrodo ter atingido $6 \mathrm{~V}$ é completamente distorcido com uma grande resistividade e uma inibição dos processos redox. Quando há um desgaste da camada de óxido é observada uma diminuição gradual da carga voltamétrica com o tempo de eletrólise.

A Figura 26 apresenta as curvas cronopotenciométricas para as diversas composições estudadas. Nesta figura é possível observar que as curvas apresentam um aumento contínuo do potencial com o tempo, com exceção do eletrodo contendo $30 \%$ de $\mathrm{IrO}_{2}$ em que o potencial permanece constante após 100 horas de experimento, mostrando ter uma estabilidade muito superior que a dos outros eletrodos.

Apesar do $\mathrm{IrO}_{2}$ possuir uma grande estabilidade anódica e uma estrutura isomorfa com o $\mathrm{SnO}_{2}$ e com $0 \mathrm{TiO}_{2}$, nos eletrodos com misturas de 1 a $10 \%$ de $\mathrm{IrO}_{2}$ não houve um aumento no tempo de vida útil do eletrodo com o aumento da quantidade $\mathrm{IrO}_{2}$ presente no eletrodo. 


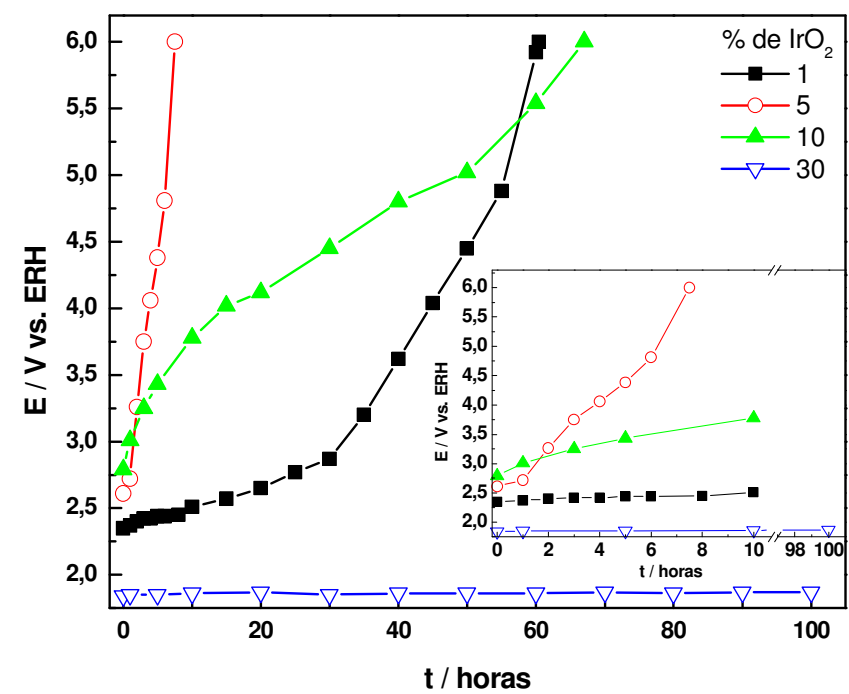

Figura 26 - Curvas cronopotenciométricas obtidas em meio de $\mathrm{H}_{2} \mathrm{SO}_{4} \quad 0,5 \mathrm{~mol} \mathrm{~L}^{-1}$ e corrente constante de $100 \mathrm{~mA} \mathrm{~cm}^{-2}$.

Os eletrodos contendo 1 e $10 \%$ de irídio sofreram desativação em tempos muito próximos (60 e 67 horas respectivamente) quando submetidos a corrente constante. Apesar desta desativação em tempos muito próximos pode-se observar na curva para o eletrodo contendo $1 \%$ de irídio que o potencial inicial é menor que para o eletrodo contendo $10 \%$ de irídio. Além disso, nas trinta horas iniciais o eletrodo contendo $1 \%$ de irídio apresenta um pequeno aumento de potencial (aproximadamente 2,9 V em $\mathrm{t}=30$ horas), enquanto que o eletrodo contendo $10 \%$ de irídio apresenta um aumento mais rápido de potencial (aproximadamente $4,4 \mathrm{~V}$ em $\mathrm{t}=30$ horas). Este comportamento demonstra a possibilidade da mudança de mecanismo de desativação dos eletrodos. Os voltamogramas cíclicos obtidos para os eletrodos contendo 1 e 10\% de irídio também apontam para uma diferença entre os mecanismos de desativação.

A Figura 27 apresenta a evolução dos voltamogramas cíclicos do eletrodo contendo $1 \%$ de irídio durante o experimento de tempo de vida útil do eletrodo. É possível observar que entre o voltamograma inicial e o voltamograma após o eletrodo ter atingido $6 \mathrm{~V}$ há uma pequena diminuição da corrente de pico do processo redox, porém este processo continua reversível sem deslocamento dos processos em comparação com o voltamograma cíclico inicial. 




Figura 27 - Voltamogramas cíclicos do eletrodo contendo 1\% do óxido de irídio em meio de $\mathrm{H}_{2} \mathrm{SO}_{4} \quad 0,5 \mathrm{~mol} \mathrm{~L}^{-1}$ a $20 \mathrm{mV} \mathrm{s}^{-1}$. Os Voltamogramas cíclicos foram obtidos antes, durante e após o experimento de cronopotenciometria.

A Figura 28 apresenta a evolução dos voltamogramas cíclicos durante o experimento de tempo de vida útil do eletrodo contendo $10 \%$ de irídio. Neste caso é possível observar que entre o voltamograma inicial, os voltamogramas no decorrer da cronopotenciometria e após o eletrodo ter atingido $6 \mathrm{~V}$ há um deslocamento gradativo do pico anódico em 1,1 V para potenciais mais positivos e do pico catódico em 1,1 $\mathrm{V}$ para potenciais menos positivos. 


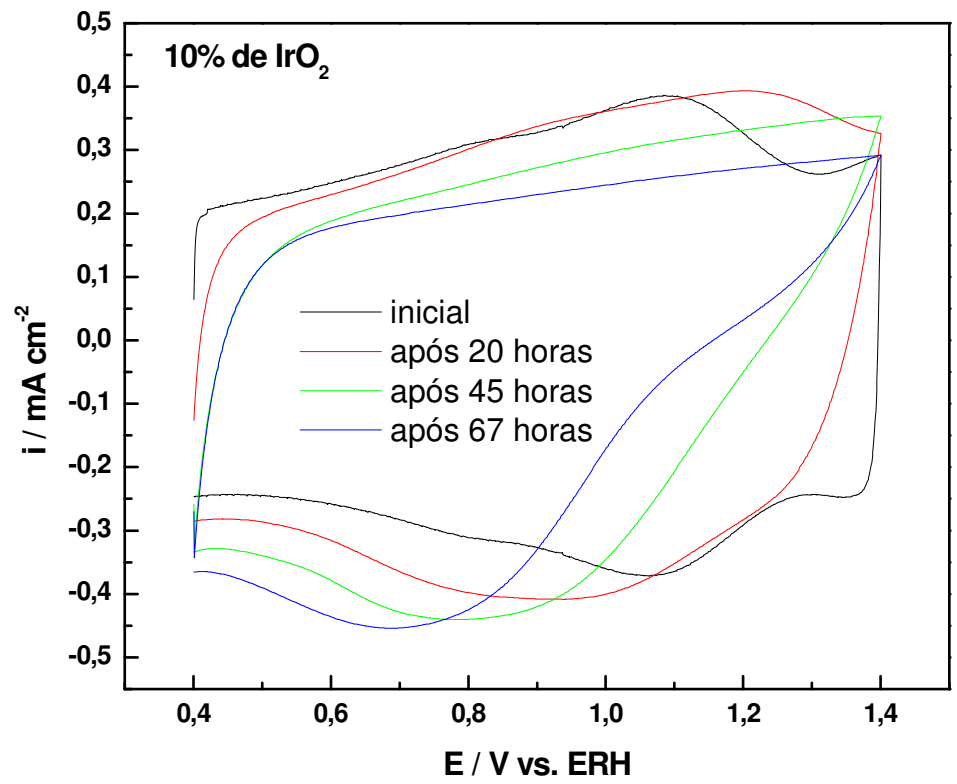

Figura 28 - Voltamogramas cíclicos do eletrodo contendo $10 \%$ do óxido de irídio em meio de $\mathrm{H}_{2} \mathrm{SO}_{4} \quad 0,5 \mathrm{~mol} \mathrm{~L}^{-1}$ a $20 \mathrm{mV} \mathrm{s}^{-1}$. Os Voltamogramas cíclicos foram obtidos antes, durante e após o experimento de cronopotenciometria.

Este comportamento diferente entre as duas composições pode estar relacionado com a formação de diferentes fases cristalinas nas duas composições como discutido na sessão 4.1.2.

No caso do eletrodo contendo $1 \%$ de irídio pode estar presente uma única fase cristalina (solução sólida) devido à baixa concentração de irídio na mistura; no entanto, para composições com maior porcentagem de irídio, pode ocorrer a formação de pelo menos duas fases - uma solução sólida de $\mathrm{SnO}_{2}$ e $\mathrm{IrO}_{2}$ e, outra, de $\mathrm{IrO}_{2}$ puro. A condutividade em filmes de óxido de estanho é atribuída a existência de vacâncias de oxigênio devido a não-estequeometria dos filmes [71]. Em eletrodos com composição de irídio de 1\%, a condutividade do filme poderia ser atribuída principalmente a este mecanismo. Em eletrodos contendo 10\% ou mais de irídio, deve ocorrer a formação de uma segunda fase rica em $\mathrm{IrO}_{2}$, a condutividade pode ser atribuída principalmente a formação de "ilhotas" compostas de óxido de irídio puro que poderiam apresentar duas disposições possíveis: i) estas ilhotas estariam separadas umas das outras ou, ii) estariam agrupadas formando um caminho contínuo que permitiria o fluxo de corrente elétrica e, conseqüentemente, o aumento da condutividade. 
A Figura 29 representa um esquema do mecanismo de interação entre os grãos, responsável pela condutividade de sistemas ricos em óxidos que apresentam condutividade metálica (por exemplo $\mathrm{IrO}_{2}$ ou $\mathrm{RuO}_{2}$ ). Na verdade, provavelmente não há um contato elétrico entre os grãos, e estes se encontram semiisolados da matriz (solução sólida) devido a separação de fases. $O$ mecanismo de condução provavelmente ocorre pelo tunelamento de elétrons através do intervalo entre dois grãos [70]. Quanto maior este intervalo maior a resistência a passagem de corrente elétrica. Assim, eletrodos mais compactos seriam melhores condutores que eletrodos de alta área superficial.

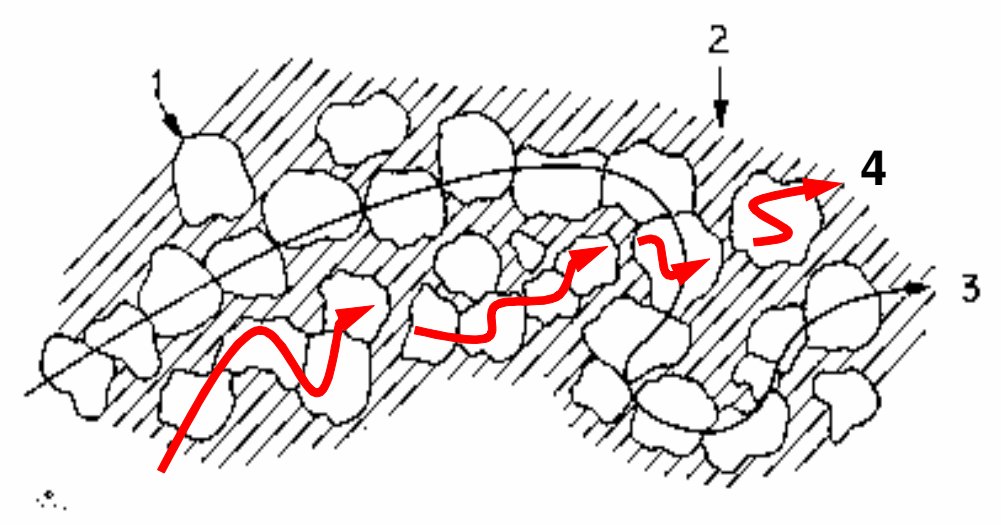

Figura 29 - Representação esquemática do mecanismo de interação entre grãos, responsável pela condutividade em sistemas do tipo ( $\mathrm{Ti}) \mathrm{IrO}_{2}$ e $(\mathrm{Ti}) \mid \mathrm{rO} \mathrm{r}_{2} / \mathrm{SnO}_{2}$. (1) Grão do óxido condutor; (2) Matriz de $\mathrm{SnO}_{2}$; (3) "Caminho" da condução eletrônica para composições com no mínimo de $30 \%$ do óxido condutor metálico $\left(\mathrm{IrO}_{2}\right)$; (4) "Caminho" da condução eletrônica para composições inferiores a 30\% do óxido condutor metálico $\left(\mathrm{IrO}_{2}\right)[70]$.

Contudo, como pode ser observado na Figura 26, o tempo de vida útil diminui quando a quantidade de $\mathrm{IrO}_{2}$ passa de 1 para $5 \%$ e volta a aumentar para o eletrodo contendo $10 \%$ de $\mathrm{IrO}_{2}$.

Aparentemente para eletrodos contendo apenas $1 \%$ de $\mathrm{IrO}_{2}$ a desativação da camada se dá provavelmente porque o óxido de estanho vai se tornando mais estequiométrico com a aplicação de corrente anódica e conseqüente diminuição da condutividade da solução sólida. Este comportamento é atribuído a eletrodos 
de $\mathrm{SnO}_{2}$ e deve ser o mecanismo principal da desativação de eletrodos contendo $1 \%$ de irídio [71].

Para os eletrodos contendo $10 \%$ de irídio o mecanismo de desativação deve estar relacionado principalmente ao crescimento da intercamada de $\mathrm{TiO}_{2}$ que possui uma alta resistividade. O aumento da resistência fica evidente ao analisarmos, na Figura 28, o deslocamento gradativo dos picos ocorrido durante o experimento de tempo de vida útil.

O eletrodo contendo $5 \%$ de irídio apresentou menor tempo de vida útil dentre as composições estudas. Este comportamento se deve aos mesmos fatores que apresenta o eletrodo de $10 \%$ de irídio (como pode ser observado nos voltamogramas cíclicos da Figura 30), contudo seu menor tempo de vida útil é causado pelo crescimento mais rápido da camada de $\mathrm{TiO}_{2}$.

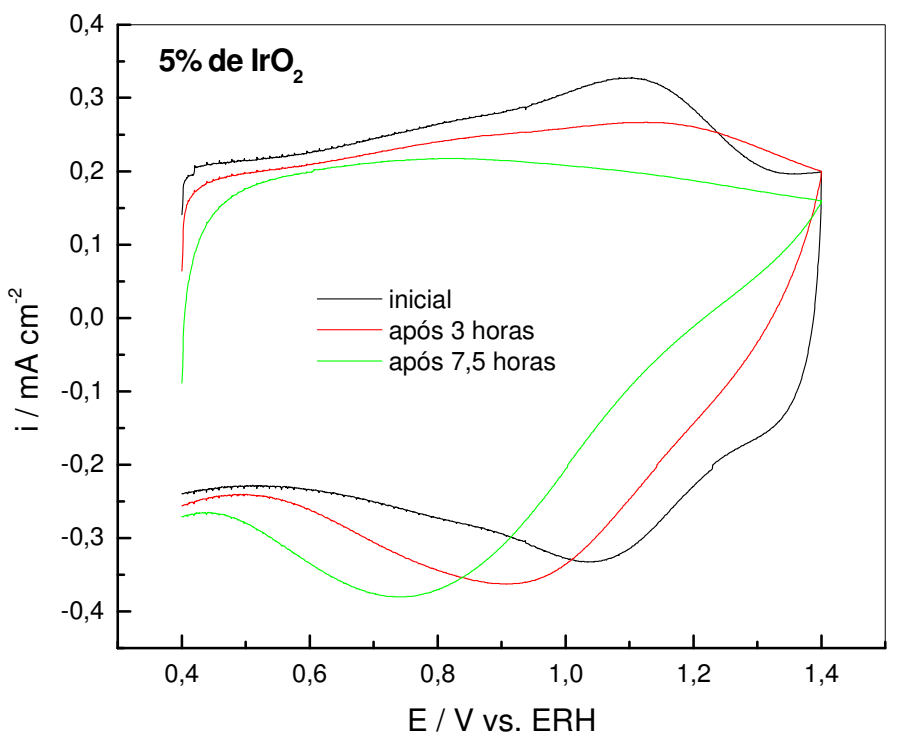

Figura 30 - Voltamogramas cíclicos do eletrodo contendo $5 \%$ do óxido de irídio em meio de $\mathrm{H}_{2} \mathrm{SO}_{4} \quad 0,5 \mathrm{~mol} \mathrm{~L}^{-1}$ a $20 \mathrm{mV} \mathrm{s}^{-1}$. Os Voltamogramas cíclicos foram obtidos antes, durante e após o experimento de cronopotenciometria.

O eletrodo contendo $30 \%$ de irídio após 100 horas apresentou potencial igual a 1,9 V. Este resultado mostra que esta composição de eletrodo é muito estável nas condições experimentais empregadas. Uma possível explicação para este comportamento é que a quantidade mínima de $\mathrm{IrO}_{2}$ necessária na composição do eletrodo, para que as ilhotas estejam agrupadas formando um caminho contínuo para o fluxo de corrente, seria em torno de $30 \%$. 
$\mathrm{Na}$ Figura 31 estão apresentados os voltamogramas cíclicos do eletrodo contendo $30 \%$ de óxido de irídio. Nesta figura pode-se observar que os processos redox permanecem reversíveis durante todo o experimento. A única mudança é um aumento da carga voltamétrica entre cada etapa dos experimentos de cronopotenciometria que, neste caso, deve-se a uma maior hidratação dos sítios internos do eletrodo.

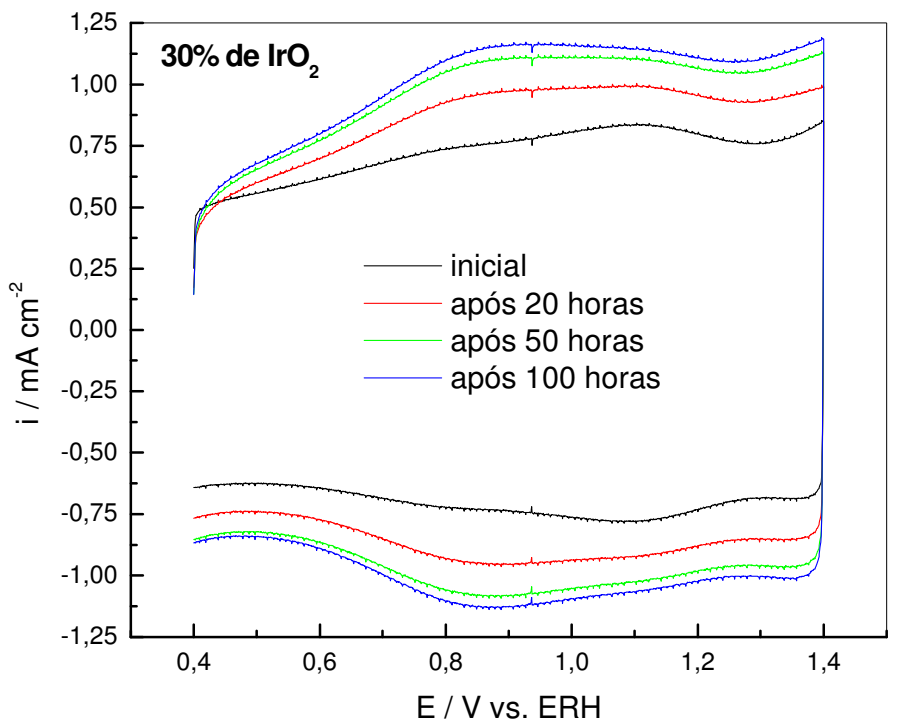

Figura 31 - Voltamogramas cíclicos do eletrodo contendo $30 \%$ do óxido de irídio em meio de $\mathrm{H}_{2} \mathrm{SO}_{4} \quad 0,5 \mathrm{~mol} \mathrm{~L}^{-1}$ a $20 \mathrm{mV} \mathrm{s}^{-1}$. Os Voltamogramas cíclicos foram obtidos antes, durante e após o experimento de cronopotenciometria.

\section{3 - Estudo da atividade eletrocatalítica para a oxidação das moléculas orgânicas}

Após a caracterização dos eletrodos foi investigada a atividade eletrocatalítica dos mesmos na presença das moléculas orgânicas (etanol, acetaldeído e ácido acético).

Primeiramente, foi realizado o estudo utilizando o ácido acético. A importância em se verificar a atividade catalítica para a eletrooxidação do ácido acético se dá devido a dificuldade em se converter o etanol a $\mathrm{CO}_{2}$ quando o caminho reacional envolve à formação deste intermediários. O ácido acético é dificilmente degradado a $\mathrm{CO}_{2}$ impedindo a oxidação completa do etanol. 
Outro intermediário possível de ser formado durante a oxidação do etanol é o acetaldeído, daí então, a importância em se verificar o comportamento dos eletrodos na presença desta molécula.

Após o estudo das moléculas acima, foi verificada a atividade catalítica para a eletrooxidação do etanol.

\subsection{1 - Estudo da eletrooxidação de ácido acético}

Apesar do ácido acético ser conhecido como uma molécula refratária, ou seja, difícil de ser oxidada mesmo em condições de fluido supercrítico [72, 73], foi realizada experimentos com esta molécula por ela ser um subproduto da eletrooxidação do etanol e também para avaliar o comportamento dos eletrodos na presença desta molécula. Foram realizados experimentos de voltametria cíclica e eletrólise a corrente constante.

$\mathrm{Na}$ Figura 32 estão demonstrados os voltamogramas cíclicos de todas as composições de eletrodo em meio de ácido sulfúrico $0,5 \mathrm{~mol} \mathrm{~L}^{-1}$ na ausência e na presença de ácido acético $0,1 \mathrm{~mol} \mathrm{~L}^{-1}$. 

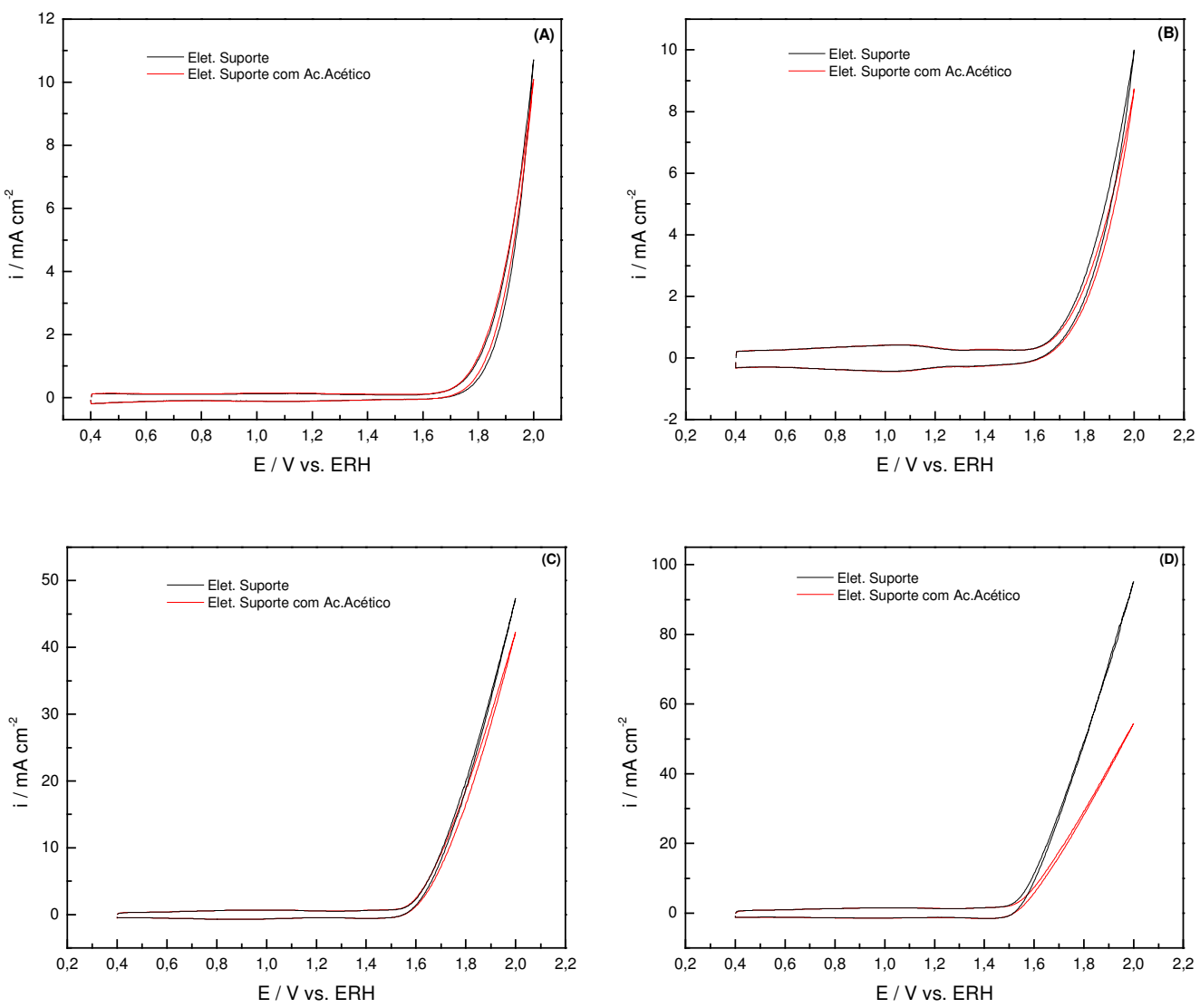

Figura 32 - Voltamogramas cíclicos em solução $\mathrm{H}_{2} \mathrm{SO}_{4} 0,5 \mathrm{~mol} \mathrm{~L}^{-1}$ a $20 \mathrm{mV} \mathrm{s}^{-1}$ na presença e ausência de ácido acético $0,1 \mathrm{~mol} \mathrm{~L}^{-1}$ para eletrodos contendo: (A) $1 \%$ de $\mathrm{IrO}_{2}$, (B) $5 \%$ de $\mathrm{IrO}_{2}$, (C) $10 \%$ de $\mathrm{IrO}_{2}$, e (D) $30 \%$ de $\mathrm{IrO}_{2}$.

Nestas figuras pode-se observar que a adição de ácido acético nas soluções de eletrólitos de suporte provocou uma diminuição da corrente associada a RDO. Pode-se observar ainda que os eletrodos com as menores porcentagens de $\mathrm{IrO}_{2}$ apresentaram uma pequena diferença na reação de desprendimento oxigênio na presença e na ausência do ácido acético, enquanto que os eletrodos maiores porcentagens de $\mathrm{IrO}_{2}$ apresentaram uma diferença mais acentuada.

Uma explicação para esta maior inibição da RDO na presença do ácido acético com os eletrodos contendo maiores porcentagens de $\mathrm{IrO}_{2}$ é que estes eletrodos são mais eletrocatalíticos para a RDO, fornecendo maiores correntes em um dado potencial que os eletrodos com menores porcentagens de $\mathrm{IrO}_{2}$, o que torna a inibição mais efetiva nestes eletrodos. 
Foram realizados experimentos de eletrólise com soluções contendo ácido acético $5 \mathrm{mmol} \mathrm{L}^{-1} \mathrm{em} \mathrm{H} \mathrm{H}_{2} \mathrm{SO}_{4} 0,5 \mathrm{~mol} \mathrm{~L}^{-1}$ para verificarmos a possibilidade de oxidações desta espécie a dióxido de carbono. Foram realizados experimentos com todos os eletrodos aplicando-se densidades de corrente de $100 \mathrm{~mA} \mathrm{~cm}^{-2}$. Os resultados das análises por CLAE mostraram que não ocorre a referida reação nestas condições, ou seja, não houve nenhuma redução na concentração dos íons acetatos em nenhuma das composições dos eletrodos.

\subsection{2 - Estudo da eletrooxidação de acetaldeído}

Assim como o ácido acético, a eletrooxidação do acetaldeído foi estudada por ser um subproduto da eletrooxidação do etanol. Antes dos experimentos de eletrólise a corrente constante, a eletrooxidação do acetaldeído com eletrodos de $\left.\mathrm{Sn}_{(1-x)}\right) \mathrm{r}_{\mathrm{x}} \mathrm{O}_{2}$ foi realizada em meio de $\mathrm{H}_{2} \mathrm{SO}_{4} \quad 0,5 \mathrm{~mol} \mathrm{~L}^{-1}$ utilizando a técnica de voltametria cíclica.

Como discutido na sessão 4.2.3, o aumento da quantidade de $\mathrm{IrO}_{2}$ provoca um deslocamento do potencial de início da RDO, logo, para os eletrodos contendo maiores quantidades de $\mathrm{IrO}_{2}$ a corrente de oxidação do acetaldeído ocorre mais próximo a RDO, podendo até ocorrer sobreposição dos processos.

$\mathrm{Na}$ Figura 33A estão mostrados os voltamogramas cíclicos do eletrodo contendo $1 \%$ de $\mathrm{IrO}_{2}$ em meio de $\mathrm{H}_{2} \mathrm{SO}_{4} 0,5 \mathrm{~mol} \mathrm{~L}^{-1}$ na ausência e na presença de acetaldeído $0,1 \mathrm{~mol} \mathrm{~L}^{-1}$. Nesta figura pode-se observar o pico de oxidação do acetaldeído em 1,38 $\vee(E R H)$, que é inferior ao potencial da RDO, a qual tem início em 1,6 $\vee(E R H)$, isso pode fazer com que esta composição de eletrodo apresente uma maior eficiência de corrente durante as eletrólises.

Nas Figuras 33 B, C e D estão demonstrados os voltamogramas cíclicos dos eletrodos contendo maiores quantidades de $\mathrm{IrO}_{2}$ em presença e ausência do acetaldeído. Para o eletrodo contendo $5 \%$ de $\mathrm{IrO}_{2}$ (Figura 33B) o pico de oxidação do acetaldeído não é bem definido como no caso anterior, ou seja, a oxidação do acetaldeído está ocorrendo juntamente com a RDO. O mesmo ocorre para o eletrodo contendo $10 \%$ de $\mathrm{IrO}_{2}$ (Figura $33 \mathrm{C}$ ) e para o eletrodo contendo $30 \%$ de $\mathrm{IrO}_{2}$ (Figura 33D), sendo que para este eletrodo não se observa pico de oxidação, ocorre somente um aumento na carga do voltamograma cíclico próximo a RDO. 

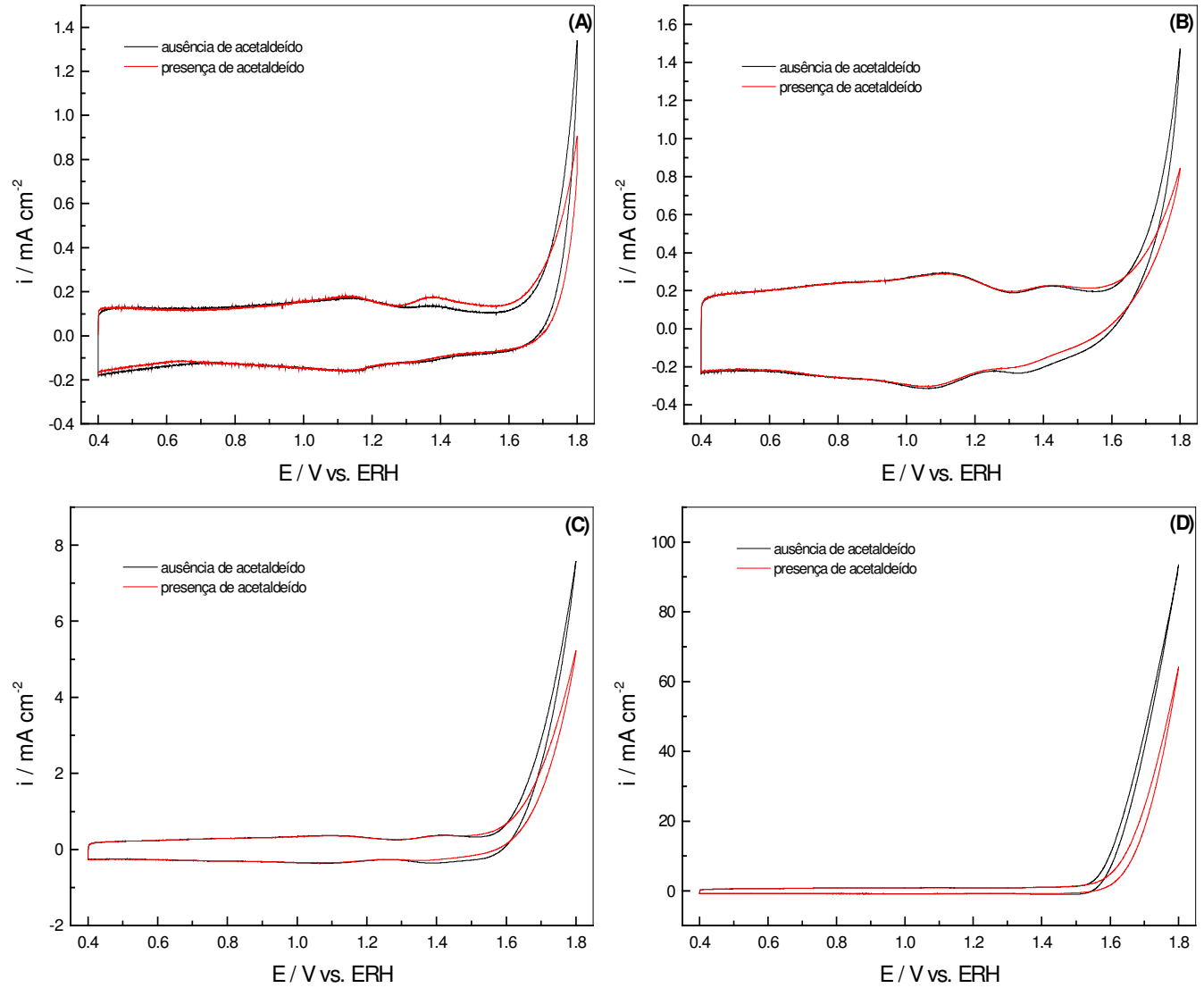

Figura 33 - Voltamogramas cíclicos em solução de $\mathrm{H}_{2} \mathrm{SO}_{4} \quad 0,5 \mathrm{~mol} \mathrm{~L}^{-1}$ a $20 \mathrm{mV} \mathrm{s}^{-1}$ na presença e ausência do acetaldeído $0,1 \mathrm{~mol} \mathrm{~L}^{-1}$ para os eletrodos contendo: (A) $1 \%$ de $\mathrm{IrO}_{2}$, (B) $5 \%$ de $\mathrm{IrO}_{2}$, (C) $10 \%$ de $\mathrm{IrO}_{2}$ e (D) $30 \%$ de $\mathrm{IrO}_{2}$.

Para os valores de densidade de carga referentes aos processos de oxidação do acetaldeído foi feita a subtração dos voltamogramas cíclicos em presença do acetaldeído dos voltamogramas cíclicos somente em eletrólito de suporte. Assim, o pico de oxidação foi facilmente identificado podendo-se obter informações mais precisas sobre a densidade de carga e densidade de corrente de oxidação do acetaldeído para cada composição eletródica. As cargas de oxidação do acetaldeído foram obtidas pela subtração da parte anódica dos voltamogramas cíclicos na presença e na ausência do acetaldeído entre os potenciais de 1,2 e 1,7 V para os eletrodos contendo 1, 5, e 10\% de $\mathrm{IrO}_{2}$ e entre 1,2 e $1,58 \mathrm{~V}$ para o eletrodo contendo $30 \%$ de $\mathrm{IrO}_{2}$.

Os valores de densidade de carga de oxidação (q $\mathbf{q}_{\text {oxi }}$ ) extraídos dos voltamogramas cíclicos estão demonstrados na Figura 34 em função da quantidade e $\mathrm{IrO}_{2}$. Também está demonstrada nesta figura a densidade de carga de oxidação normalizada pela carga anódica $\left(\mathbf{q}_{\mathbf{a}}\right)$ em função da quantidade de $\mathrm{IrO}_{2}$. A carga anódica utilizada para normalizar a carga de oxidação foi 
determinada a partir dos voltamogramas cíclicos com varredura de potenciais entre 0,4 e $1,4 \mathrm{~V}(\mathrm{ERH})$ a $20 \mathrm{mV} \mathrm{s}^{-1}$ para cada composição.

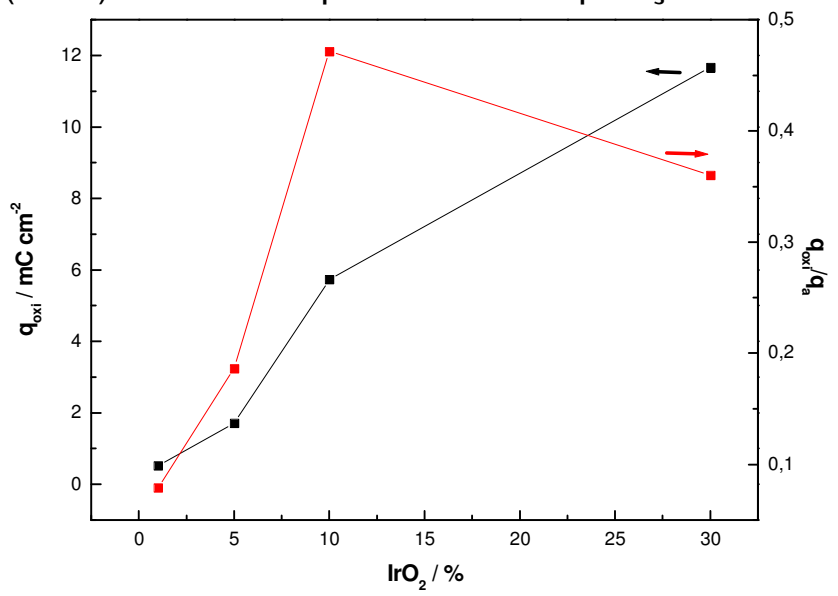

Figura 34 - Gráfico da densidade de carga de pico da eletrooxidação do acetaldeído ( $\mathbf{q}_{\text {oxi }}$ ) e $\mathbf{q}_{\text {oxi }} / \mathbf{q}_{\mathbf{a}}$ em função da quantidade de $\mathrm{IrO}_{2}$ contida no eletrodo.

Pode-se observar que quanto maior a quantidade de $\mathrm{IrO}_{2}$ na composição do eletrodo maior é a carga de oxidação do acetaldeído, portanto, o eletrodo contendo $30 \%$ de $\mathrm{IrO}_{2}$ é o que possui a maior atividade global. Contudo, quanto maior a quantidade de $\mathrm{IrO}_{2}$ maior é a área real dos eletrodos, como pode ser observado no estudo da área eletroquimicamente ativa representada pela carga da dupla camada elétrica $\left(\mathbf{q}_{\mathrm{a}}\right.$ e $\left.\mathbf{q}_{\mathrm{c}}\right)$. Portanto, normalizando-se os valores das densidades de cargas relacionadas a eletrooxidação do acetaldeído pela carga $\mathbf{q}_{\mathbf{a}}$ e fazendo-se um gráfico das cargas normalizadas em função da quantidade de $\mathrm{IrO}_{2}$ obtém-se valores relacionados à atividade intrínseca dos eletrodos, ou seja, valores independentes da área real do eletrodo. A curva da $\mathbf{q}_{\mathbf{o x i}} / \mathbf{q}_{\mathbf{a}}$, mostra que 0 eletrodo com maior atividade intrínseca para a eletrooxidação do acetaldeído é o eletrodo contendo $10 \%$ de $\mathrm{IrO}_{2}$.

Foram realizados também experimentos de eletrólises com soluções contendo $5 \mathrm{mM}$ acetaldeído em eletrólito de suporte com todos os eletrodos a uma densidade de corrente de $20 \mathrm{~mA} \mathrm{~cm}^{-2}$. A Figura 35 apresenta um gráfico do consumo do acetaldeído e outro com a formação do ácido acético formado em função do tempo de eletrólise. Na Figura 35B, a porcentagem de formação do ácido acético é relativa ao acetaldeído consumido, ou seja, a seletividade para a formação do ácido acético. 

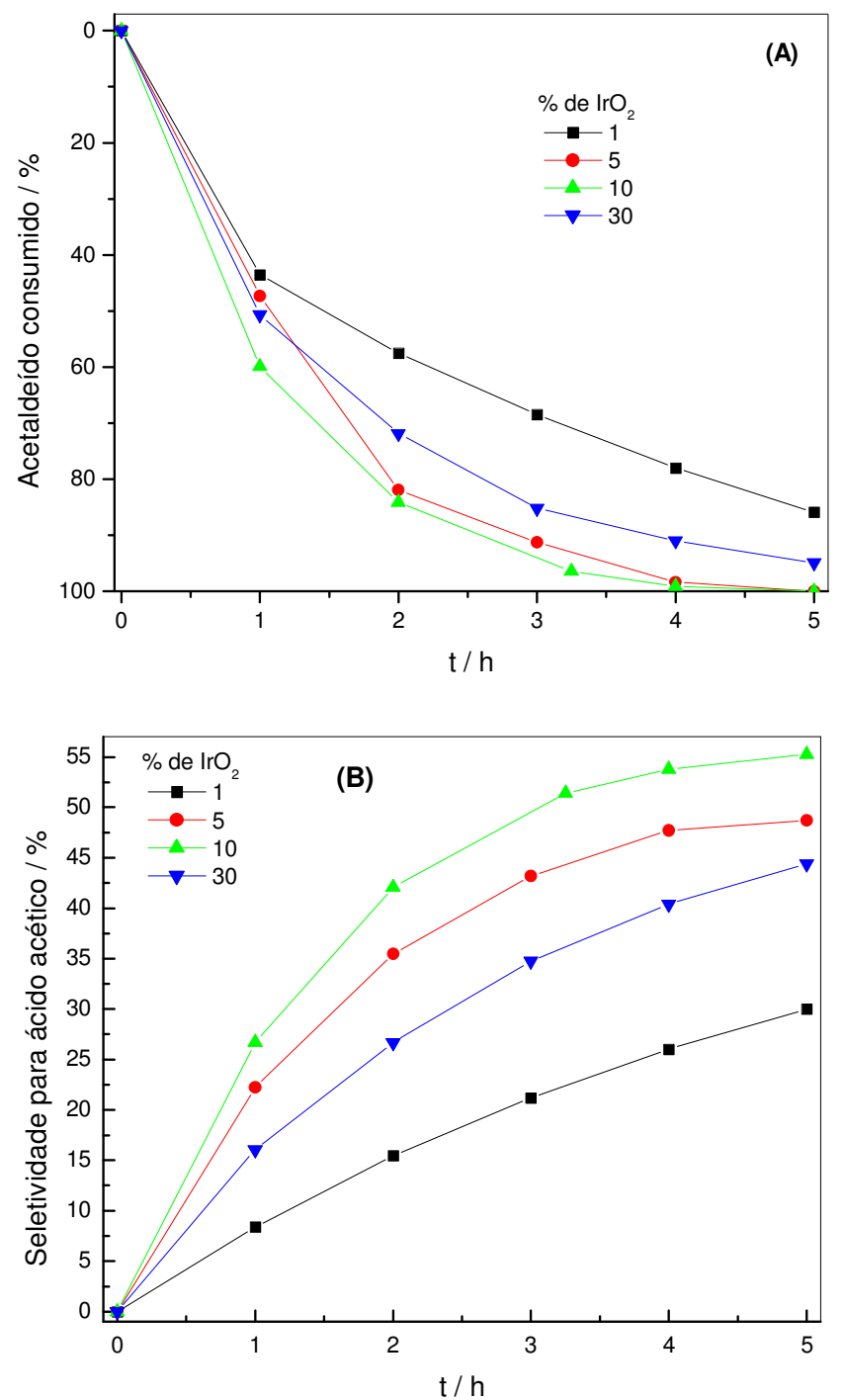

Figura 35 - Gráficos do consumo do acetaldeído (A), seletividade para a formação do ácido acético (B) em função do tempo de eletrólise para todas as composições de eletrodos. Concentração inicial de acetaldeído $=5 \mathrm{mmol} \mathrm{L}^{-1}$, corrente aplicada $=20 \mathrm{~mA} \mathrm{~cm}^{-2}$.

Como pode ser visto na Figura 35, o acetaldeído é oxidado sobre todos os eletrodos e o seu consumo nesta condição pode ser completo, ou quase, para os eletrodos contendo 5 e $10 \%$ de $\mathrm{IrO}_{2}$ num tempo de 4 horas de eletrólise. Os produtos 
identificados foram o ácido acético e o dióxido de carbono. O balaço de massa foi inferior a 70\%, isso se deve provavelmente pela perda de acetaldeído por evaporação e perda de $\mathrm{CO}_{2}$ no sistema de coleta deste gás. Os resultados finais das eletrólises estão apresentados na Tabela III.

Tabela III: Porcentagem de acetaldeído consumido e de produtos formados após 300 minutos de eletrólise em meio ácido para todas as composições dos eletrodos. Concentração inicial de acetaldeido $=5 \mathrm{mM}$, corrente aplicada $=20 \mathrm{~mA}$ $\mathrm{cm}^{-2}$.

\begin{tabular}{ccccc}
\hline \% IrO $_{2}$ & $\begin{array}{c}\text { Acetaldeído } \\
\text { Consumido } \\
(\%)\end{array}$ & $\begin{array}{c}\text { Ácido Acético } \\
\text { Formado } \\
(\%)^{*}\end{array}$ & \multicolumn{2}{c}{$\mathbf{C O}_{2}$} \\
& $\begin{array}{c}\text { Formado } \\
(\%)^{\star \mathbf{a}}\end{array}$ & $(\%)^{\star \star}$ \\
\hline $\mathbf{1}$ & 85,8 & 30,0 & 13,2 & 70 \\
$\mathbf{5}$ & 100 & 48,6 & 14,0 & 51,4 \\
$\mathbf{1 0}$ & 100 & 55,2 & 14,3 & 44,8 \\
$\mathbf{3 0}$ & 94,8 & 44,5 & 18,1 & 55,5 \\
\hline
\end{tabular}

* Relativo ao acetaldeído consumido.

a detectado por CLAE

** Estimado pela diferença entre acetaldeído consumido e ácido acético formado

O eletrodo contendo a maior concentração de $\mathrm{SnO}_{2}$ foi o que apresentou o menor rendimento para a reação de oxidação do acetaldeído, porém, foi o que apresentou a menor seletividade para a formação de ácido acético. Os eletrodos contendo 5 e $10 \%$ de $\mathrm{IrO}_{2}$ apresentaram maior velocidade de consumo de acetaldeído formando preferencialmente ácido acético.

No entanto, para o eletrodo contendo $30 \%$ de $\mathrm{IrO}_{2}$, foi observada também uma velocidade de consumo de acetaldeído relativamente alta, porém, com menor seletividade para a formação de ácido acético e maior para a formação de $\mathrm{CO}_{2}$ em relação aos eletrodos contendo 5 e $10 \%$ de $\mathrm{IrO}_{2}$. Neste caso houve um desvio da tendência de que quanto maior a quantidade de $\mathrm{IrO}_{2}$ na composição do eletrodo, maior a seletividade para formação de ácido acético e menor para a formação de $\mathrm{CO}_{2}$. 


\subsubsection{Estudo da eletrooxidação de etanol}

Antes dos experimentos de eletrólise a corrente constante, a eletrooxidação de etanol com eletrodos de $\mathrm{Sn}_{(1-x)} \mid r_{x} \mathrm{O}_{2}$ foi realizada em meio de $\mathrm{H}_{2} \mathrm{SO}_{4} \quad 0,5 \mathrm{~mol} \mathrm{~L}^{-1}$ utilizando a técnica de voltametria cíclica, a qual permitiu verificar a reatividade dos eletrodos.

$\mathrm{Na}$ Figura 36A estão mostrados os voltamogramas cíclicos do eletrodo contendo $1 \%$ de $\mathrm{IrO}_{2}$ em meio de $\mathrm{H}_{2} \mathrm{SO}_{4}$ 0,5 $\mathrm{mol} \mathrm{L}^{-1}$ (linha preta) e em $\mathrm{H}_{2} \mathrm{SO}_{4}$ 0,5 $\mathrm{mol} \mathrm{L}^{-1}$ com etanol 0,1 $\mathrm{mol} \mathrm{L}^{-1}$ (linha vermelha). Nesta figura pode-se observar $\mathrm{O}$ pico de oxidação de etanol em 1,5 V (ERH), que é inferior ao potencial da RDO, a qual tem início em 1,7 V (ERH).

Como já foi comentado anteriormente, o aumento da quantidade de $\mathrm{IrO}_{2}$ provoca um deslocamento da RDO, logo, para os eletrodos contendo maiores quantidades de $\mathrm{IrO}_{2}$ o pico de oxidação de etanol ocorre mais próximo a RDO, podendo até ocorrer sobreposição com o pico de oxidação de etanol.

Nas Figuras 36B, C e D estão demonstrados os voltamogramas cíclicos dos eletrodos contendo maiores quantidades de $\mathrm{IrO}_{2}$ em presença e ausência de etanol. Para o eletrodo contendo $5 \%$ de $\mathrm{IrO}_{2}$ (Figura 36B) a $\mathrm{RDO}$ tem início em 1,6 $\vee(E R H)$, ou seja, juntamente com a oxidação do etanol. O mesmo ocorre para o eletrodo contendo $10 \%$ de $\mathrm{IrO}_{2}$ (Figura 36C) e para o eletrodo contendo $30 \%$ de $\mathrm{IrO}_{2}$ (Figura 36D), sendo que para este eletrodo não se observa pico de oxidação, ocorre somente um aumento na carga do voltamograma cíclico próximo a RDO. 

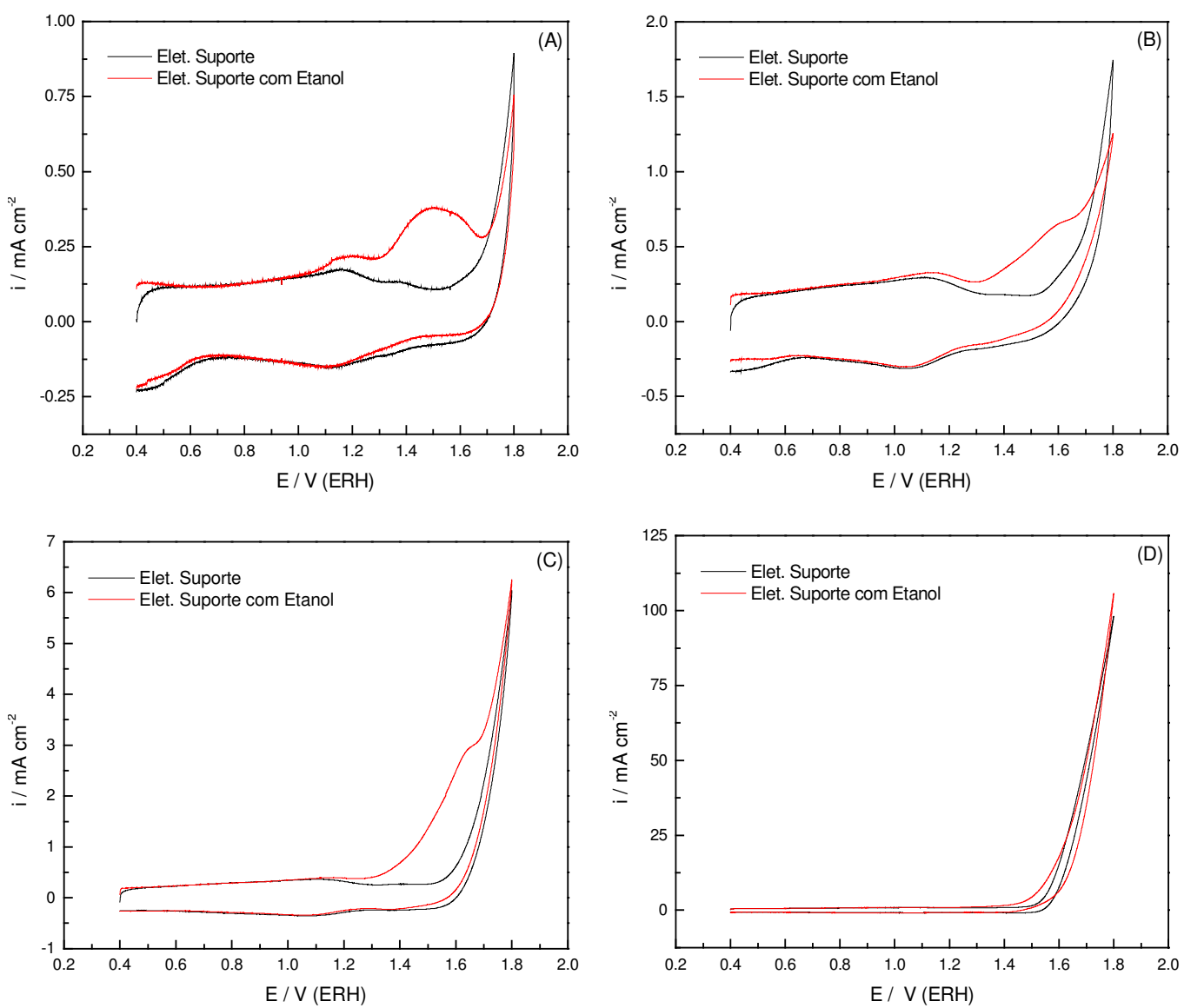

Figura 36 - Voltamogramas cíclicos em solução de $\mathrm{H}_{2} \mathrm{SO}_{4} \quad 0,5 \mathrm{~mol} \mathrm{~L}^{-1}$ a $20 \mathrm{mV} \mathrm{s}^{-1}$ na presença e ausência de etanol $0,1 \mathrm{~mol} \mathrm{~L}^{-1}$ para os eletrodos contendo: (A) $1 \%$ de $\mathrm{IrO}_{2}$, (B) $5 \%$ de $\mathrm{IrO}_{2}$, (C) $10 \%$ de $\mathrm{IrO}_{2}$ e (D) $30 \%$ de $\mathrm{IrO}_{2}$.

Para melhor visualização e identificação dos processos de oxidação de etanol em meio ácido foi feita a subtração dos voltamogramas cíclicos dos eletrodos $\left.\mathrm{Sn}_{(1-\mathrm{x})}\right) \mathrm{r}_{\mathrm{x}} \mathrm{O}_{2}$ em eletrólito suporte dos voltamogramas contendo também o etanol. Assim, o pico de oxidação foi facilmente identificado podendo-se obter informações mais precisas sobre a densidade de carga e densidade de corrente de oxidação de etanol para composição eletródica.

Na Figura 37 está demonstrada a porção anódica dos voltamogramas cíclicos da oxidação de etanol subtraídos dos voltamogramas cíclicos dos eletrodos em eletrólito suporte, para cada composição eletródica. O eletrodo contendo $30 \%$ de $\mathrm{IrO}_{2}$ apresentou maiores densidades de corrente de oxidação 
comparados às outras composições. Os eletrodos contendo 1 e $5 \%$ de $\mathrm{IrO}_{2}$ também apresentaram valores significativos de densidades de corrente de oxidação os quais são mais facilmente visualizadas no gráfico inserido na Figura 37.

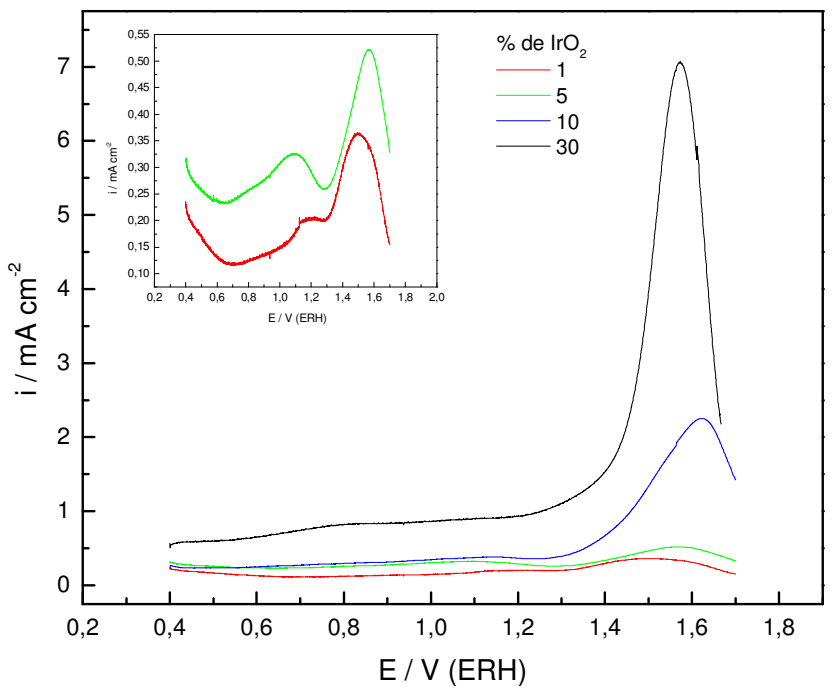

Figura 37 - Curva da porção anódica dos voltamogramas cíclicos da oxidação de etanol subtraídos dos voltamogramas cíclicos dos eletrodos em eletrólito suporte, para os eletrodos contendo $1 \%, 5 \%, 10 \%$ e $30 \%$ de $\mathrm{IrO}_{2}$.

Os valores de densidade de carga ( $\mathbf{q}_{\text {oxi }}$ ) extraídos dos voltamogramas cíclicos estão demonstrados na Figura 38 em função da quantidade e $\mathrm{IrO}_{2}$. Também está demonstrada nesta figura a densidade de carga normalizada pela carga anódica $\left(\mathbf{q}_{\mathbf{a}}\right)$ em função da quantidade de $\mathrm{IrO}_{2}$. As cargas voltamétricas utilizadas para normalizar as cargas de oxidação foram determinadas a partir dos voltamogramas cíclicos com varredura de potenciais entre 0,4 e 1,4 V (ERH) a $20 \mathrm{mV} \mathrm{s}^{-1}$ para cada composição. As cargas de oxidação do etanol foram obtidas integrando as curvas da Figura 37 entre os potenciais de 1,2 e 1,7 V. 


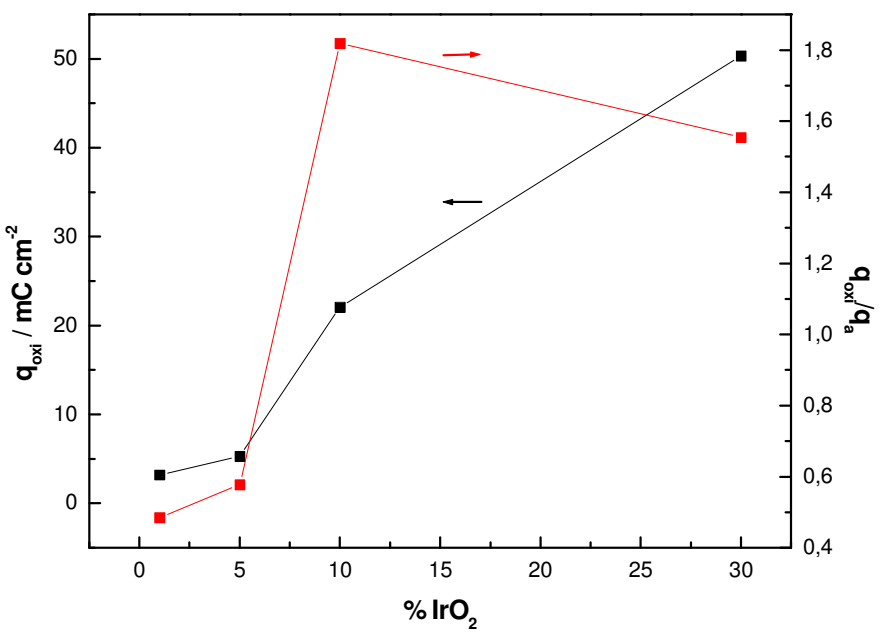

Figura 38 - Gráfico da densidade de carga de pico da eletrooxidação do etanol ( $\left.\mathbf{q}_{\text {oxi }}\right)$ e $\mathbf{q}_{\text {oxi }} / \mathbf{q}_{\mathbf{a}}$ em função da quantidade de $\mathrm{IrO}_{2}$ contida no eletrodo.

Como podemos observar o maior valor de densidade de carga é obtido pelo eletrodo contendo $30 \%$ de $\mathrm{IrO}_{2}$, que é o que possui a maior atividade global. Contudo, ao se analisar a curva da $\mathbf{q}_{\text {oxi }} / \mathbf{q}_{\mathrm{a}} \mathrm{o}$ eletrodo com maior atividade é o que contem $10 \%$ de $\mathrm{IrO}_{2}$, que mostra ser o eletrodo com maior atividade intrínseca.

Os dados atividade intrínseca $\left(\mathbf{q}_{\text {oxi }} / \mathbf{q}_{\mathbf{a}}\right.$ ) mostram que há um aumento da atividade dos eletrodos aumentando-se a concentração de $\mathrm{IrO}_{2}$ de 1 até $10 \%$ e que a atividade decai para o eletrodo contendo $30 \%$ de $\mathrm{IrO}_{2}$. Estes resultados demonstram que o consumo do etanol é favorecido pela presença de $\mathrm{IrO}_{2}$. Além disso, a diminuição da atividade intrínseca para concentrações de $\mathrm{IrO}_{2}$ de $30 \%$ pode significar que nem toda a área do eletrodo estaria acessível para a eletrooxidação do etanol. Este comportamento demonstra que os eletrodos devem apresentar poros ou trincas pequenas que não contribuiriam como área efetiva para a eletrooxidação do etanol.

O comportamento apresentado na Fig. 38 coincide com o observado para a eletrooxidação do acetaldeído (Fig. 34) o que comprova que o eletrodo contendo $10 \%$ de $\mathrm{IrO}_{2}$ se trata de uma composição com a maior atividade intrínseca para oxidação destas moléculas.

Para verificar a eficiência eletrocatalítica dos eletrodos de $S n_{(1-x)} \mid r_{x} O_{2}$ para a oxidação de etanol foram realizados experimentos de eletrólise a corrente constante $\left(100 \mathrm{~mA} \mathrm{~cm}^{-2}\right)$ por um período de 4 horas. Durante este período foram 
retiradas alíquotas para análise do consumo de etanol e dos produtos de oxidação, o que foi feito por meio de CLAE.

As Figuras 39, 40 e 41 apresentam os cromatogramas obtidos em diferentes tempos de eletrólise realizadas com os eletrodos contendo 1 e $30 \%$ de irídio. Nestas figuras pode-se observar o consumo do etanol e a formação dos produtos com o tempo de eletrólise.

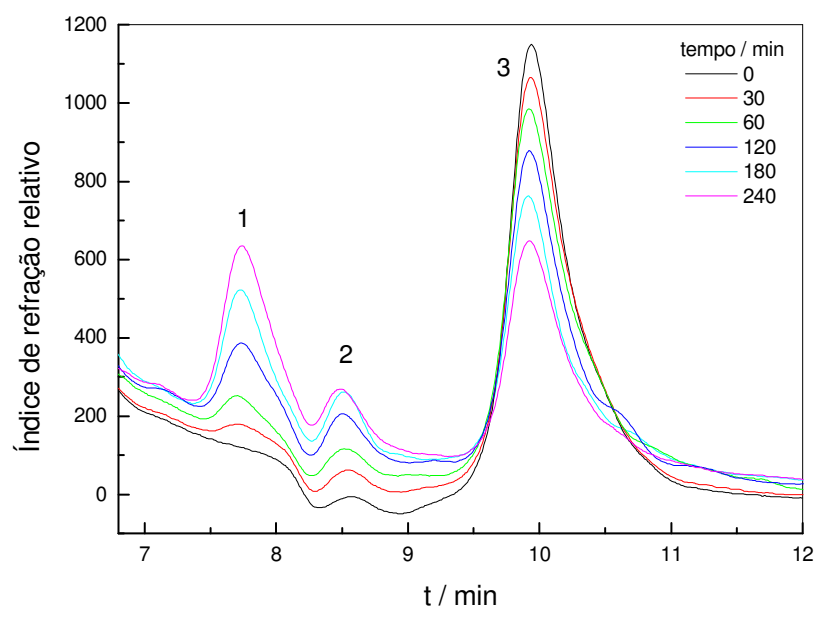

Figura 39 - Ampliação dos cromatogramas obtidos em diferentes tempos de eletrólise com eletrodo contendo $1 \%$ de irídio realizada a $100 \mathrm{~mA} \mathrm{~cm}$. Condições: Coluna: da Bio Rad mod. HPX-87H(300 mm/7,8 mm), T=30 ${ }^{\circ} \mathrm{C}$, Fase Móvel $\mathrm{H}_{2} \mathrm{SO}_{4} 3,33 \mathrm{mmol} \mathrm{L}^{-1}$, Fluxo: 0,6 $\mathrm{mL} \mathrm{min}^{-1}$, detector: índice de refração. Os picos são referentes ao (1) ácido acético, (2) acetaldeído e (3) etanol. 




Figura 40 - Ampliação dos cromatogramas obtidos em diferentes tempos de eletrólise com eletrodo contendo $30 \%$ de irídio realizada a $100 \mathrm{~mA} \mathrm{~cm}$. Condições: Coluna: da Bio Rad mod. HPX-87H(300 mm/7,8 mm), T=30 ${ }^{\circ} \mathrm{C}$, Fase Móvel $\mathrm{H}_{2} \mathrm{SO}_{4} 3,33 \mathrm{mmol} \mathrm{L}^{-1}$, Fluxo: 0,6 $\mathrm{mL} \mathrm{min}^{-1}$, detector: índice de refração. Os picos são referentes ao (1) ácido acético e (2) etanol.



Figura 41 - Ampliação dos cromatogramas obtidos em diferentes tempos de eletrólise com eletrodo contendo $30 \%$ de irídio realizada a $100 \mathrm{~mA} \mathrm{~cm}{ }^{-2}$. Condições: Coluna: da Bio Rad mod. HPX-87H(300 mm/7,8 mm), T=30 ${ }^{\circ} \mathrm{C}$, Fase Móvel $\mathrm{H}_{2} \mathrm{SO}_{4} 3,33 \mathrm{mmol} \mathrm{L}^{-1}$, Fluxo: 0,6 $\mathrm{mL} \mathrm{min}^{-1}$, detector: U.V. $\lambda=210 \mathrm{~nm}$. O pico é referente a formação de ácido acético. 
Na Figura 42 está demonstrado o consumo de etanol e formação de ácido acético em função do tempo de eletrólise para todas as composições eletródicas. Todos os eletrodos apresentaram comportamento semelhante para o consumo de etanol, entretanto, pode-se observar nesta figura que há uma menor velocidade na formação de ácido acético para o eletrodo contendo $1 \%$ de $\mathrm{IrO}_{2} \mathrm{em}$ relação às outras composições.
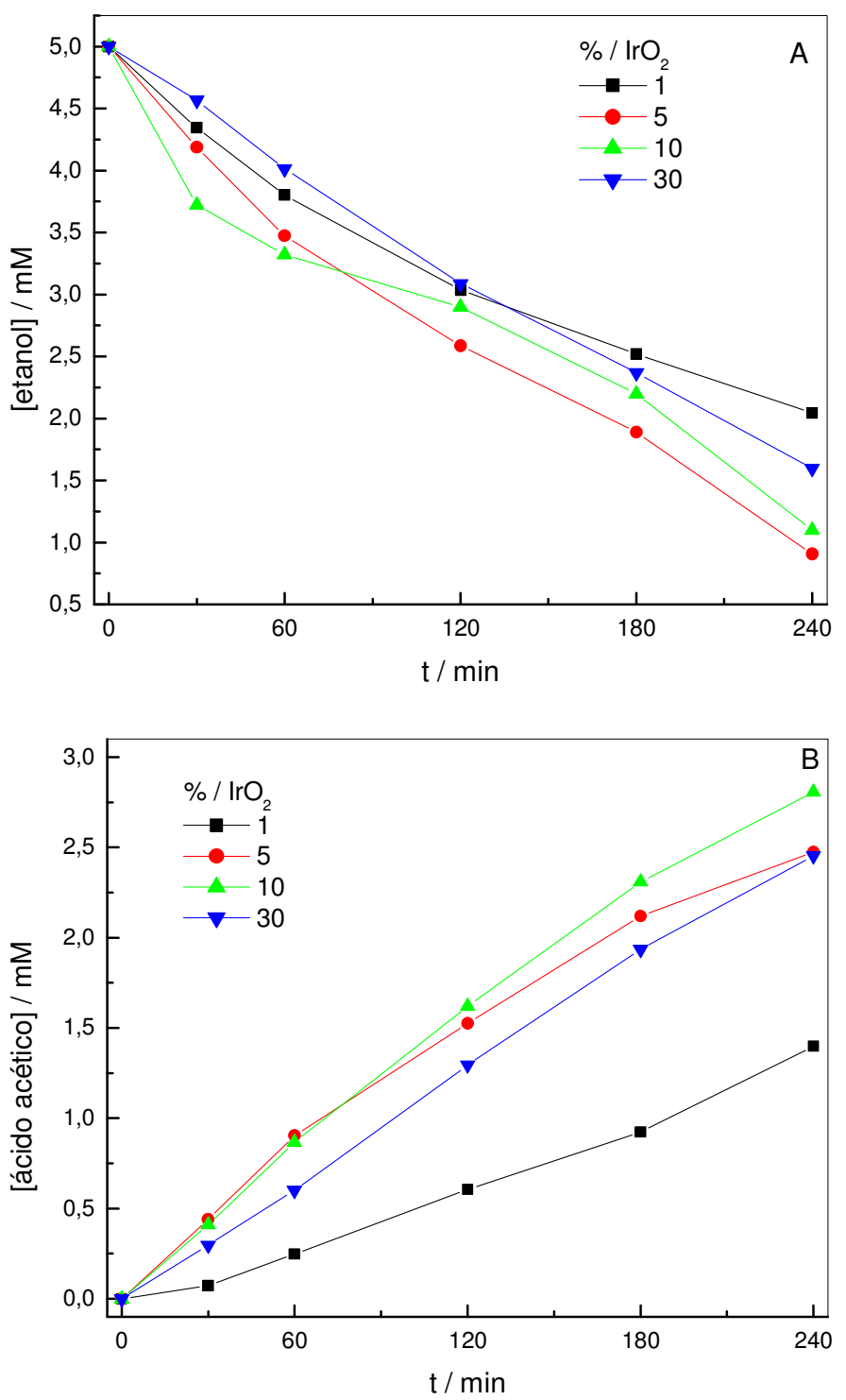

Figura 42 - Gráficos do consumo de etanol (A) e formação de ácido acético (B) em função do tempo de eletrólise para todas as composições de eletrodos. Concentração inicial de etanol $=5 \mathrm{mmol} \mathrm{L}^{-1}$, corrente aplicada $=100 \mathrm{~mA} \mathrm{~cm}{ }^{-2}$. 
Além do ácido acético, foi quantificado acetaldeído como produto na eletrólise com o eletrodo contendo $1 \% \mathrm{IrO}_{2}$. A concentração de $\mathrm{CO}_{2}$ formado foi muito inferior a esperada, então ela foi estimada pela diferença entre o etanol consumido e acetaldeído e ácido acético formados considerando um balanço de massa de $100 \%$.

$\mathrm{Na}$ Tabela IV pode-se observar que houve um consumo acentuado de etanol, que ficou entre 60 e $82 \%$ para os eletrodos contendo 1 e $5 \%$ de $\mathrm{IrO}_{2}$ respectivamente. Uma outra observação é que os eletrodos contendo 10 e $30 \%$ de $\mathrm{IrO}_{2}$ oxidam etanol preferencialmente a ácido acético, enquanto que os eletrodos de 1 e $5 \%$ de $\mathrm{IrO}_{2}$ apresentaram menores porcentagens de formação de ácido acético e ocorre a formação de $\mathrm{CO}_{2}$ em maior quantidade (valor estimado). Este comportamento pode ser atribuído a presença do $\mathrm{SnO}_{2}$ em maiores quantidades na superfície dos eletrodos, o qual favorece a oxidação de espécies orgânicas até $\mathrm{CO}_{2}$ [23].

Tabela IV: Tabela das concentrações e rendimento do consumo de etanol e formação dos reagentes após 240 minutos de eletrólise em meio ácido para todas as composições dos eletrodos. Concentração inicial de etanol $=5 \mathrm{mM}$, corrente aplicada $=100 \mathrm{~mA} \mathrm{~cm}^{-2}$.

\begin{tabular}{|c|c|c|c|c|c|c|c|c|}
\hline \multirow[t]{3}{*}{$\% \mathrm{IrO}_{2}$} & \multicolumn{2}{|c|}{ Etanol } & \multicolumn{2}{|c|}{$\begin{array}{c}\text { Ácido Acético } \\
\text { Formado }\end{array}$} & \multicolumn{2}{|c|}{$\begin{array}{l}\text { Acetaldeído } \\
\text { Formado }\end{array}$} & \multicolumn{2}{|c|}{$\begin{array}{c}\mathrm{CO}_{2} \\
\text { Formado** }\end{array}$} \\
\hline & {[]$/ /$} & $\%$ & [ ]// & $(\%)^{*}$ & [ ] / & $(\%)^{*}$ & {$[$ ] $/$} & (\%) \\
\hline & $\mathrm{mM}$ & & $\mathrm{mM}$ & & $\mathrm{mM}$ & & $\mathrm{mM}$ & \\
\hline 1 & 3 & 60 & 1,40 & 46,7 & 0,21 & 7,0 & 2,78 & 46,3 \\
\hline 5 & 4,1 & 82 & 2,47 & 60,2 & 0 & 0 & 3,26 & 39,8 \\
\hline 10 & 3,9 & 78 & 2,90 & 74,4 & 0 & 0 & 2,00 & 25,6 \\
\hline 30 & 3,4 & 68 & 2,50 & 73,5 & 0 & 0 & 1,80 & 26,5 \\
\hline
\end{tabular}

* Relativo ao etanol consumido.

** Estimado pela diferença entre etanol consumido e ácido acético e acetaldeído formados.

Para entendermos o que deve estar ocorrendo na superfície do eletrodo é necessário pensar a respeito dos possíveis mecanismos para a oxidação do 
etanol. A formação de $\mathrm{CO}_{2}$ pode ocorrer através de diferentes caminhos, ou seja, (1) pode ocorrer a quebra da ligação carbono-carbono do etanol e cada intermediário formado geraria duas moléculas de $\mathrm{CO}_{2}$ (2) o etanol pode oxidar-se a acetaldeído e este se oxidar a $\mathrm{CO}_{2}$. O acetaldeído formado pode também oxidar-se a ácido acético. $O$ acetaldeído foi detectado apenas nas eletrólises realizadas com eletrodos contendo $1 \%$ de $\mathrm{IrO}_{2}$ demonstrando que esta espécie, se formada, deve ser rapidamente oxidada na presença de $\mathrm{IrO}_{2}$. A presença de $\mathrm{Ir}$ na superfície do eletrodo não favorece, no entanto, a formação de dióxido de carbono, o que é um indicativo de que na presença de Ir o acetaldeído deve se oxidar rapidamente a ácido acético. $O$ ácido acético, por sua vez, é uma espécie dificilmente oxidável. Desta forma podemos supor que o óxido de estanho deve favorecer a oxidação do acetaldeído ou etanol a dióxido de carbono enquanto que - $\mathrm{IrO}_{2}$ deve favorecer a oxidação do acetaldeído a ácido acético, dando origem a uma competição na superfície do eletrodo.

Foram também realizados um outro conjunto de eletrólises com a mesma concentração de etanol da anterior, mas a uma densidade de corrente de $20 \mathrm{~mA}$ $\mathrm{cm}^{-2}$ com o objetivo de avaliar o efeito da densidade de corrente no rendimento das eletrólises. Os resultados obtidos estão apresentados na Tabela V. A Figura 43 mostra o gráfico do consumo do etanol e outro com a formação do ácido acético em função do tempo de eletrólise. Nestes experimentos as condições de coleta de gases foram melhoradas e foi possível detectar a presença de $\mathrm{CO}_{2}$ porém, da mesma forma que anteriormente, os balanços de massa mostraram-se inferiores a $100 \%$. Devido a isto, na Tabela $V$ são apresentados os dados de concentração de $\mathrm{CO}_{2}$ determinado por CLAE e estimados para um balanço de massa de $100 \%$. 
Tabela V: Porcentagem de etanol consumido e de produtos formados após 240 minutos de eletrólise em meio ácido para todas as composições dos eletrodos. Concentração inicial de etanol $=5 \mathrm{mM}$, corrente aplicada $=20 \mathrm{~mA} \mathrm{~cm}^{-2}$.

\begin{tabular}{|c|c|c|c|c|c|}
\hline \multirow{2}{*}{$\% \mathrm{IrO}_{2}$} & \multirow{2}{*}{$\begin{array}{c}\begin{array}{c}\text { Etanol } \\
\text { Consumido }\end{array} \\
(\%)\end{array}$} & \multirow{2}{*}{$\begin{array}{c}\text { Ácido Acético } \\
\text { Formado } \\
(\%)^{*}\end{array}$} & \multirow{2}{*}{$\begin{array}{c}\text { Acetaldeído } \\
\text { Formado } \\
(\%)^{*}\end{array}$} & \multicolumn{2}{|c|}{$\begin{array}{c}\mathrm{CO}_{2} \\
\text { Formado }\end{array}$} \\
\hline & & & & $(\%)^{\star \mathbf{a}}$ & $(\%)^{\star \star}$ \\
\hline 1 & 36,6 & 21,0 & 9,9 & 47,1 & 69,1 \\
\hline 5 & 47,1 & 51,3 & 0 & 28,6 & 48,7 \\
\hline 10 & 48,9 & 50,5 & 0 & 36,2 & 49,5 \\
\hline 30 & 34,2 & 39,2 & 0 & 28,7 & 60,8 \\
\hline
\end{tabular}

* Relativo ao etanol consumido.

a detectado por CLAE

** Estimado pela diferença entre etanol consumido e ácido acético e acetaldeido formados. 

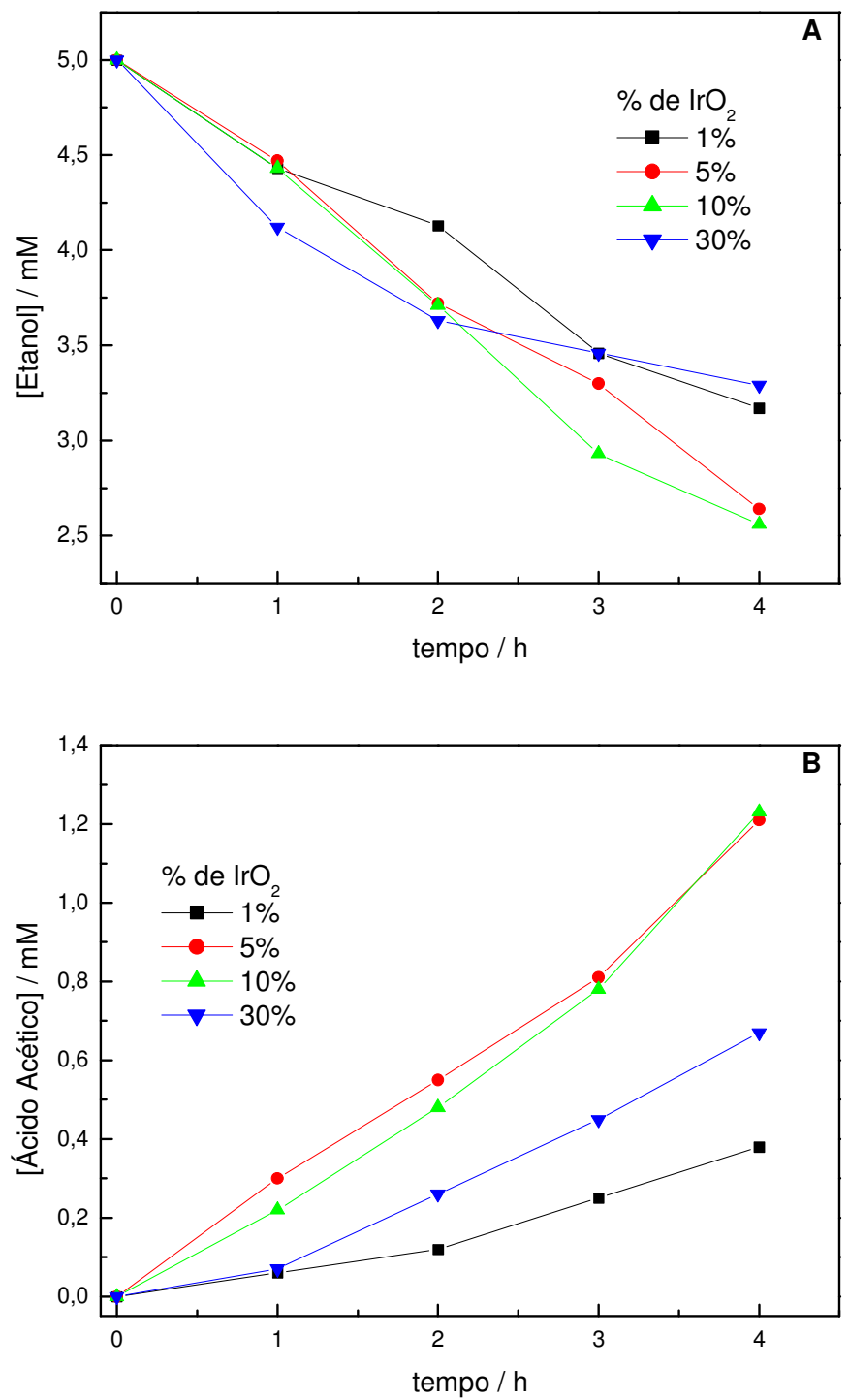

Figura 43 - Gráficos do consumo do etanol (A) e formação de ácido acético (B) em função do tempo de eletrólise para todas as composições de eletrodos. Concentração inicial de etanol $=5 \mathrm{mmol} \mathrm{L}^{-1}$, corrente aplicada $=20 \mathrm{~mA} \mathrm{~cm}^{-2}$.

Os dados apresentados na Tabela $\mathrm{V}$ mostram primeiramente que, embora a densidade de tenha sido diminuída de 100 para $20 \mathrm{~mA} \mathrm{~cm}{ }^{-2}$, o consumo de etanol não diminui na mesma proporção, ou seja, uma maior eficiência de corrente foi obtida. Da mesma forma que a $100 \mathrm{~mA} \mathrm{~cm}{ }^{-2}$, acetaldeído só foi identificado para eletrodos contendo $1 \%$ de $\mathrm{IrO}_{2}$ confirmando que a reação de oxidação de acetaldeído a ácido acético deve ser mais lenta sobre $\mathrm{SnO}_{2}$ do que sobre $\mathrm{IrO}_{2}$. 
A taxa de conversão de etanol a $\mathrm{CO}_{2}$ foi superior ao resultado obtido com maior densidade de corrente. A maior taxa de conversão de etanol a $\mathrm{CO}_{2}$ foi obtida para os eletrodos mais ricos em $\mathrm{Sn}$, diminuindo para conteúdos intermediários e voltando a aumentar para o eletrodo contendo $30 \%$ de $\mathrm{IrO}_{2}$. $\mathrm{Na}$ Figura 43B pode-se observar que o eletrodo contendo $30 \%$ de $\mathrm{IrO}_{2}$ apresentou uma velocidade de formação de ácido acético maior que a do eletrodo contendo $1 \%$ e menor que a dos eletrodos contendo 5 e $10 \%$ de $\mathrm{IrO}_{2}$. $\mathrm{Na}$ eletrólise realizada a $100 \mathrm{~mA} \mathrm{~cm}^{-2}$ a velocidade do eletrodo contendo $30 \%$ de $\mathrm{IrO}_{2}$ foi similar a dos eletrodos contendo 5 e $10 \%$ de $\mathrm{IrO}_{2}$, portanto, considerando o conjunto de eletrodos em cada condição, a $20 \mathrm{~mA} \mathrm{~cm}{ }^{-2}$ houve uma diminuição relativa da velocidade de formação de ácido acético para o eletrodo contendo $30 \%$ de $\mathrm{IrO}_{2}$. Neste caso, este comportamento poderia explicar a maior seletividade para formação de $\mathrm{CO}_{2}$ neste eletrodo.

Foram realizados ainda, experimentos de eletrólise com soluções contendo concentrações de etanol de $20 \mathrm{mM}$ e a uma densidade de corrente de $20 \mathrm{~mA} \mathrm{~cm}^{-2}$. Os resultados obtidos estão apresentados na Tabela VI e na Figura 44, onde é apresentado o gráfico do consumo do etanol e outros dois: um com a formação do ácido acético e outro com a formação do acetaldeído em função do tempo de eletrólise.

Tabela VI: Porcentagem de etanol consumido e de produtos formados após 240 minutos de eletrólise em meio ácido para todas as composições dos eletrodos. Concentração inicial de etanol $=20 \mathrm{mM}$, corrente aplicada $=20 \mathrm{~mA} \mathrm{~cm}{ }^{-2}$.

\begin{tabular}{cccccc}
\hline & Etanol & \multicolumn{2}{c}{$\begin{array}{c}\text { Ácido Acético } \\
\text { Consumido }\end{array}$} & $\begin{array}{c}\text { Acetaldeído } \\
\text { Formado }\end{array}$ & \multicolumn{2}{c}{${\mathbf{~} \mathbf{~ O O}_{2}}_{2}$} \\
\cline { 2 - 7 } & $(\%)$ & $(\%)^{*}$ & $(\%)^{*}$ & $(\%)^{\star \mathbf{a}}$ & $(\%)^{\star *}$ \\
\hline $\mathbf{1}$ & 19,9 & 23,7 & 14,7 & 11,3 & 61,6 \\
$\mathbf{5}$ & 26,4 & 52,3 & 9,4 & 10,4 & 38,3 \\
$\mathbf{1 0}$ & 26,1 & 69,7 & 0 & 13,0 & 30,3 \\
$\mathbf{3 0}$ & 26,9 & 24,8 & 1,5 & 18,8 & 73,7 \\
\hline
\end{tabular}

* Relativo ao etanol consumido.

a detectado por CLAE

** Estimado pela diferença entre etanol consumido e ácido acético e acetaldeido formados. 

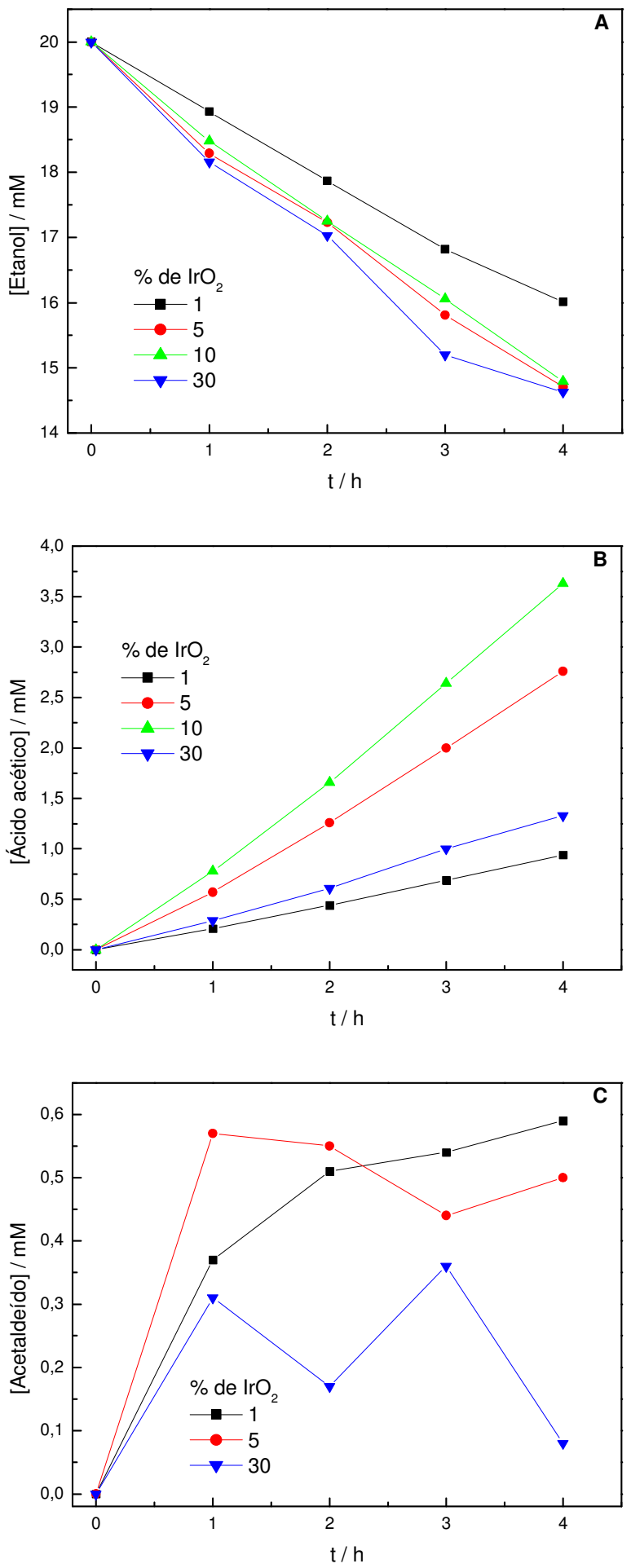

Figura 44 - Gráficos do consumo do etanol (A), formação do ácido acético (B) e formação do acetaldeído (C) em função do tempo de eletrólise para todas as composições de eletrodos. Concentração inicial de etanol $=20 \mathrm{mmol} \mathrm{L}^{-1}$, corrente aplicada $=20 \mathrm{~mA} \mathrm{~cm}^{-2}$. 
Analisando primeiramente o consumo de etanol vemos que o consumo percentual é menor do que para soluções contendo $5 \mathrm{mmol} \mathrm{L}^{-1}$ de etanol mas o consumo real é maior pois a concentração inicial foi 4 vezes maior. Nos resultados do eletrodo com $10 \%$ de $\mathrm{IrO}_{2}$ o consumo foi de aproximadamente $49 \%$ (2,45 $\left.\mathrm{mmol} \mathrm{L}^{-1}\right)$ na eletrólise realizada com solução de $5 \mathrm{mmol} \mathrm{L}^{-1}$ e um consumo de aproximadamente $26 \%\left(5,22 \mathrm{mmol} \mathrm{L}^{-1}\right)$ na eletrólise realizada com solução de $20 \mathrm{mmol} \mathrm{L}^{-1}$, ou seja, consumiu-se mais etanol utilizando a mesma quantidade de energia.

Em relação a quantidade de ácido acético formado, observa-se que há uma ordem de velocidade de formação para as diferentes composições eletródicas: $10 \%>5 \%>30 \%>1 \%$ de $\mathrm{IrO}_{2}$. Os eletrodos contendo 1 e $30 \%$ de $\mathrm{IrO}_{2}$ são os que apresentam menores taxas de conversão a esta espécie, enquanto que para o eletrodo contendo $10 \%$ de $\mathrm{IrO}_{2}$ esta conversão chega a aproximadamente $70 \%$. Relacionando esta observação com os resultados de atividade intrínseca determinados pelos dados de voltametria cíclica, pode-se afirmar que os eletrodos contendo $10 \%$ de $\mathrm{IrO}_{2}$ apresentam uma alta atividade para a reação de eletrooxidação de etanol e que o principal produto formado é o ácido acético. $O$ acetaldeído, por sua vez, foi detectado principalmente para os eletrodos mais ricos em $\mathrm{SnO}_{2}$ e apenas uma pequena quantidade para os eletrodos contendo $30 \%$ de $\mathrm{IrO}_{2}$. O fato de termos detectado maiores concentrações de acetaldeído formado nas eletrólises realizadas em soluções mais concentradas de etanol pode estar relacionado a uma competição entre o aldeído e o álcool pelos sítios ativos do eletrodo. Assim, para soluções mais concentradas de etanol, a reação de acetaldeído não ocorreria com a mesma facilidade tornando possível a detecção desta espécie em solução. A quantidade de $\mathrm{CO}_{2}$ formada, de acordo com os dados estimados, mostra novamente uma alta taxa de conversão para os eletrodos contendo 1 e $30 \%$ de $\mathrm{IrO}_{2}$. Os eletrodos que formam preferencialmente ácido acético apresentam taxas menores de formação de $\mathrm{CO}_{2}$ pois o ácido acético não deve se oxidar a $\mathrm{CO}_{2}$, conforme discutido anteriormente. Assim, o etanol pode ser oxidado preferencialmente a dióxido de carbono ou ácido acético e que o favorecimento de formação de um ou outro produto está relacionada com a composição do eletrodo. Contudo, além da dependência da composição para a formação preferencial de algum dos produtos, a velocidade com que o etanol é oxidado parece conduzir os produtos de oxidação por mecanismos diferentes. 
Isso foi observado para a oxidação do etanol em maiores densidades de corrente, onde o eletrodo contendo $30 \%$ de $\mathrm{IrO}_{2}$ formou preferencialmente ácido acético. Já para densidades de corrente de $20 \mathrm{~mA} \mathrm{~cm}^{-2}$, em ambas as concentrações, foi favorecida a formação de $\mathrm{CO}_{2}$.

O eletrodo contendo $30 \%$ de $\mathrm{IrO}_{2}$, apesar de ser a composição com menor porcentagem de $\mathrm{SnO}_{2}$, é a que possui a maior área ativa, ou seja, é o eletrodo com o maior número de sítios ativos expostos em sua superfície. Assim, há também uma maior quantidade de sítios de Sn expostos que nas outras composições de eletrodos contendo maior porcentagem de $\mathrm{SnO}_{2}$. Acreditamos que, uma vez formado, o acetaldeído pode ser oxidado a $\mathrm{CO}_{2}$ ou ácido acético. Os sítios de Ir devem favorecer a reação que forma o ácido enquanto que a quebra da ligação $\mathrm{C}-\mathrm{C}$ deve ser favorecida sobre sítios de Sn levando a formação de $\mathrm{CO}_{2}$. Para altas densidades de corrente $\mathrm{O}$ acetaldeído pode ser formado e oxidado rapidamente a ácido em sítios de Ir. Para densidades de correntes menores há uma oxidação mais lenta e deve haver uma competição entre sítios de Ir e Sn pelo acetaldeído, com Sn favorecendo a formação de $\mathrm{CO}_{2}$ e isso poderia ser explicado pela maior quantidade de sítios de Sn na superfície deste eletrodo.

\subsection{4 - Estudo da eletrooxidação por FTIR in situ}

Nesta etapa do trabalho foi realizada a investigação de intermediários e produtos de reação da eletrooxidação de etanol correlacionando dados de FTIR in situ com dados de eletrólise com o objetivo de propor um mecanismo reacional. Para utilizar a técnica de FTIR in situ, por se tratar de uma técnica de reflectância especular, é preciso que o eletrodo não absorva o feixe incidente e possibilite a detecção do sinal das espécies formadas. Para isso foram preparados eletrodos depositando o filme de óxido sobre ouro polido. Contudo o aspecto voltamétrico é

similar aos eletrodos preparados sobre $\mathrm{Ti}^{0}$. A Figura 45 apresenta 0 voltamograma cíclico do eletrodo contendo $1 \%$ de $\mathrm{IrO}_{2}$ em sua composição. 


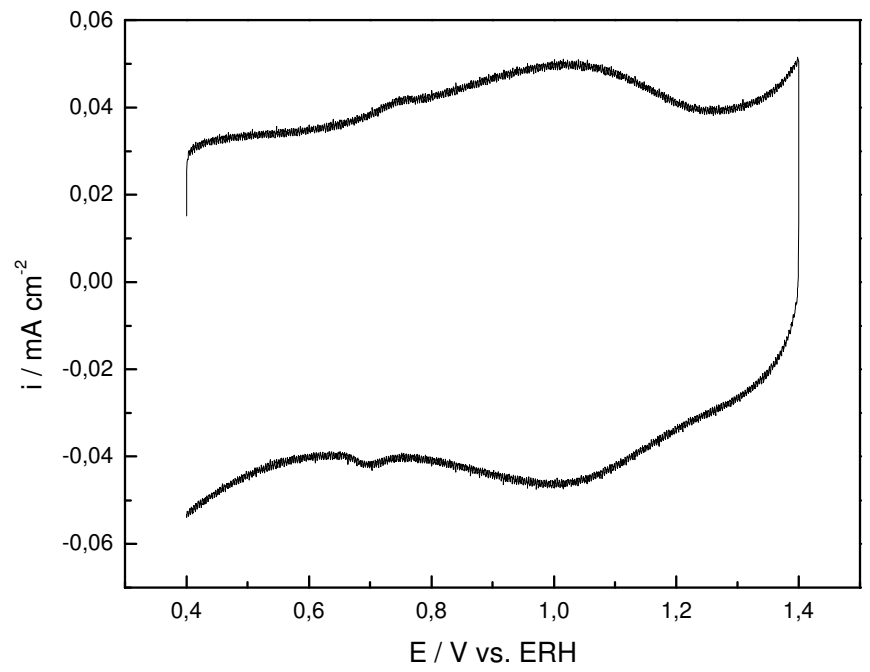

Figura 45 - Voltamogramas cíclicos em solução de $\mathrm{HClO}_{4}$ 0,1 mol L-1 a $20 \mathrm{mV} \mathrm{s}^{-1}$ para o eletrodo contendo $1 \%$ de $\mathrm{IrO}_{2}$ preparado sobre ouro polido.

Antes dos experimentos de eletrólise e FTIR in situ, a eletrooxidação de etanol com o eletrodo contendo $1 \%$ de $\mathrm{IrO}_{2}$ foi realizada pela técnica de voltametria cíclica, a qual permitiu verificar o comportamento deste eletrodo em duas diferentes concentrações de etanol. Nas Figuras 46 e 47 estão os voltamogramas cíclicos em eletrólito suporte na ausência e presença de etanol $0,1 \mathrm{~mol} \mathrm{~L}^{-1}$ (Fig.46) e 1,0 mol L-1 (Fig.47). Na Figura 46 não há um pico de oxidação, há somente um pequeno aumento na corrente em potenciais mais positivos que $1 \mathrm{~V}$ em relação a corrente em eletrólito suporte (que pode ser melhor visualizado no VC inserido na Figura 46), e também uma inibição da RDO no potencial de inversão $(1,8 \mathrm{~V})$. Contudo, na Figura 47 onde a concentração de etanol é bem mais alta é possível observar um grande aumento da corrente de eletrooxidação do etanol em relação a corrente em eletrólito suporte. 


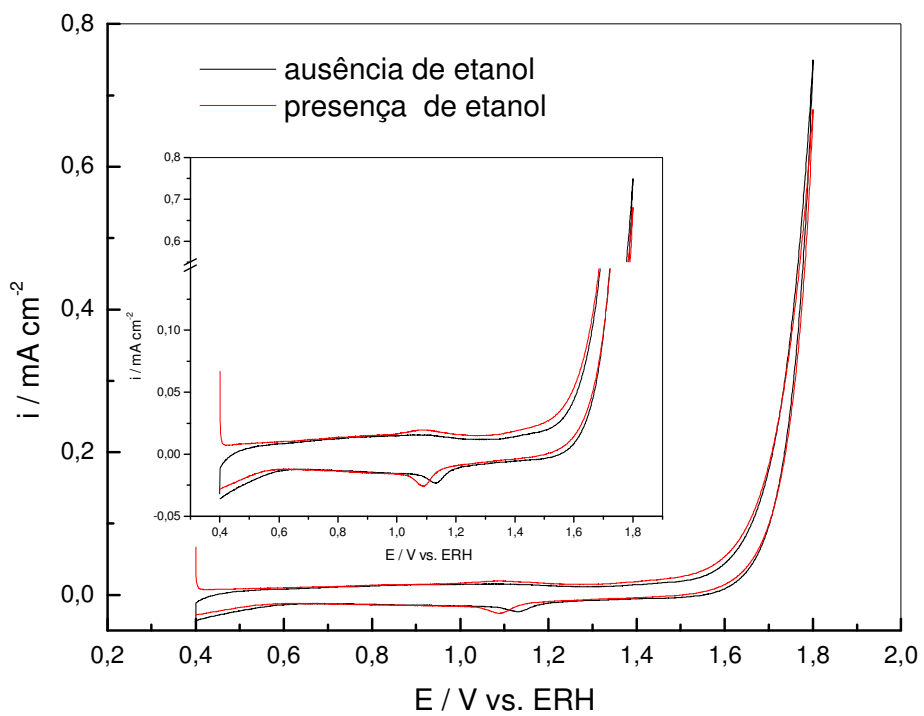

Figura 46 - Voltamogramas cíclicos em solução de $\mathrm{HClO}_{4} 0,1 \mathrm{~mol} \mathrm{~L}^{-1}$ a $5 \mathrm{mV} \mathrm{s}^{-1}$ na presença e ausência de etanol $0,1 \mathrm{~mol} \mathrm{~L}^{-1}$ para o eletrodo contendo $1 \%$ de $\mathrm{IrO}_{2}$.



Figura 47 - Voltamogramas cíclicos em solução de $\mathrm{HClO}_{4} 0,1 \mathrm{~mol} \mathrm{~L}^{-1}$ a $5 \mathrm{mV} \mathrm{s}^{-1}$ na presença e ausência de etanol $1,0 \mathrm{~mol} \mathrm{~L}^{-1}$ para o eletrodo contendo $1 \%$ de $\mathrm{IrO}_{2}$.

As eletrólises foram realizadas em $15 \mathrm{~mL}$ de solução de etanol $0,1 \mathrm{~mol} \mathrm{~L}^{-1}$ em meio de $\mathrm{HClO}_{4} \quad 0,1 \mathrm{~mol} \mathrm{~L}^{-1}$ que foi a mesma condição utilizada nos experimentos de FTIR in situ. Durante as eletrólises aplicou-se $20 \mathrm{~mA} \mathrm{~cm}{ }^{-2}$ por quatro horas. As análises dos produtos de reação por HPLC indicam que em 
todas as composições de eletrodo tanto acetaldeído (AAld) quanto ácido acético (HAc) são os principais produtos formados e que $\mathrm{CO}_{2}$ é formado em menor quantidade. A Figura 48 apresenta um resumo dos resultados das eletrólises, onde está demonstrado o gráfico do rendimento do consumo de etanol e a seletividade dos produtos identificados após 4 horas de eletrólise com todas as composições eletródicas.

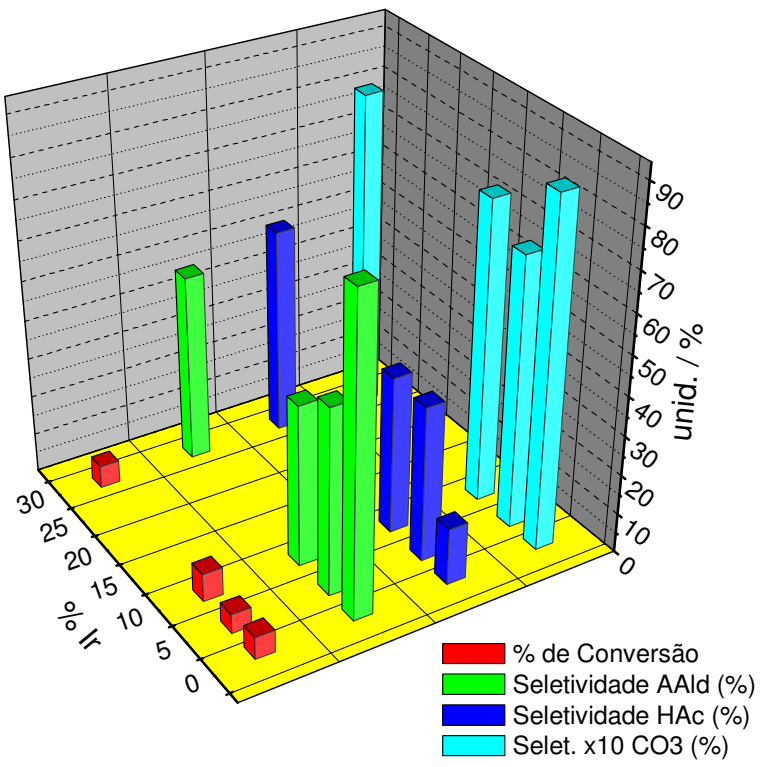

Figura 48 - Gráfico do rendimento do consumo de etanol e da seletividade dos produtos identificados (acetaldeído=AAld, ácido acético=HAC e $\mathrm{CO}_{2}$ ) em função da composição eletródica. Foram eletrolisadas $15 \mathrm{~mL}$ de etanol $0,1 \mathrm{~mol} \mathrm{~L}^{-1} \mathrm{em}$ meio de $\mathrm{HClO}_{4}$ 0,1 mol L-1 e corrente constante de $20 \mathrm{~mA} \mathrm{~cm}^{-2}$ por 4 horas. As colunas que representam o $\mathrm{CO}_{2}$ formado foram multiplicadas por um fator de dez.

Nesta figura pode-se observar um rendimento $(\tau)$ maior de etanol para as composições de $10 \%$ de $\operatorname{IrO}_{2}(\tau=7,1 \%$ ), seguido pelos eletrodos de 30 e $1 \%$ de $\mathrm{IrO}_{2}(\tau=5,7$ e $5,6 \%$ respectivamente) e o menor rendimento para a composição de $5 \%$ de $\mathrm{IrO}_{2}(\tau=4,8 \%)$. Há também uma tendência em aumentar a quantidade de ácido acético formado com o aumento da quantidade de $\mathrm{IrO}_{2}$ na composição do eletrodo mostrando que $\circ \mathrm{IrO}_{2}$ aumenta a seletividade do eletrodo para esta molécula. Contudo, na formação do acetaldeído ocorreu uma tendência oposta a do ácido acético, ou seja, há uma maior seletividade para a sua formação com a 
diminuição da quantidade de $\mathrm{IrO}_{2}$ na composição do eletrodo. Os eletrodos com as maiores taxas de produção de $\mathrm{CO}_{2}$ foram os contendo 1 e $30 \%$ de $\mathrm{IrO}_{2}(8,7$ e $8,1 \%$ respectivamente). Resultados anteriores mostraram que o ácido acético não é oxidado nestes eletrodos. Assim, o $\mathrm{CO}_{2}$ formado seria proveniente da quebra da ligação C-C do acetaldeído ou diretamente do etanol.

$\mathrm{Na}$ Tabela VII foi colocada a razão entre a seletividade de acetaldeído e ácido acético para as diferentes composições de eletrodo. A formação de $\mathrm{CO}_{2}$ segue a tendência de formação do acetaldeído provavelmente porque suas formações são favorecidas pela maior quantidade de $\mathrm{SnO}_{2}$ na composição do eletrodo. Contudo, apesar da razão AAld/HAc diminuir com o aumento de $\mathrm{IrO}_{2}$ na composição do eletrodo na Tabela VII , o eletrodos contendo $30 \%$ de $\mathrm{IrO}_{2}$ só produziu menos $\mathrm{CO}_{2}$ que o eletrodo contendo $1 \%$ de $\mathrm{IrO}_{2}$. Isto pode ser explicado por um efeito de área ativa real, a qual aumenta com o aumento de $\mathrm{IrO}_{2}$ na composição do eletrodo, e que no caso do eletrodo contendo $30 \%$ de $\mathrm{IrO}_{2}$ é muito superior que a dos outros. Esta maior área poderia fazer com que este eletrodo tivesse uma área ativa real com sítios de $\mathrm{SnO}_{2}$ maior que os outros eletrodos.

Tabela VII - Relação entre acetaldeído e ácido acético formados após 4 horas de eletrólises para as diferentes composições de eletrodo.

\begin{tabular}{ccc}
\hline$\%$ de $\mathrm{IrO}_{2}$ & AAld $/$ HAc & HAc / AAld \\
\hline 1 & 5,53 & 0,18 \\
5 & 1,20 & 0,83 \\
10 & 1,02 & 0,97 \\
30 & 0,90 & 1,10 \\
\hline
\end{tabular}

Com o objetivo de verificar a natureza das espécies adsorvidas durante a reação de oxidação de etanol sobre os eletrodos de composição $\mathrm{Sn}_{(1-x)} \mid r_{x} \mathrm{O}_{2}$, foram realizados experimentos de espectroscopia de infravermelho in situ.

Para a aquisição dos espectros escolheram-se dois métodos: SPAIRS e SNIFTIRS. No método de SNIFTIRS foi registrada a refletividade da superfície eletródica em dois potenciais alternados, neste caso a modulação do potencial foi de $300 \mathrm{mV}$ com o potencial variando de 0,5 a 1,8 V. No método de SPAIRS foram obtidos espectros em um intervalo de potenciais entre 0,4 e 1,8 V durante 
experimentos de VC a uma velocidade de varredura de $1 \mathrm{mV} \mathrm{s}^{-1}$. Na seqüência os dados foram normalizados utilizando o espectro de referência adquirido em 0,4 V.

Os espectros obtidos tanto pela técnica de SNIFTIRS como por SPAIRS estão mostrados nas Figura 49, 50 e 51.

Devido ao modo de aquisição dos dados, a técnica de SNIFITIRS é mais apropriada para detectar as bandas de absorção das espécies de CO adsorvidas na superfície eletródica. Considerando um eletrodo que contenha Pt em sua superfície a espécie $\mathrm{CO}$ pode adsorver aos sítios de três formas diferentes, $\mathrm{CO}_{\mathrm{M}}$ (multiligado), $\mathrm{CO} L$ (linearmente ligado) e $\mathrm{CO}_{\mathrm{B}}$ (ligado em forma de ponte) [74]. A espécie $\mathrm{CO}_{\mathrm{M}}$ apresenta, em potenciais em torno de $100 \mathrm{mV}$, uma banda de absorção em torno de $1895 \mathrm{~cm}^{-1}$. Esta espécie é o estado precursor da espécie $\mathrm{CO} \mathrm{L}$, a qual apresenta banda de absorção em torno de $2050 \mathrm{~cm}^{-1}$ e somente em valores de potenciais mais elevados. A espécie $C_{B}$ pode ser detectada em baixos valores de potenciais $\left(100 \mathrm{mV}\right.$ ) com banda de absorção de $1850 \mathrm{~cm}^{-1}$.

Nos espectros de SNIFITIRS (Figura 49) obtidos para os eletrodos de $\mathrm{Sn}_{(1-}$ x) $\mid r_{\mathrm{x}} \mathrm{O}_{2}$ durante a oxidação do etanol não foram observadas bandas referentes a formação das espécies $\mathrm{CO}$ nas respectivas regiões. O não aparecimento das bandas de absorção de CO pode ser atribuído ao alto potencial aplicado $(>0,5 \mathrm{~V})$ para aquisição dos espectros. Neste potencial a velocidade de consumo destas espécies deve ser muito elevada impossibilitando a sua detecção por esta técnica. A formação destas espécies é favorecida em potenciais inferiores, em torno de $200 \mathrm{mV}$, onde o $\mathrm{CO}$ se adsorve e permanece sobre a superfície eletródica sendo possível de ser detectado. 

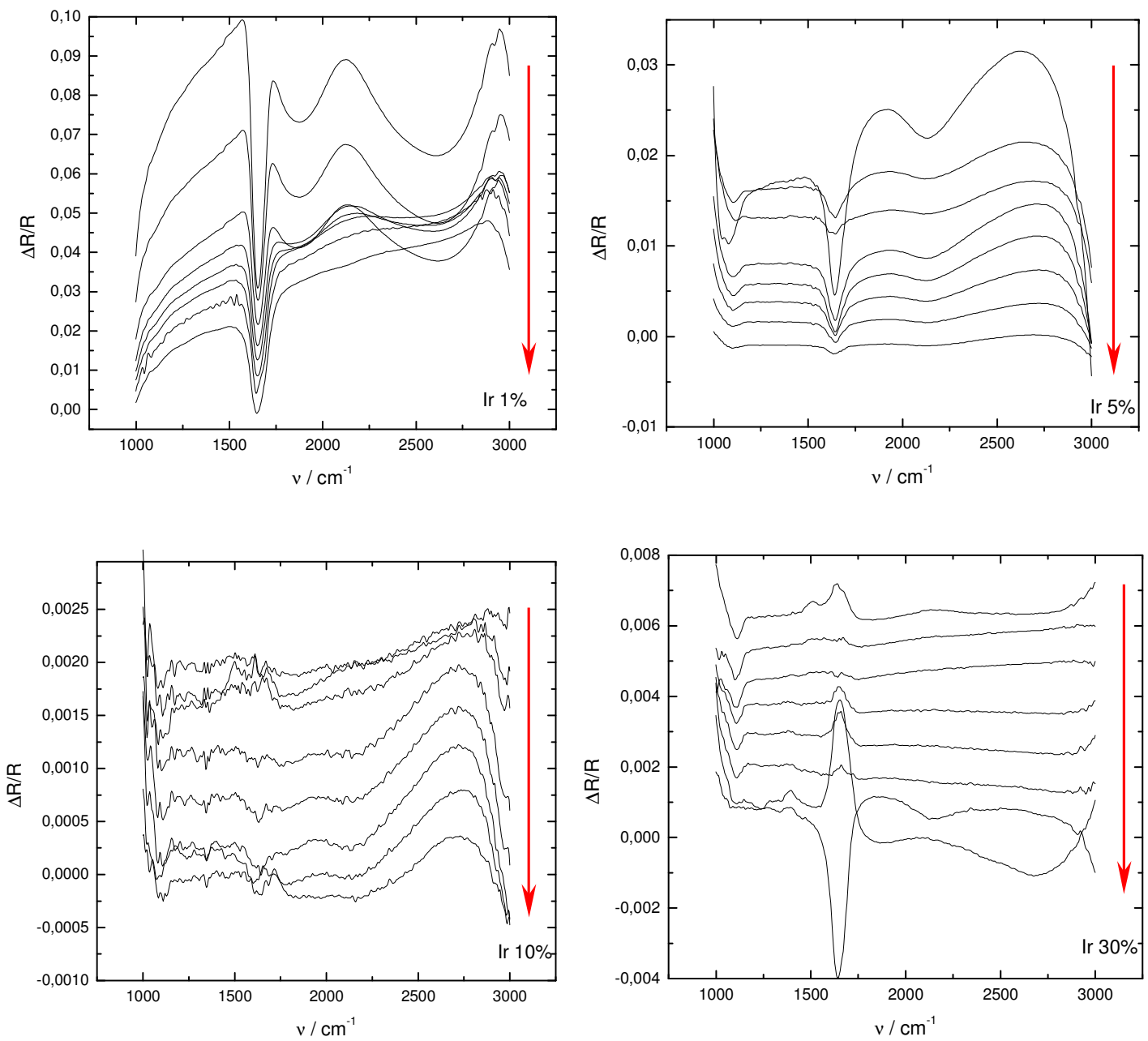

Figura 49 - Espectros de FTIR in situ obtidos pelo método de SNIFITIRS com modulação de $300 \mathrm{mV}$ para todas as composições eletródicas durante a oxidação do etanol. Os potenciais de modulação foram entre: [0,5-0,8V], [0,7-1,0V], [0,9$1,2 \mathrm{~V}], \quad[1,1-1,4 \mathrm{~V}], \quad[1,2-1,5 \mathrm{~V}], \quad[1,3-1,6 \mathrm{~V}], \quad[1,4-1,7 \mathrm{~V}]$ e $[1,5-1,8 \mathrm{~V}]$ que estão representados pelos espectros em ordem decrescente nos gráficos.

Para a realização da técnica de SPAIRS é registrado um voltamograma cíclico a uma velocidade de varredura de $1 \mathrm{mV} \mathrm{s}^{-1}$, tal voltamograma cíclico apresentou perfil similar àquele apresentado na Figura 46. A técnica de SPAIRS permitiu detectar algumas bandas de absorção. Em todas as composições de eletrodo foi verificada a formação de $\mathrm{CO}_{2}$ com o aparecimento de uma banda negativa em $2345 \mathrm{~cm}^{-1}$. Para o eletrodo com $10 \%$ de $\mathrm{IrO}_{2}$ a banda foi observada a partir de 1,2V e para as demais composições, a partir de 1,3V. 
As Figuras 50 e 51 mostram os espectros em função do potencial aplicado para todas as composições de eletrodo na eletrooxidação de etanol e acetaldeído respectivamente. Além da banda de absorção referente ao $\mathrm{CO}_{2}$ em $2345 \mathrm{~cm}^{-1}$ outra banda sempre presente em todos os espectros, próxima a $1650 \mathrm{~cm}^{-1}$ foi atribuída a água interfacial, porém, bandas devido ao acetaldeído ou outras espécies (vibração da carbonila em torno de $1700 \mathrm{~cm}^{-1}$ ) pode também ser considerada. A banda de absorção observada em torno de $1111 \mathrm{~cm}^{-1}$ e é atribuída ao $\mathrm{ClO}_{4}^{-}$.

Bandas de absorção negativas são observadas próximas a 1720, 1400 (observado apenas para a composição com $30 \%$ de $\mathrm{IrO}_{2}$ ) e $1280 \mathrm{~cm}^{-1}$. Estas bandas são respectivamente atribuídas ao estiramento do grupo carbonila $(\mathrm{C}=\mathrm{O})$ proveniente dos grupamentos $-\mathrm{COOH}$ ou $-\mathrm{CHO}$, ao estiramento simétrico do $\mathrm{C}-\mathrm{O}$ proveniente da espécie adsorvida $\mathrm{CH}_{3} \mathrm{COO}$, e ao estiramento do $\mathrm{C}-\mathrm{O}$ e deformação do grupo $\mathrm{OH}$ proveniente do $-\mathrm{COOH}$ (1370 e $1280 \mathrm{~cm}^{-1}$ ) [75]. As bandas localizadas entre 1280 e $1400 \mathrm{~cm}^{-1}$ provavelmente descrevem o grupamento simétrico do ácido acético [76]. Estas bandas de absorção podem ser de um grupamento carbonila de um grupo ácido ou de um grupo aldeído, mas dizer qual dos dois exatamente é muito difícil, pois, a banda $\mathrm{C}=\mathrm{O}$ para um grupo ácido ou para um grupo aldeído são separadas por apenas $5 \mathrm{~cm}^{-1}$ que é aproximadamente o valor da resolução do equipamento de FTIR. Uma observação importante foi que o número de onda da banda de absorção próxima a $1280 \mathrm{~cm}^{-1}$ permanece inalterada com a variação do potencial indicando que esta espécie não se encontra adsorvida a superfície que provavelmente corresponde a ácido acético em solução acumulado próximo ao eletrodo. 

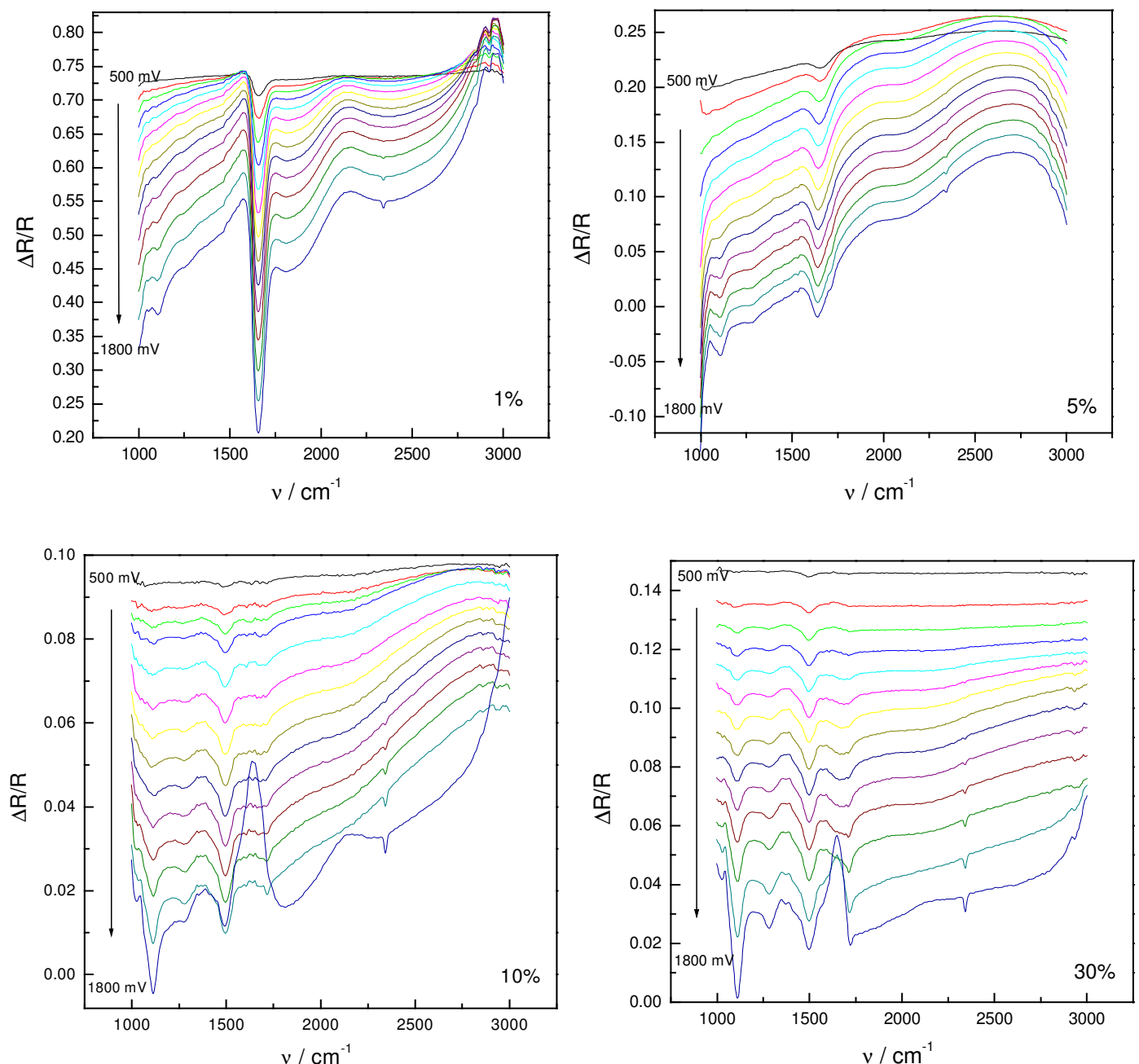

Figura 50 - Espectros de FTIR in situ obtidos pelo método de SPAIRS entre 0,4 e 1,8 $\mathrm{V}$ em passos de $0,1 \mathrm{~V}$ para todas as composições eletródicas durante a oxidação do etanol. 



Figura 51 - Espectros de FTIR in situ obtidos pelo método de SPAIRS entre 0,4 e $1,8 \mathrm{~V}$ em passos de $0,1 \mathrm{~V}$ para todas as composições eletródicas durante a oxidação do acetaldeído.

Os espectros dos eletrodos contendo 10 e $30 \%$ de $\mathrm{IrO}_{2}$ no potencial de 1,8 $\mathrm{V}$ apresentam uma banda positiva relativamente grande entre 1600 e $1700 \mathrm{~cm}^{-1}$ que é devido ao consumo de água, uma vez que neste potencial estes eletrodos podem realizar a RDO com bastante intensidade.

Para uma melhor comparação da quantidade de $\mathrm{CO}_{2}$ formada durante 0 experimento de SPAIRS foi feito um gráfico da intensidade da banda de $\mathrm{CO}_{2} \mathrm{em}$ função do potencial para todas as composições eletródicas que está apresentado na Figura 52. Nesta figura pode-se observar que a composição de $1 \%$ de $\mathrm{IrO}_{2}$ foi a que apresentou a maior intensidade de formação de $\mathrm{CO}_{2}$, contudo a banda 
aparece apenas em potenciais acima de $1,4 \mathrm{~V}$, enquanto que para o eletrodo contendo $10 \%$ de $\mathrm{IrO}_{2}$ ela aparece a partir de 1,2 V.

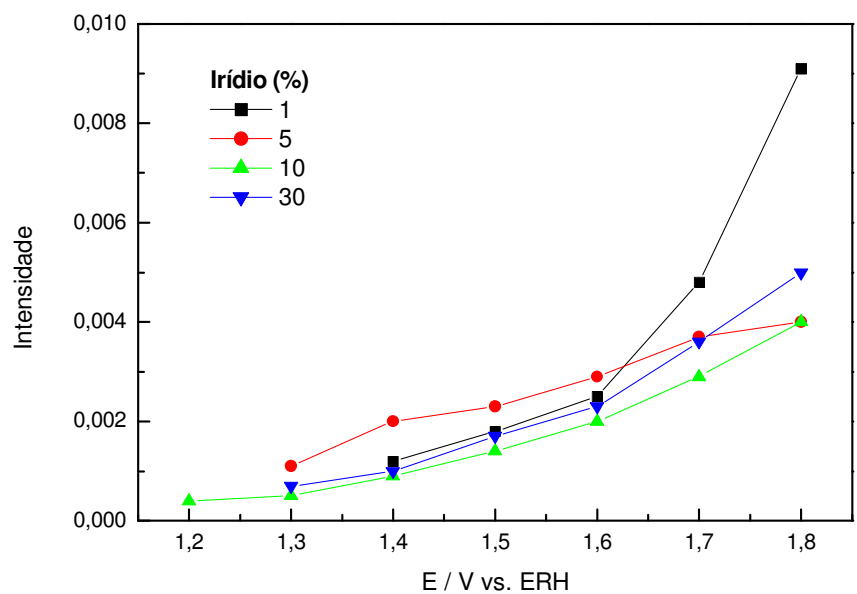

Figura 52 - Gráfico da intensidade das bandas de $\mathrm{CO}_{2}$ localizadas em $2345 \mathrm{~cm}^{-1}$ (extraídas da Figura 50) em função do potencial para todas as composições eletródicas.

A eletrooxidação de álcoois em eletrodos deste tipo é feita em potenciais de desprendimento de oxigênio (RDO) [17] sendo que em potenciais menores não há um pico bem definido referente a eletrooxidação da molécula orgânica, como pode ser observado nas Figuras 46 e 47.

Foram observados como principais produtos de oxidação do etanol, acetaldeído e ácido acético em maior quantidade e $\mathrm{CO}_{2}$ em menor quantidade. Conforme a Tabela VII e as bandas obtidas nos SPAIRS em $1280 \mathrm{~cm}^{-1}$, a maior quantidade de $\mathrm{IrO}_{2}$ na composição do eletrodo favorece a formação de ácido acético enquanto que a menor favorece o acúmulo de acetaldeído. Em todas as eletrólises o potencial de trabalho foi superior ao início da RDO, ou seja, maior que $1,6 \mathrm{~V}$. Contudo, nos eletrodos com maior quantidade de óxido de $\mathrm{IrO}_{2} \mathrm{a}$ adsorção dissociativa da $\mathrm{H}_{2} \mathrm{O}$ ocorre com maior facilidade. A oxidação da água gera espécies $\mathrm{OH}_{\text {ads }}$ que são as espécies necessárias para a oxidação das moléculas orgânicas. Esta oxidação poderia ocorrer similarmente ao mecanismo 
de eletrooxidação do etanol sobre Pt em meio ácido proposto por Hitmi et al. [60] e Lamy et al. [77] como nas seguintes reações:

$$
\begin{aligned}
& \mathrm{Pt}-\mathrm{CHOH}-\mathrm{CH}_{3} \quad \rightarrow \quad \mathrm{Pt}+\mathrm{CHO}-\mathrm{CH}_{3}+\mathrm{e}^{-}+\mathrm{H}^{+} \\
& \mathrm{Pt}+\mathrm{H}_{2} \mathrm{O} \rightarrow \quad \mathrm{Pt}-\mathrm{OH}_{\mathrm{ads}}+\mathrm{H}^{+}+\mathrm{e}^{-} \\
& \left(\mathrm{CH}_{3}-\mathrm{CHO}\right)+\mathrm{Pt}-\mathrm{OH}_{\mathrm{ads}} \rightarrow \quad \mathrm{CH}_{3}-\mathrm{COOH}+\mathrm{H}^{+}+\mathrm{e}^{-}
\end{aligned}
$$

$\mathrm{O} \mathrm{CO}_{2}$ formado, identificado tanto por SPAIRS quanto por CLAE, poderia ser explicado pela quebra da ligação C-C do acetaldeído ou diretamente do etanol ou por um mecanismo similar ao mecanismo sugerido pelos autores Péres et al. [78] e Iwasita e Pastor [79] onde:

$$
\begin{array}{ll}
\mathrm{Pt}+\mathrm{CH}_{3} \mathrm{CHO} \quad \rightarrow & \mathrm{Pt}-\left(\mathrm{CO}-\mathrm{CH}_{3}\right)_{\mathrm{ads}}+\mathrm{H}^{+}+\mathrm{e}^{-} \\
\mathrm{Pt}+\mathrm{Pt}-\left(\mathrm{CO}-\mathrm{CH}_{3}\right)_{\text {ads }} \rightarrow & \mathrm{Pt}-(\mathrm{CO})_{\text {ads }}+\mathrm{Pt}-\left(\mathrm{CH}_{3}\right)_{\mathrm{ads}} \\
\mathrm{Pt}-(\mathrm{CO})_{\mathrm{ads}}+\mathrm{Pt}_{-} \mathrm{OH}_{\mathrm{ads}} & \rightarrow \quad \mathrm{CO}_{2}+\mathrm{H}^{+}+\mathrm{e}^{-}+2 \mathrm{Pt}
\end{array}
$$

\subsection{5 - Experimentos de eletrólise utilizando uma célula tipo filtro-prensa em fluxo}

As eletrólises foram realizadas em células do tipo filtro-prensa com fluxo contínuo de solução. $O$ uso de célula deste tipo possibilita a simulação de um processo industrial em escala de laboratório, seja com a finalidade em eletrossíntese ou tratamento de efluentes.

O uso de reator em fluxo (célula filtro-prensa) é um sistema bem adequado para uma aplicação industrial de algumas reações eletroquímicas por apresentarem algumas vantagens em relação ao sistema estacionário. Dentre as vantagens, as células em fluxo são muito compactas e podem ser utilizados vários módulos acoplados de acordo com a necessidade do processo. Há também a possibilidade de montar células com grande área superficial com pequeno volume fazendo com que a queda ôhmica diminua. Um tipo de eletrodo que pode ser utilizado em célula filtro-prensa é o eletrodo formado por óxidos 
metálicos chamado de ADE. Na literatura podem ser encontrados alguns trabalhos utilizando célula filtro-prensa com eletrodos na eletrooxidação de aldeídos e fenol [80-83].

O gráfico da Figura 53 resume o rendimento do consumo de etanol e a seletividade dos produtos identificados após 5 horas de eletrólise com todas as composições eletródicas. Foram eletrolisadas $100 \mathrm{~mL}$ de solução de etanol 0,1 mol L-1 em meio de $\mathrm{HClO}_{4}$ 0,1 $\mathrm{mol} \mathrm{L}^{-1}$ com um fluxo de $6,25 \mathrm{~mL} \mathrm{~min}^{-1}$ e corrente constante de $20 \mathrm{~mA} \mathrm{~cm}^{-2}$.

Nesta figura pode-se observar um rendimento $(\tau)$ maior na oxidação de etanol para a composição de $10 \%$ de $\operatorname{IrO}_{2}(\tau=18,6 \%)$, seguido pelas composições de 1 e $30 \%$ de $\mathrm{IrO}_{2}$ ( $\tau$ de 14,4 e $13,8 \%$, respectivamente) e o menor rendimento para a composição de $5 \%$ de $\operatorname{IrO}_{2}$ ( $\tau$ de $7,5 \%$ ). Quanto aos produtos de oxidação do etanol formados há uma tendência em aumentar a quantidade de ácido acético com o aumento da quantidade de $\mathrm{IrO}_{2}$ na composição do eletrodo mostrando que o $\mathrm{IrO}_{2}$ aumenta a seletividade do eletrodo para esta molécula. O acetaldeído mostrou uma tendência oposta a do ácido acético, ou seja, há uma maior seletividade para a sua formação com a diminuição da quantidade de $\mathrm{IrO}_{2}$ na composição do eletrodo. As tendências de formação dos produtos não se aplicam para o eletrodo com composição de $30 \%$ de $\mathrm{IrO}_{2}$, devido provavelmente a sua maior área superficial.

$\mathrm{Na}$ Figura 53 as colunas que representam $\circ \mathrm{CO}_{2}$ formado foram multiplicadas por um fator de dez para melhor visualização. Isto foi feito porque os eletrodos apresentaram uma baixa seletividade para a formação desta molécula. A formação do $\mathrm{CO}_{2}$ segue a tendência oposta do ácido acético sendo o eletrodo com a maior taxa de produção de $\mathrm{CO}_{2}$ foi o contendo $1 \%$ de $\mathrm{IrO}_{2}$. 


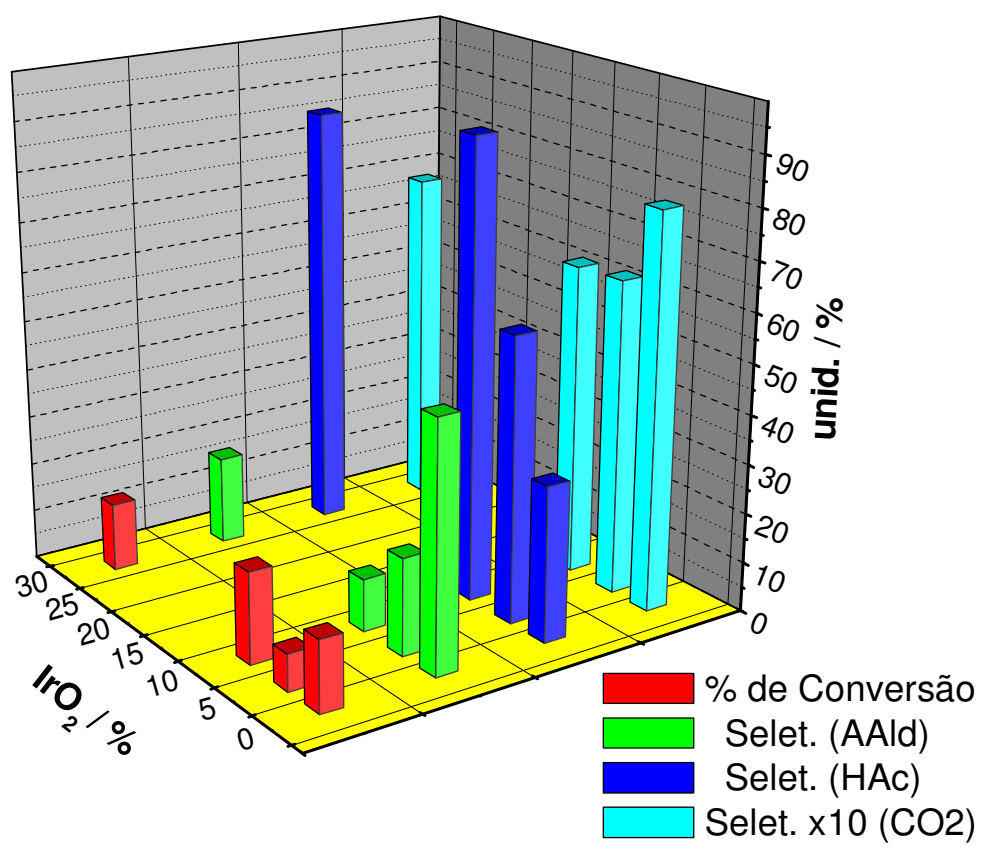

Figura 53 - Gráfico do rendimento do consumo de etanol e da seletividade dos produtos identificados (acetaldeído=AAld e ácido acético=HAC) e $\mathrm{CO}_{2}$ em função da composição eletródica. Foram eletrolisadas $100 \mathrm{~mL}$ de etanol $0,1 \mathrm{~mol} \mathrm{~L}^{-1} \mathrm{em}$ meio de $\mathrm{HClO}_{4}$ 0,1 mol L-1 com um fluxo de $6,25 \mathrm{~mL} \mathrm{~min}^{-1}$ e corrente constante de $20 \mathrm{~mA} \mathrm{~cm}{ }^{-2}$ por 5 horas. As colunas que representam $\mathrm{O} \mathrm{CO}_{2}$ formado foram multiplicadas por um fator de dez.

Para avaliar a influência do fluxo no resultado final da eletrólise, foram feitas eletrólises por 5 horas na mesma condição das anteriores, porém, variandose o fluxo da solução a ser eletrolisada. Os fluxos utilizados foram 6,25, 23,50 e $42,75 \mathrm{~mL} \mathrm{~min}{ }^{-1}$. Nestas eletrólises foi utilizado o eletrodo contendo $1 \%$ de $\mathrm{IrO}_{2}$ na composição, pois este eletrodo foi o que apresentou as melhores taxas de conversão de acetaldeído e $\mathrm{CO}_{2}$. Os resultaram indicaram que o rendimento do consumo de etanol e a seletividade para formação do ácido acético praticamente não variaram. A eletrólise realizada no fluxo de $23,50 \mathrm{~mL} \mathrm{~min}^{-1}$ apresentou a 
maior taxa de formação de acetaldeído e a menor taxa de formação de $\mathrm{CO}_{2}$ e no fluxo de $6,25 \mathrm{~mL} \mathrm{~min}^{-1}$ ocorreu a maior taxa de formação de $\mathrm{CO}_{2}$ e uma taxa intermediária de formação de acetaldeído conforme pode ser observado na Figura 54.

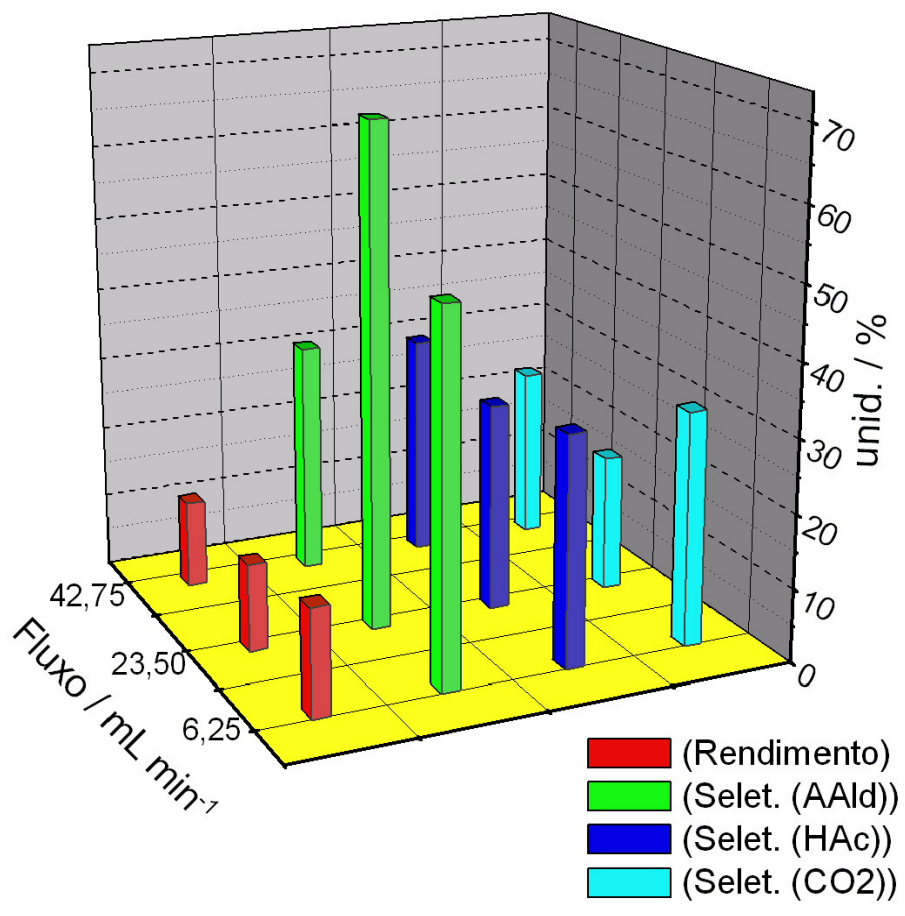

Figura 54 -Gráfico do rendimento do consumo de etanol e da seletividade dos produtos identificados (acetaldeído=AAld e ácido acético=HAC) em função do fluxo da solução. Foram eletrolisadas $100 \mathrm{~mL}$ de etanol $0,1 \mathrm{~mol} \mathrm{~L}^{-1} \mathrm{em}$ meio de $\mathrm{HClO}_{4}$ 0,1 mol L-1 com um fluxo de 6,25, 23,50 e 42,75 mL min${ }^{-1}$ e corrente constante de $20 \mathrm{~mA} \mathrm{~cm}{ }^{-2}$ por 5 horas no eletrodo contendo $1 \%$ de $\mathrm{IrO}_{2}$. As colunas que representam o $\mathrm{CO}_{2}$ formado foram multiplicadas por um fator de dez.

A partir do resultado anterior concluiu-se que o menor fluxo $\left(6,25 \mathrm{~mL} \mathrm{~min}^{-1}\right)$ foi o melhor para a realização das eletrólises. Assim, com estes parâmetros otimizados foram realizadas uma série de eletrólises neste fluxo com o eletrodo contendo $1 \%$ de $\mathrm{IrO}_{2}$. Estas eletrólises foram realizadas por 6 horas a uma corrente de $20 \mathrm{~mA} \mathrm{~cm}^{-2} \mathrm{com}$ diferentes concentrações iniciais de etanol e foram 
retiradas alíquotas de tempos em tempos para análises. Isto foi feito para verificar o comportamento e seguir a cinética da reação em uma mesma condição.

A Figura 55 mostra o comportamento do consumo do etanol, a formação de ácido acético e acetaldeído, e a relação entre as seletividades de acetaldeído e ácido acético em função do tempo de eletrólise.
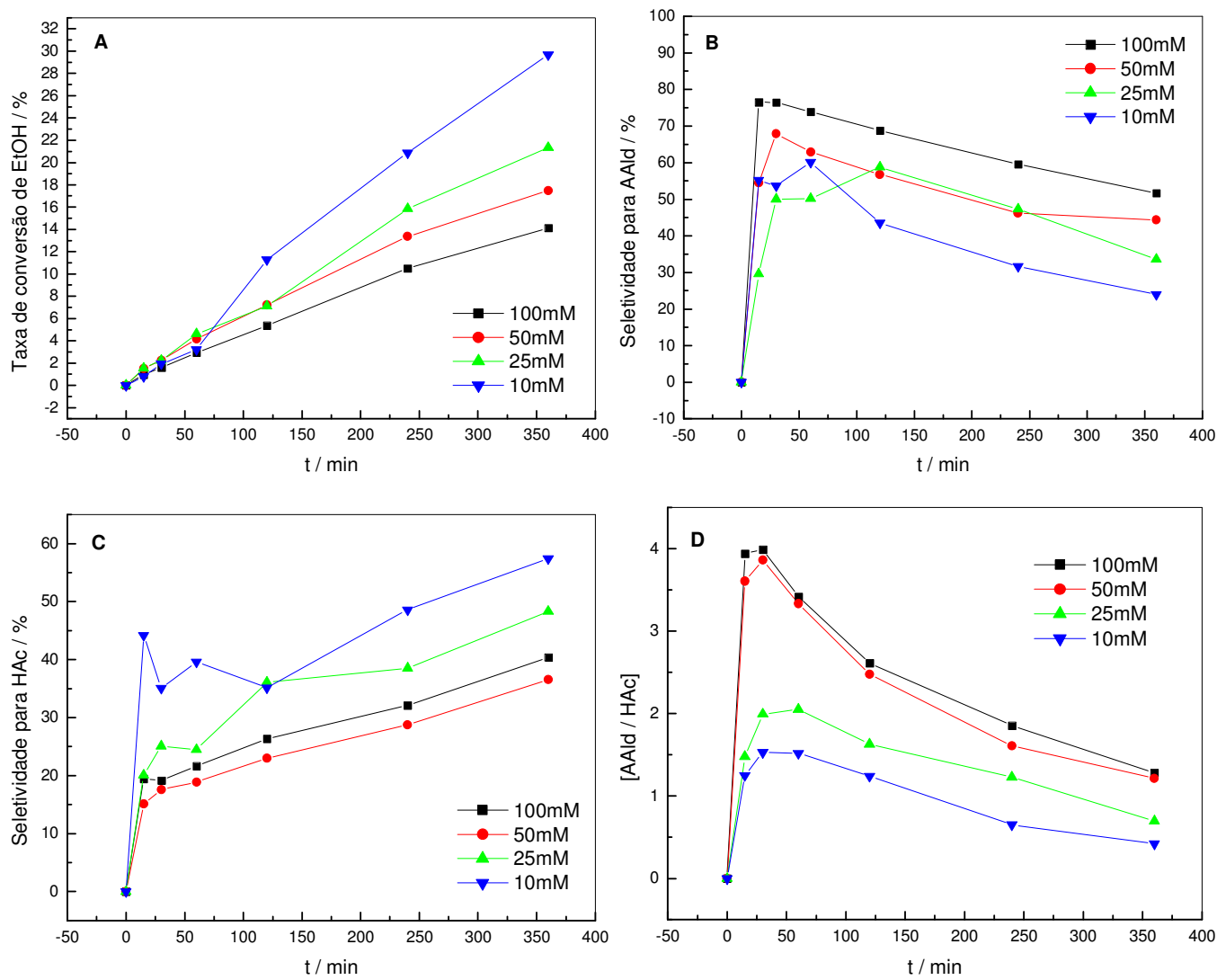

Figura 55 - Gráfico do rendimento da oxidação de etanol $[A]$, da seletividade dos produtos identificados (acetaldeído=AAld [B] e ácido acético=HAc [C]) e AAld/AHc [D] em função do tempo de eletrólise. Foram eletrolisadas $100 \mathrm{~mL}$ de etanol em diferentes concentrações em meio de $\mathrm{HClO} 4$ 0,1 mol L-1 com o eletrodo contendo $1 \%$ de $\mathrm{IrO} 2$ e corrente constante de $20 \mathrm{~mA} \mathrm{~cm}-2$ por 6 horas.

Como era de se esperar nas menores concentrações iniciais de etanol a sua oxidação foi mais rápida. Esta maior velocidade de oxidação do etanol favoreceu a seletividade para a formação de ácido acético (Figura 55C). Pode-se observar também na Figura 55B que na primeira hora de eletrólise há alta seletividade para a formação de acetaldeído, principalmente para as maiores concentrações iniciais de etanol (50 e 100 mM). A partir da primeira hora ocorre 
uma queda na seletividade de formação do acetaldeído, provavelmente porque parte dele deve estar sendo oxidado a ácido acético. Este comportamento fica mais evidente no gráfico da relação de seletividade entre acetaldeído e ácido acético na Figura 55D.

A Figura 56 apresenta as seletividades para a formação de $\mathrm{CO}_{2} \mathrm{e}$ acetaldeído ao final das 6 horas de eletrólise em função da concentração de etanol inicial.

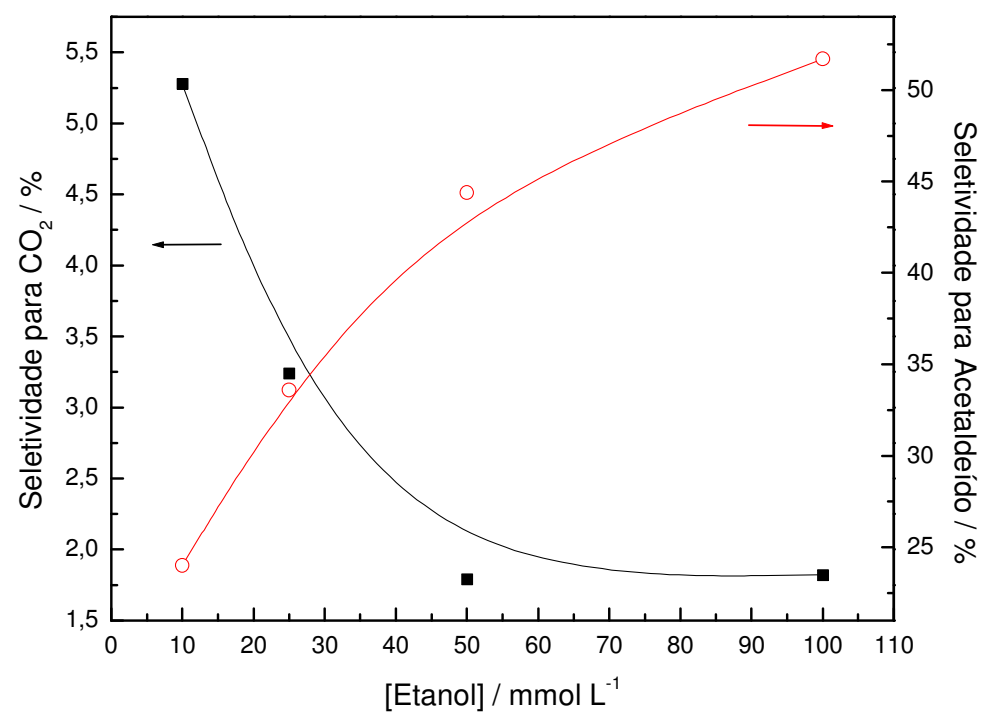

Figura 56 - Gráfico das seletividades para a formação de $\mathrm{CO}_{2}$ e acetaldeído ao final de 6 horas de eletrólise em função da concentração de etanol inicial.

Pode-se observar nesta figura que a seletividade para a formação de $\mathrm{CO}_{2}$ diminui com o aumento da concentração de etanol inicial. Baseando-se nos resultados anteriores era esperado um comportamento inverso. Nos resultados de eletrólise em célula convencional, sempre que se observava uma alta velocidade para a formação de ácido acético, ou seja, uma formação preferencial de ácido acético, havia uma inibição para a formação de $\mathrm{CO}_{2}$. Neste caso, o que pode ter ocorrido é uma contaminação da solução de $\mathrm{NaOH}$ do sistema de coleta de $\mathrm{CO}_{2}$ com acetaldeído. Esta contaminação interfere no resultado da análise do carbonato, pois ele apresenta um pico negativo no detector de índice de refração diferencial praticamente no mesmo tempo de retenção do acetaldeído (com um 
pico positivo), portanto, o pico do $\mathrm{CO}_{2}$ é parcialmente anulado pelo pico do acetaldeído. Isso teria ocorrido pela evaporação de parte do acetaldeído formado durante a eletrólise. Na Figura 56 pode-se observar que com o aumento da concentração inicial de etanol houve um aumento da formação de acetaldeído, aumentando também a possibilidade desta contaminação. 


\section{CAPÍTULO V}

\section{Conclusões}

Os resultados da caracterização ex situ dos eletrodos de composição $\mathrm{Ti} / \mathrm{Sn}_{(1-\mathrm{x})} \mid \mathrm{r}_{\mathrm{x}} \mathrm{O}_{2}$ preparados por decomposição térmica se mostraram coerentes com as características descritas na literatura, onde eletrodos preparados termicamente apresentam uma morfologia do tipo barro rachado. Pela técnica de difração de Raios-X foram encontradas fortes evidências de formação de solução sólida entre os óxidos de estanho e de Irídio. As análises de EDX comprovaram que o método permitiu a obtenção de filmes homogêneos e com estequiometria bastante controlada.

com exceção dos eletrodos contendo somente $\mathrm{SnO}_{2}$ em sua composição, as curvas voltamétricas apresentaram um formato típico do eletrodo de $\mathrm{Ti} / \mathrm{IrO}_{2}$. A carga voltamétrica e a capacitância da dupla camada elétrica mostraram-se fortemente dependentes da concentração do $\mathrm{IrO}_{2}$ e variaram da mesma forma com a composição, ambas podendo ser utilizadas como uma medida relativa de área eletroquimicamente ativa.

$\mathrm{O}$ aumento da concentração de $\mathrm{IrO}_{2}$ na mistura dos óxidos, além de um aumento de área ativa, acarreta também um aumento do efeito catalítico para a reação de desprendimento de oxigênio.

Nos experimentos de estabilidade eletroquímica conclui-se que 0 mecanismo de desativação dos eletrodos está fortemente ligado a estrutura cristalina da mistura dos óxidos, e a condutividade do óxido de estanho. Para os eletrodos contendo $1 \%$ de irídio possivelmente estaria ocorrendo a formação de uma solução sólida. Neste caso a condutividade deste eletrodo estaria ligada a defeitos na rede do $\mathrm{SnO}_{2}$, ou seja, deficiência de oxigênio, e sua desativação se daria pela perda destes defeitos. Nos eletrodos com maiores porcentagens de 
óxido de irídio estaria provavelmente ocorrendo a formação de duas fases. Uma delas seria a solução sólida com propriedades físico-químicas similares a do óxido de estanho, e outra de óxido de irídio, que pode conter pequenas quantidades de $\mathrm{SnO}_{2}$, com alta condutividade formando ilhotas distribuídas aleatoriamente na solução sólida.

Dentre os eletrodos, o que apresentou maior estabilidade foi o contendo $30 \%$ de óxido de irídio. Este comportamento era o esperado por se tratar de composição típica de $A D E^{\circledR}$. Neste caso a alta concentração de óxido de irídio proporcionou uma disposição das ilhotas formando um "caminho" de condução independente da condutividade da solução sólida.

Nos eletrodos com porcentagens de 5 e $10 \%$ de óxido de irídio o mecanismo de desativação estaria ligado ao crescimento de uma intercamada de $\mathrm{TiO}_{2}$ entre o titânio metálico e a camada ativa. O eletrodo contendo $1 \%$ de óxido de irídio apresentou uma maior estabilidade que os eletrodos contendo 5 e 10\% devido a formação de uma única fase (solução sólida) e a inibição do crescimento da intercamada de $\mathrm{TiO}_{2}$.

Conclui-se então que o método de preparação permitiu um excelente controle da estequiometria e reprodutibilidade dos eletrodos, e a adição de $1 \%$ de IrO ${ }_{2}$ no $\mathrm{SnO}_{2}$ causou um acentuado aumento na estabilidade do eletrodo, o que permitiu a sua aplicação nas eletrólises.

Foram realizadas eletrólises em soluções contendo ácido acético e verificou-se que esta espécie não deve sofrer processos de eletrooxidação nas condições empregadas. Foi verificada também a atividade para a eletrooxidação do acetaldeído e foi observado que este é facilmente oxidado em todos os eletrodos, sendo que sua velocidade de consumo foi maior nas composições intermediárias, com formação preferencial de ácido acético.

No estudo por voltametria cíclica em presença do etanol foi possível observar o processo da eletrooxidação do etanol em potencial menor que o potencial da RDO. Para eletrodos contendo baixas quantidades de $\mathrm{IrO}_{2}$ pode-se observar a formação de um pico relativo a oxidação do etanol. Isso demonstra que em concentrações menores de $\mathrm{IrO}_{2}$ a $\mathrm{RDO}$ desloca-se para potenciais mais positivos e desta forma se pode observar o pico de oxidação da espécie orgânica. Para quantidades maiores de $\mathrm{IrO}_{2}$ os processo de oxidação do etanol e a RDO deve ocorrer na mesma região de potenciais. 
Nas análises dos produtos formados, durante as eletrólises do etanol, foi quantificado ácido acético para todas as composições de eletrodo, entretanto, os eletrodos contendo 5 e $10 \%$ de $\mathrm{IrO}_{2}$ formaram esta espécie preferencialmente, como ocorreu na oxidação do acetaldeído. A formação de acetaldeído foi observada em quantidades apreciáveis somente no eletrodo contendo $1 \%$ de $\mathrm{IrO}_{2}$ nas eletrólises com a menor concentração inicial de etanol e nas eletrólises com maior concentração inicial de etanol para os eletrodos contendo 1, 5 e $30 \%$ de $\mathrm{IrO}_{2}$. Foi verificado que o acetaldeído se oxida facilmente em todos os eletrodos, isso mostra porque o acetaldeído não foi encontrado, em alguns casos, como produto da oxidação do etanol, ou seja, uma vez formado ele deve ser facilmente oxidado. Quando são utilizadas concentrações maiores de etanol, deve haver uma competição entre etanol e acetaldeído que faz com que parte do acetaldeído formado possa ser detectada em solução.

A quantidade de $\mathrm{CO}_{2}$ formada foi maior para os eletrodos contendo $1 \mathrm{e}$ $30 \%$ de $\mathrm{IrO}_{2}$. No caso do eletrodo contendo $30 \%$ de $\mathrm{IrO}_{2}$ esta composição favoreceria a formação de partículas menores e os $70 \%$ de $\mathrm{SnO}_{2}$ presentes neste eletrodo estariam distribuídos em uma grande área superficial favorecendo a formação de $\mathrm{CO}_{2}$.

É importante notar que a menor quantidade de ácido acético foi obtida para os eletrodos contendo $1 \%$ de $\mathrm{IrO}_{2}$. Levando-se em consideração que o ácido acético é um produto difícil de ser degradado, podemos dizer que este eletrodo apresenta uma vantagem em relação aos demais em termos de degradação de substâncias orgânicas.

Nos experimentos de FTIR realizados com a técnica de SPAIRS mostraram que ocorre a formação de $\mathrm{CO}_{2}$ em todas as composições de eletrodo tanto na eletrooxidação do etanol como para o acetaldeído, porém, ela é favorecida pelo eletrodo contendo $1 \%$ de $\mathrm{IrO}_{2}$ na sua composição. Durante a oxidação tanto do etanol quanto do acetaldeído utilizando a técnica de SNIFTIRS não foi observada a formação de CO adsorvido na superfície de nenhum dos eletrodos, assim, caso seja formado, o CO deve ser oxidado rapidamente.

Os parâmetros para eletrólises realizadas em célula do tipo filtro-prensa foram otimizados para o eletrodo contendo $1 \%$ de $\mathrm{IrO}_{2}$ e foi observada uma maior seletividade para $\mathrm{CO}_{2}$ com o menor fluxo $\left(6,25 \mathrm{~mL} \mathrm{~min}^{-1}\right)$ e que as menores concentrações favorecem a formação de ácido acético. 
Neste trabalho, portanto, foi demonstrada a viabilidade da utilização de eletrodos de $\mathrm{SnO}_{2}$ contendo $1 \%$ de $\mathrm{IrO}_{2}$ para reações de oxidação de substâncias orgânicas. Foi verificado que esta composição de eletrodo apresenta boa estabilidade e permite a quebra da ligação C-C do etanol produzindo preferencialmente $\circ \mathrm{CO}_{2}$. 


\section{CAPÍTULO VI}

\section{Referências}

1 - C. Bock, B. MacDougall e Y. LePage, J. Electrochem. Soc.,151 (2004) A1269.

2 - H.M. Villullas, F.I. Mattos-Costa, P.A.P. Nascente e L.O.S. Bulhões, Electrochim. Acta, 49 (2004) 3909.

3 - M. Watanabe, Y. Furuuchi e S. Motoo, , J. Electroanal. Chem., 191 (1985) 367.

4 - K. Scott, W.M. Taama e P. Argyropoulos, J. Power Soucers, 79 (1999) 43.

5 - A. J. Motheo, E. R. Gonzales, G. Tremiliosi-Filho, P. Olivi, A. R. de Andrade, B. Kokoh, J-M. Léger, E. M. Belgsir e C. Lamy, J. Braz. Chem. Soc., 11 (2000) 16.

6 - L.D. Burke e O. J. Murphy, J. Electroanal. Chem., 101 (1979) 351.

7 - H. B. Beer, U. S. Pat. 877901 (1961).

8 -S. Trasatti $(E d)$, Electrodes for conductive metallic oxides, Parte A e B, Elsevier, Amsterdam, (1980) e (1981).

9 - D. Galizzioli, F. Tantardini e S. Trasatti, J. Appl. Electrochem., 5 (1975) 203.

10 - E. J. M. O'Sullivan e J. R. White, J. Electrochem. Soc., 136 (1989) 2576.

11 - D. T. Shieh e B. J. Hwang, J. Electrochem. Soc., 142 (1995) 816.

12 - S. M. Lin e T. C. Wen, J. Appl. Electrochem., 25 (1995) 73.

13 - A. R. De Andrade, P. M. Donate, P. P. D. Alves, C. H. V. Fidellis e J. F. C. Boodts, J. Electrochem. Soc., 145 (1998) 3839.

14 - Ch. Comninellis e C. Pulgarin, J. Appl. Electrochem., 21 (1991) 703.

15 - Ch. Comninellis e A. Nerini, J. Appl. Electrochem., 25 (1995) 23.

16 - Ch. Comninellis e A. De Battisti, J. Chim. Phys., 93 (1996) 673.

17 - O. Simond e Ch. Comninellis, Electrochim. Acta, 42 (1997) 2013.

18 - G. Fóti, D. Gandini, Ch. Comninellis, A. Perret e W. Haenni, Electrochem. Solid St., 2 (1999) 228.

19 - A. Katayama, J. Phys. Chem., 84 (1980) 376. 
20 - A. Aramata, I. Toyoshima e M. Enyo, Eletrochim. Acta, 37 (1992) 1317.

21 - J-W. Kim e S-M. Park, J. Electrochem. Soc., 146 (1999) 1075.

22 - Ch. Comninellis e C. Pulgarin, J. Appl. Electrochem., 23 (1993) 108.

23 - O. Simond, V. Schaller e Ch. Comninellis, Electrochim. Acta, 42 (1997) 2009.

24 - A. L. Santos, Dissertação de Mestrado, Faculdade de Filosofia, Cênicas e Letras de Ribeirão Preto - USP, 1999.

25 - R. M. Takeuchi, Dissertação de Mestrado, Faculdade de Filosofia, Cênicas e Letras de Ribeirão Preto - USP, 1999.

26 - L. Smart e E. Moore, Solid State Electrochemistry - An Introduction, Chapman \& Hall, Londres, Cap. 2 e 3.

27 - B. Correa-Lozano, Ch. Comninellis e A. De Battisti, J. Appl. Electrochem. 27 (1997) 970.

28 - F. Vicent, E. Morallón, C. Quijada, L. Vázquez, A. Aldaz e F. Cases, J. Appl. Electrochem, 28 (1998) 607.

29 - M. Ito, Y. Murakami, H. Kaji, K. Yahikosawa e Y. Takasu, J. Eletrochem. Soc., 143 (1996) 32.

30 - Y. Murakami, M. Ito, H. Kaji e Y. Takasu, Appl. Surf. Sci. 121/122 (1997) 314.

31 - L. Nanni, S. Polizzi, A. Benedetti e A. De Battist, J. Eletrochem. Soc., 146 (1999) 220.

32 - O. R. Camara e S. Trasatti, Electrochim. Acta, 41 (1995) 419.

33 - C. Mousty, G. Fóti, Ch. Comninellis e V. Reid, Electrochim. Acta, 45 (1999) 451.

34 - A. de Oliveira-Sousa, M. A. S. da Silva, S. A. S. Machado, L. A. Avaca e P. de Lima-Neto, Electrochim. Acta, 45 (2000) 4467.

35 - G. Fóti, C. Mousty, V. Reid e Ch. Comninellis, Electrochim. Acta, 44 (1998) 813.

36 - J. C. Giuntini, W. Granier, J. V. Zanchetta e A. Taha, J. Mat. Science Letters, 9 (1990) 1383.

37 - Y-J. Lin e C-J. Wu, Surf. Coat. Technol., 88 (1997) 239.

38 - C. Terrier, J. P. Chatelon, R. Berjoan e J. A. Roger, Thin Solid Films, 263 (1995) 37.

39 - T. D. Senguttuvan e L. K. Malhotra, Thin Solid Films, 289 (1996) 22.

40 - Ch. Comninellis e G. P. Vercesi, J. Appl. Electrochem., 21 (1991) 136.

41 - M. P. Pechini e N. Adams, US Pat.,3330697,1967. 
42 - P. Olivi, E. C. Pereira, E. Longo, J. A. Varela e L. O. S. Bulhões, J. Electrochem. Soc, 140 (1993) L81.

43 - R. M. Faria, L. H. C. Mattoso, M. Ferreira, O. N. Oliveira Jr, D. Gonçalves e L. O. S. Bulhões, Thin Solid Films, 221 (1992) 5.

44 - T. A. F. Lassali, J. F. C. Boodts e L. O. S. Bulhões, J. Non-Crystalline Solids, 273 (2000) 129.

45 - B. Correa-Lozano, Ch. Comninellis e A. De Battisti, J. Electrochem. Soc, 143 (1996) 203.

46 - L. Lipp e D. Pletcher, Electrochim. Acta, 42 (1997) 1091.

47 - I. M. Kodintsev e S. Trasatti, Langmuir, 8 (1992) 283.

48 - T. A. F. Lassali, L. O. S. Bulhões, L. M. C. Abeid e J. F. C. Boodts, J. Electrochem. Soc., 144 (1997) 3348.

49 - S. Park, H. Zheng e J. D. Mackenzie, Materials Letters, 22 (1995) 175.

50 - Yu. E. Roginskaya e O. V. Morozova, Electrochim. Acta, 40 (1995) 817.

51 - A. De Battisti, G. Lodi, M. Cappadoria, G. Battaglin, e R. I. Kotz, J. Eletrochem. Soc. 136 (1989) 2596.

52 - Ch.Conminellis e G. P.Vercesi, J. Appl. Electrochem., 21 (1991) 335.

53 - S. Ardizzone, G. Fregonara e S. Trasatti, Electrochim. Acta, 35 (1990) 263.

54 - G. Spinolo, S. Ardizzone e S. Trasatti, J. Electroanal. Chem., 423 (1997) 49.

55 - C. P. De Pauli e S. Trasatti, J. Electroanal. Chem., 396 (1995) 161.

56 - S. Trasatti, Electrochim. Acta, 45 (2000) 2377.

57 - L. M. Da Silva, L. A. De Faria e J. F. C. Boodts, Electrochim. Acta, 47 (2001) 395.

58 - J. P. I. De Souza, S. L. Queiroz e F. C. Nart, Quim. Nova, 23 (2000) 384.

59 - N. R. De Tacconi, R. O. Lezna, B. Beden, F. Hahn e C. Lamy, J. Electroanal. Chem. 379 (1994) 329.

$60-$ H. Hitmi, E. M. Belgsir, J.-M. Léger, C. Lamy e R. O. Lezna, Electrochim. Acta, 39 (1994) 407.

61 - J. P. I. De Souza, S. L. Queiroz, K. Bergamaski, E. R. Gonzalez e F. C. Nart, J. Phys. Chem. B, 106 (2002) 9825.

62 - E. C. P. E. Rodrigues - Dissertação de Mestrado, Faculdade de Filosofia, Cênicas e Letras de Ribeirão Preto - USP, 1999. 
63 - L. A. Da Silva, V. A. Alves, S. Trasatti e J. F. C. Boodts, J. Electroanal. Chem., 427 (1997) 97.

64 - T. A. F. Lassali, S. C. De Castro e J. F. C. Boodts, Electrochim. Acta, 43 (1998) 2515.

65 - G. P. Vercesi, J. Y. Salamin e Ch. Comninellis, Electrochim. Acta, 36 (1991) 991.

66 - C. Angelinetta, S. Trasatti, Lj. D. Atanasoska e R. T. Atanasoski, J. Electroanal. Chem., 214 (1986) 535.

67 - L. A. Da Silva, V. A. Alves, M. A. P. Da Silva, S. Trasatti e J. F. C. Boodts, Electrochim. Acta, 41 (1996) 1279.

68 - L. A. Da Silva, V. A. Alves, S. C. de Castro e J. F. C. Boodts, Colloids and Surfaces A: Physicochem. Eng. Aspects, 170 (2000) 119.

69 - J. F. C. Boodts, comunicação privada.

70 - S. Trasatti., Electrochim. Acta, 36 (1991) 225.

71 - B. Correa-Lozano, Ch. Comninellis e A. De Battisti, J. Appl. Electrochem., 26 (1996) 683.

72 - J. Silva-Chong, E. Méndez, J. L. Rodríguez, M. C. Arévalo e E. Pastor, Electrochim. Acta, 47 (2002) 1441.

73 - X. D. Xu, Y. Matsumura, J. Stenberg e M. J. Antal, Ind. Eng. Chem. Res., 35 (1996) 2522.

74 - B. Beden, F. Hahn, J. M. Léger, C. Lamy, C. L. Pedriel, N. R. De Tacconi, R. O. Lezna e A. J. Arvia, J. Electroanal. Chem. 301 (1991) 129.

75 - X. H. Xia, H.-D. Liess e T. Iwasita, J. Electroanal. Chem., 437 (1997) 233.

76 - T. Iwasita,B. Rasch, E. Cattaneo e W. Vielstich, Electrochim. Acta, 43 (1989) 1073.

77 - C. Lamy, A. Lima, V. LeRhun, F. Delime, C. Coutanceau e J.-M. Léger, J. Power Sources, 105 (2002) 283.

78 - J. M. Peres, B. Beden, F. Hahn, A. Aldaz e C. Lamy, Electroanal. Chem., 262 (1989) 251.

79 - T. Iwasita e E. Pastor, Electrochim. Acta, 39 (1994) 531.

80 - G. R. P. Malpass e A. J. Motheo, J. Appl. Electrochem., 31 (2001) 1351.

81 - R. L. Pelegrino, R. A. Di Iglia, C. G. Sanches, L. A. Avaca e R. Bertazzoli, J. Braz. Chem. Soc., 13 (2002) 60.

82 - G. R. P. Malpass e A. J. Motheo, J. Braz. Chem. Soc., 14 (2003) 65. 
83 - G. R. P. Malpass e A. J. Motheo, J. Braz. Chem. Soc., 14 (2003) 645. 